University of South Florida

DIGITAL COMMONS

@ UNIVERSITY OF SOUTH FLORIDA
Digital Commons @ University of

South Florida

$12-1-2004$

\title{
Designing Bus Transfer Facilities for Maximum Transit Agency and Community Benefit
}

CUTR

Follow this and additional works at: https://digitalcommons.usf.edu/cutr_nctr

\section{Recommended Citation}

"Designing Bus Transfer Facilities for Maximum Transit Agency and Community Benefit," National Center for Transit Research (NCTR) Report No. CUTR-NCTR-RR-2003-13, Center for Urban Transportation Research, University of South Florida, 2004.

DOI: https://doi.org/10.5038/CUTR-NCTR-RR-2003-13

Available at: https://scholarcommons.usf.edu/cutr_nctr/24

This Technical Report is brought to you for free and open access by the National Center for Transit Research (NCTR) Archive (2000-2020) at Digital Commons @ University of South Florida. It has been accepted for inclusion in Research Reports by an authorized administrator of Digital Commons @ University of South Florida. For more information, please contact digitalcommons@usf.edu. 
Developing Bus Transfer Facilities for Maximum Transit Agency and Community Benefit

December 2004



NCTR 527-13 FDOT BC 137-53 



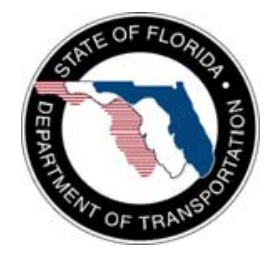

\title{
State of Florida Department of Transportation
}

Public Transit Office

605 Suwannee Street

Tallahassee, FL 32399-0450

(850) 414-4500

Project Manager: Amy W. Datz, Transit Planning Program Manager

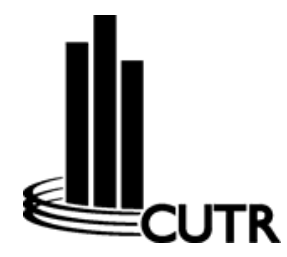

\author{
National Center for Transit Research \\ Center for Urban Transportation Research \\ University of South Florida \\ 4202 E. Fowler Avenue, CUT 100 \\ Tampa, FL 33620-5375
}

(813) 974-3120

Project Staff: Joel Volinski, Director, National Center for Transit Research at CUTR Oliver Page, Graduate Research Assistant

The opinions, findings and conclusions expressed in this publication are those of the authors and not necessarily those of the U.S. Department of Transportation or the State of Florida Department of Transportation. 



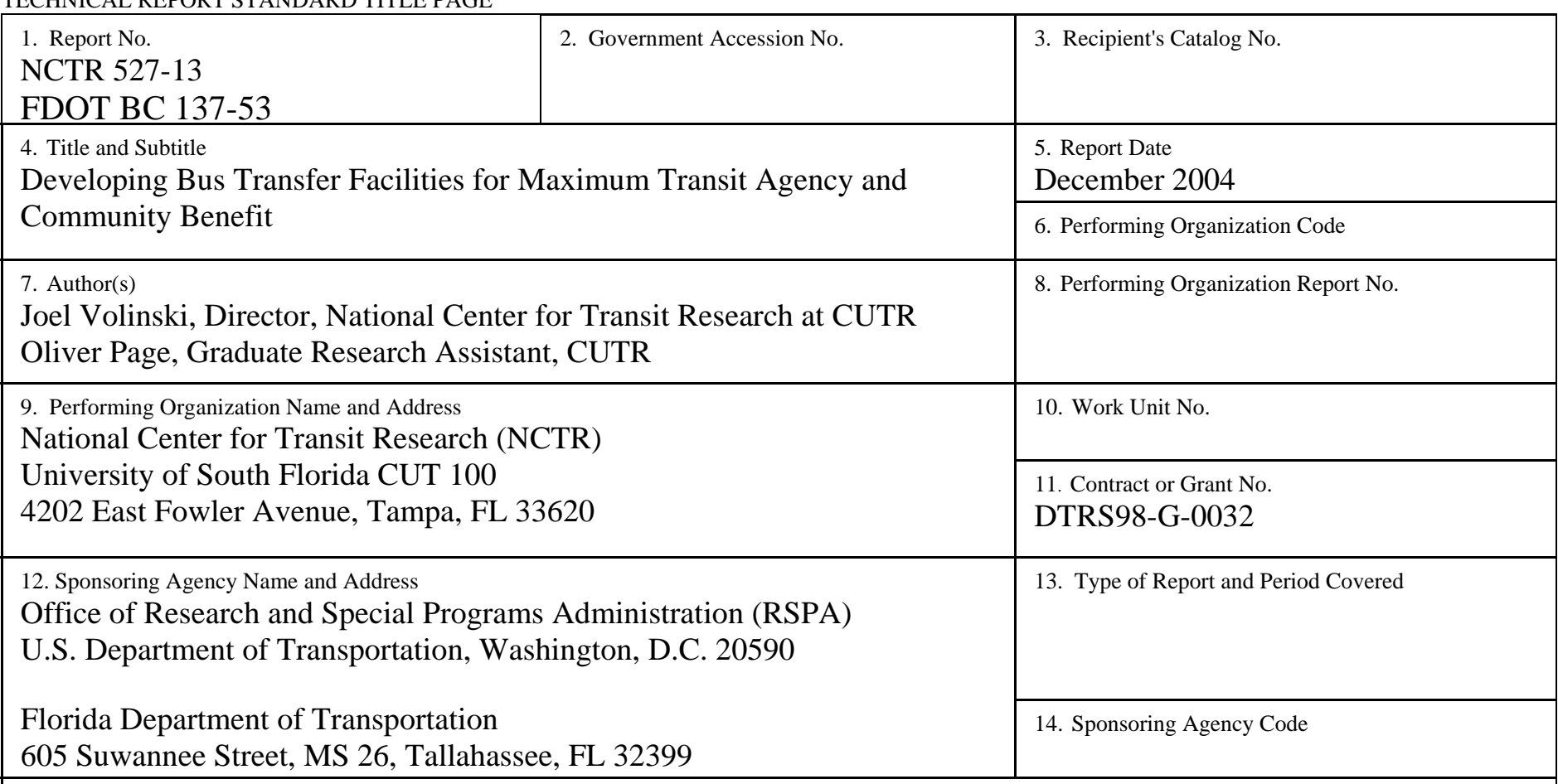

15. Supplementary Notes

Supported by a grant from the USDOT Research and Special Programs Administration, and the Florida Department of Transportation

16. Abstract

Bus transfer centers are often regarded as 'undesirable neighbors' that are difficult to site and difficult to gain support for due to noise, exhaust, traffic congestion, and the presence of unwanted passengers. In fact, there are some locations where major bus transfer activities are not only not welcome, but are probably not in the best interests of the surrounding development. However, many transit agencies are elevating the acceptance and relevance of transit in their service areas by making their transfer centers true community assets rather than nuisances. This often means finding the right location for a transit center for both the surrounding community and the passengers, replacing run down development with new facilities, incorporating exciting and inspiring architecture and design, and improving the pedestrian amenities and safety and security of the immediate area around the transfer center. Some communities have greatly expanded the concept of bus transfer centers by using them as locations for vital health and human services, as well as other conveniences that improve the quality of life for the residents of the surrounding community. In addition, others have utilized the advantage of their Federal grants to build transit centers that provide opportunities for joint development that help to generate revenues that can be used for other public improvements in the immediate area, which help to attract additional private investment and positive development where there once was blight. This report highlights how four transit agencies used their bus transfer centers to not only improve their image and community relations, but to serve as catalysts for positive development in the surrounding areas.

17. Key Words

Public transportation, bus transfer centers, livable communities, joint development
18. Distribution Statement

Available to the public through the National Technical Information Service (NTIS), 5285 Port Royal Road, Springfield, VA 22161, (703) 487-4650, http://www.ntis.gov/, and through the NCTR web site at http://www.nctr.usf.edu/.

\begin{tabular}{|l|l|l}
$\begin{array}{l}\text { 20. Security Classif. (of this page) } \\
\text { Unclassified }\end{array}$ & $\begin{array}{l}\text { 21. No. of pages } \\
100\end{array}$ & 22. Price \\
\hline
\end{tabular}

19. Security Classif. (of this report) Unclassified 



\section{Table of Contents}

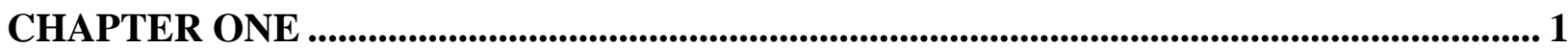

Introduction - Purpose of Report .................................................................................................................................

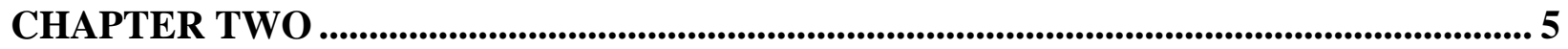

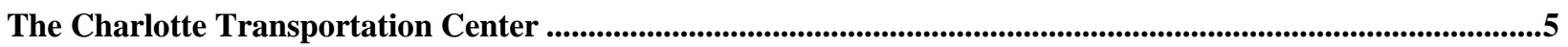

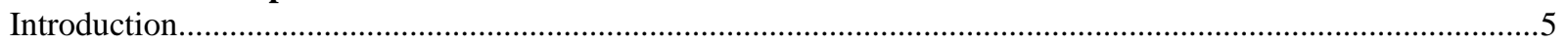

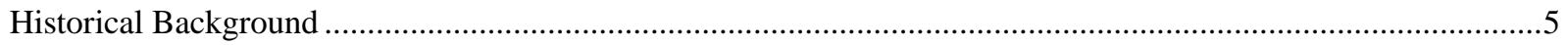

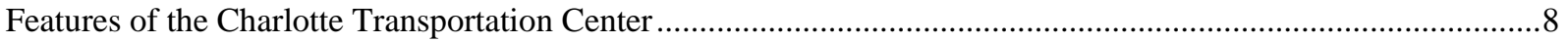

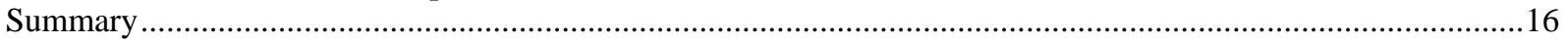

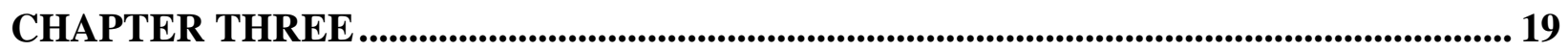

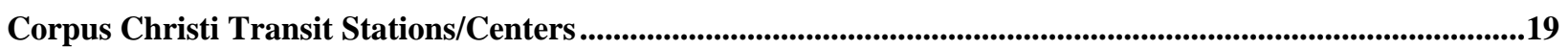

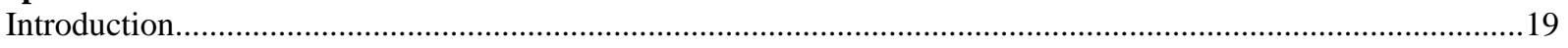

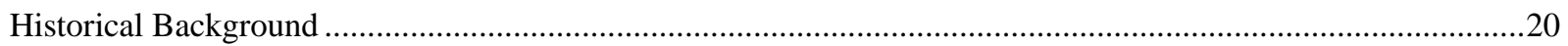

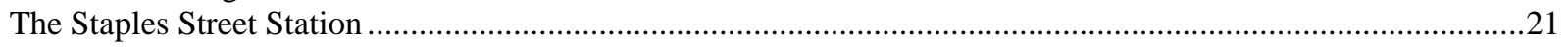

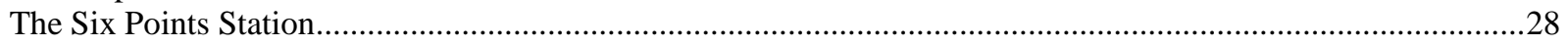

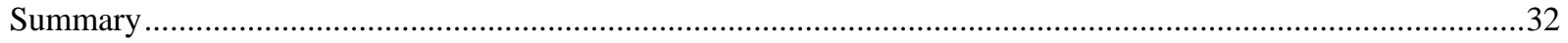

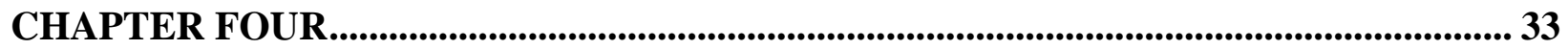

The Cedar Rapids Ground Transportation Center....................................................................................................33

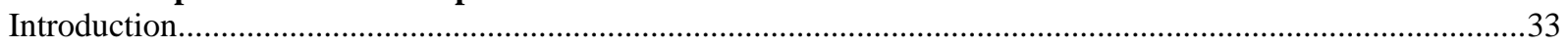

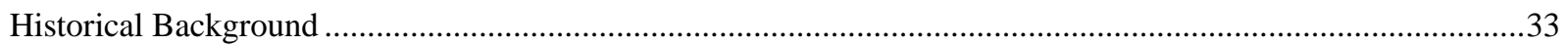

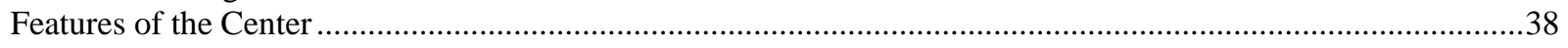

Contributions of the Ground Transportation Center Toward Positive Community Development in the

Surrounding Area............................................................................................................................................

CHAPTER FIVE

The Transit Centers of Columbus, Ohio .........................................................................................................................53

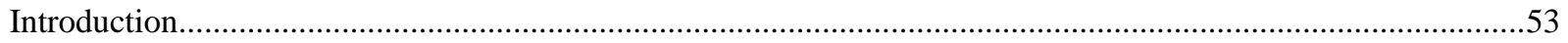

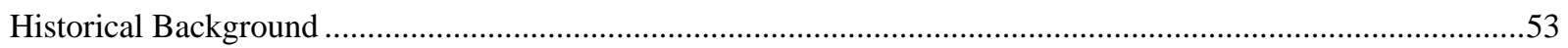

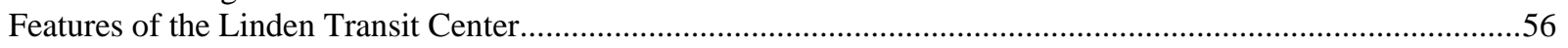

Contributions of the Transit Center Toward Positive Community Development ....................................................61

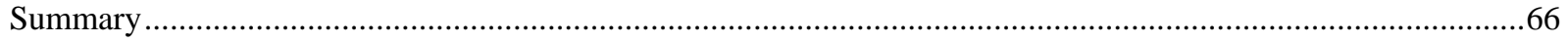

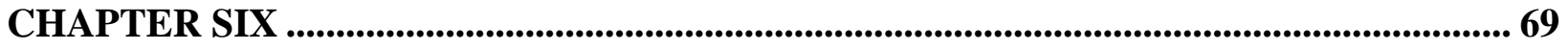

Summary of Best Practices .............................................................................................................................................69

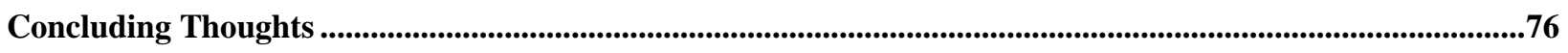

ADDENDUM

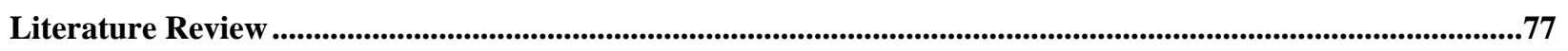

Acknowledgements ................................................................................................................................................................89

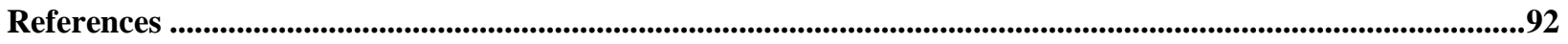





\section{Chapter One}

\section{Introduction - Purpose of Report}

Many transit agencies throughout the United States are in the process of planning for or building new transit transfer centers. Some are doing so as part of the process of modifying their onceradial transit system to a service pattern that is more grid-like to provide better service in the sprawling suburbs. These grid transit systems and the urban form they struggle to serve often require transit passengers to make one or more transfers to reach their destination. Other communities are simply recognizing that their current passengers should have better amenities than simple shelters, and if the agency hopes to attract new passengers they will need to provide attractive facilities as well as attractive service. Other transit agencies have used existing streets as transit malls to accommodate bus transfer activities, but have found that such transfer activities are no longer welcome by existing businesses on the same street or by residential areas nearby. In fact, bus transfer centers are usually not regarded as the best of neighbors. As seen by many, transit buses are large, loud, and exhaust-spewing vehicles that take spaces on the street that could be used for general parking and add to traffic congestion on streets used as transit malls. In addition, a number of shopping centers have requested that transit agencies remove their bus transfer activities from in front of their malls. All these forces have required transit agencies to reconsider where they should place transfer centers and how they can become better accepted.

The idea behind this report was developed as a result of a small bit of research conducted by CUTR staff in 1998 for the Tulsa Metropolitan Transit Authority (TMTA). That agency was trying to build a new transit transfer station on a commercial boulevard across the street from a residential community. Homeowners of the residential community put up a considerable amount of resistance to the rezoning that would be necessary to allow a bus transfer center to be built at that site. CUTR was asked by the transit authority's director to determine if there was evidence of damage to communities as a result of having bus transfer facilities located near them. The TMTA needed quick answers and could only manage to offer $\$ 5,000$ for a rapidly prepared synthesis on the subject. CUTR researchers conducted telephone interviews with almost 30 transit agencies around the country to find out what their experiences had been when trying to 
locate bus transfer facilities near residential areas and to see if they could provide any information on the impact of such facilities on nearby neighborhoods.

CUTR prepared a white paper for the TMTA director that indicated that many transit agencies simply avoided any attempt to locate a bus transfer center near a residential area. One transit staff member likened the experience to trying to build a prison or a half-way house near a residential community and said the effort simply wasn't worth it. However, most of the respondents to the survey said that they had had no terrible experiences and offered a number of ideas on how to work with communities to get a transit center approved and accepted.

In November of 1999, the author of this report was invited to speak to the chamber of commerce in Rochester, New York where the Rochester-Genesee Regional Transit Authority was having difficulties getting a site approved for a new major transit transfer center in downtown Rochester. The author shared his insights from the synthesis research done for Tulsa, but also heard Michael Melaniphy, General Manager of the Charlotte Area Transit System, describe the transfer center in Charlotte, North Carolina and the positive role it played in that city's downtown. Barry Goodman of The Goodman Group, a private consulting firm, also commented on how his firm believed transit facilities can serve as catalysts for positive urban development through the creative use of Federal grants. It seemed there were examples of transit transfer centers that were having positive impacts on their surrounding areas, and it was a subject worthy of additional research.

The purpose of this report is to share the best practices used at four different transit agencies that were successful in building transit transfer centers that have contributed to positive community development in their immediate surroundings. Information in this report was gathered through site visits and interviews with 40 different local officials in the four cities. A literature search revealed a great deal of information on the technical aspects of bus transfer centers in terms of internal design and geometrics for bus movements, safety, and fundamental amenities that should be provided for transit customers. This report makes no attempt to duplicate the excellent information that already exists on that subject matter. However, there was relatively little information on the subject of how transit transfer centers could contribute to positive development in the areas surrounding them. Hence, this report does not offer specific 
information on the geometric design of the transit function at the various centers visited. Rather, this report focuses on how the transit agencies visited were able to participate as enablers and facilitators of positive community development through leveraging grants and working with nontraditional partners as they designed and built their transit centers. The key lessons learned through this research are summarized below.

- Transit managers need to expand their self-image beyond being mobility managers to include possibilities to serve as facilitators of community development. They have access to grants that can help pay for improvements and spur new development.

- A new bus transfer facility should serve more than just the needs of transit passengers; it should be consistent with a comprehensive plan and help the surrounding community accomplish its broader development goals. The question to ask is, "What can we do to help our community succeed?”

- Transit centers can be more beneficial to surrounding communities when done in partnership with a broad array of public and private partners who are concerned with positive community development. Additional partners can bring more resources to bear and help generate support for the facility.

- Complete community involvement in the planning of a new transit center is vital to ensure it includes functions deemed important and beneficial by the community, and to help ensure community support for the facility.

- The transit center can accommodate many non-traditional, non-transit purposes and should strongly consider including them if they help gain community acceptance and if they help the prosperity of the surrounding area.

- Thoughtful architectural design that incorporates local cultural characteristics can not only greatly enhance the acceptance of the transfer facility, but can also create the center as a gateway to the community that people will feel proud of. When completed, the facility should look like it has always belonged there.

- There needs to be a no-tolerance stance taken when it comes to crime and vandalism if the center is to be regarded as a community asset. The transit center will not be a community asset unless it invests whatever is necessary to provide top-flight security and maintenance at the facility.

- The transit agency should take steps as quickly as possible to address the issues of bus noise and exhaust. Minimizing these irritants will help gain community acceptance. 
The details of these lessons learned in four transit systems are more thoroughly described in the "Best Practices" chapter of the report. It is hoped that the lessons learned from these examples, summarized as best practices in the final chapter of this report, will be adopted by other communities to help enhance transit's relevance and performance in their unique settings. 


\section{Chapter Two}

\section{The Charlotte Transportation Center}

\section{Introduction}

The Transportation Center in Charlotte, North Carolina is an impressive bus transfer facility that includes 20 bus bays under cover, with another six bus bays located on the street adjacent to the covered terminal. Over 45,000 passengers per day utilize this facility to start, end, or transfer bus rides. This facility is well accepted in the community and is regarded as an integral element of the positive development of downtown Charlotte that has helped this rapidly growing city realize its full potential as the second largest banking center in the United States. The Charlotte Transportation Center might well be regarded

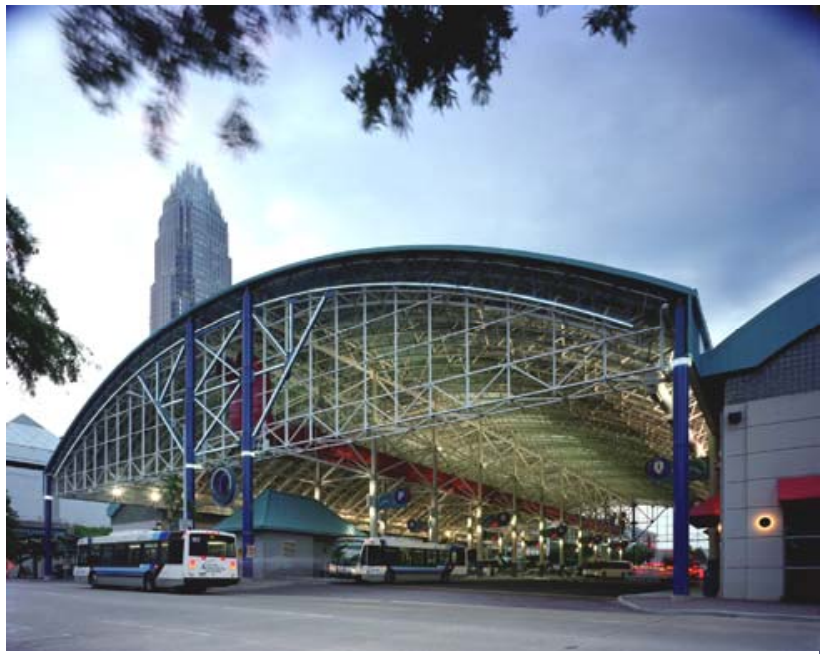

The Charlotte Transportation Center with Bank of America headquarters behind. as the penultimate example of public/private partnership in the development and management of a bus transfer center. While some of the circumstances regarding this facility's development might be unique and not likely to be transferable, there are still numerous lessons to be learned by other jurisdictions from the Charlotte Transportation Center.

\section{Historical Background}

The Charlotte Area Transit System (CATS) is the provider of public transportation services in the city of Charlotte and the surrounding areas in Mecklenberg County. The City of Charlotte is a rapidly growing area that currently has a population of 614,000, with almost 400,000 people living in the remainder of the unincorporated county. The route design of the CATS' system can be categorized as a classic radial bus transit service. Downtown Charlotte is clearly the predominant job center in the county and the location where the vast majority of transit lines 
meet. People wishing to complete a bus trip that requires a transfer must usually make that transfer in downtown Charlotte.

In the mid-1990s, CATS utilized the "transit mall" concept to allow bus routes to meet and transfer passengers. This activity took place in the heart of downtown Charlotte, at the intersection of Tryon and Trade Streets known locally as “The Square.” Bus shelters lined Tryon Street and provided the only form of protection from the weather for bus passengers. As many as 20 buses would converge on these streets every half hour, boarding, disembarking, or transferring thousands of passengers during peak hours.

Charlotte was continuing to grow and prosper as a national and international center of banking. The city is the corporate headquarters of Bank of America and Wachovia. Both of these companies were investing heavily in the Charlotte community. Bank of America, by far the largest banking company in the United States, was building a 60-story office tower and other high rise offices in the center of the city along Tryon Street.

A number of people were recognizing that traffic congestion was increasing, particularly along Tryon Street and would only get worse as Charlotte continued to grow. Many more thousands of cars were now mixing with over 50 buses per hour on Tryon. By the early 1990s, Hugh McColl, CEO of Bank of America (at the time called Nations Bank), realized that two issues needed to be addressed. One issue was the congestion on Tryon caused by the confluence of dozens of buses making frequent stops, mixed in with thousand of other vehicles. The second issue was the fact that the bus passengers did not have a comfortable and convenient place to transfer from one bus to another in a bus system that experienced a high rate of transfers. It was becoming increasingly clear, particularly to the business community, that these issues needed to be addressed and resolved. There are also unconfirmed stories that the corporate community was concerned that the white collar professional business district was being dominated by the blue-collar service workers that constituted the majority of the bus ridership waiting along Tryon Street.

Mr. McColl requested a meeting with city managers to discuss his thoughts for how these issues could be resolved. He believed a dedicated transit transfer center should be built as close to the center of downtown as possible. Many downtown employees, including his own employees, 
used the bus to get to work, and a transfer center needed to be located as close as possible to the concentration of jobs. A transfer center located away from Tryon Street would help relieve the traffic congestion that would soon get much worse, and provide appropriate shelter and convenience for passengers who were transferring from one bus to another. There were also other government jobs and services located in "Uptown Charlotte" that were not as accessible to bus passengers as they might be if the transfer activity took place a few blocks south of Tryon.

Mr. McColl asked city managers how much it would cost to build a transit center within a short walking distance of the heart of downtown. The city owned a 2.5 acre parcel of land within two blocks of Tryon that was used for surface parking. They also advised Mr. McColl that the cost to build such a center would, of course, vary depending on the features of the center. Three scenarios were developed, one calling for a minimalist center that simply called for bus bays, shelters, lighting, restrooms, and some form of customer information that would cost approximately \$3 million. The second scenario called for a more elaborate facility with a single roof covering the entire site along with the amenities noted above and a drivers' lounge. That sort of facility was estimated to cost approximately \$6 million. The third scenario called for all the features included in the first two scenarios, but also called for mixed uses for retail shopping, restaurants, full customer information services, offices for community services, and excellent security. This third option was estimated to cost \$9.6 million to construct. Mr. McColl told the city managers that he thought the third scenario was clearly the preferred alternative. He also offered for Bank of America to pay for the construction of the facility if the city would donate the land noted above.

By almost any standard, this would be regarded as quite a generous gesture by a corporate citizen. As noted earlier, some suggest that another motive behind building the Transportation Center was to move the primarily lower income bus passengers off Tryon Street which also serves as the gateway to the city center. In fact, it is quite likely that a number of people probably felt uncomfortable going through "the gauntlet" of bus passengers as they walked to their offices or other places of employment or shopping destinations on Tryon Street. Similarly, businesses probably did not feel comfortable with dozens of bus passengers in front of their doors who had no plans to shop at their business. Even if there might have been some classbigotry involved, the development of the Charlotte Transportation Center has ultimately proven 
to be a win-win-win solution. It is hardly as if the bus transfer center was shunted away to some hidden spot. It is only two blocks south of "The Square" and is in the middle of a booming downtown. Bus passengers benefited from a new, clean, convenient, safe, and comfortable place to wait for, and transfer to, buses in a place very close to 90 percent of all the jobs in downtown Charlotte. Vehicular traffic was able to operate more smoothly and safely on Tryon Street. In addition, The Square flourished as the showcase for the city and the businesses along Tryon Street were able to develop to their fullest potential without the sidewalks in front of their businesses serving as an inadequate bus transfer center. Regardless of what people might think about the motivation for the development of the center, the logic of its development from a transportation and community development perspective was impeccable.

\section{Features of the Charlotte Transportation Center}

\section{Design}

The Charlotte Transportation Center (CTC) includes 20 bus bays that are under the cover of a single barrel-vaulted pavilion that creates a grand space similar to venerable train stations such as Victoria Station in London. The 200-foot truss-supported curved roof is flanked by two lower, but complimentary, roofs that enclose climate-controlled space for a variety of activities and services. The exterior of these roofs are painted a pleasant North Carolina-blue that is highly visible from the many office towers that exist on all sides of the facility.

The area of the Transportation Center under the large roof is not enclosed (allowing buses to freely enter and leave). The interior of this area looks powerful and impressive at the street level to the passing pedestrian or vehicle driver. Through its design, the Transportation Center adds to the life of the city. 
The curved nature of the roof lines gives an appropriate sense of motion to this facility. Quite a bit of sunlight enters through both the east and west ends of the facility, as well as through skylights in the roof. Hence, the interior of this large covered facility does not appear dreary. It is further enlivened through rich and bright paint colors that cover exposed piping, support columns, awnings, kiosks, and bus bay signs in the bus transfer portion of the facility. The interior of spaces under the climate controlled roofs are similarly bright and cheery. Bright neon lighting signage provides a bit more pizzazz to the ambience. There is a generous use of ceramic tiles with multiple colors

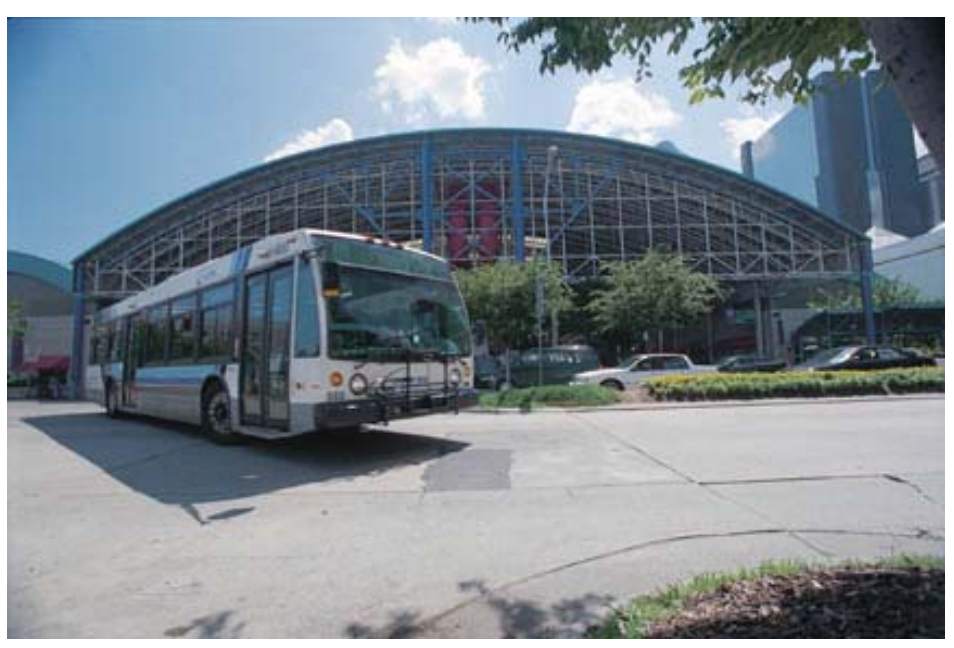

The Charlotte Transportation Center is reminiscent of great train stations in the world. and rich paint colors on the walls of the public spaces in the climate-controlled portions of the Transportation Center. The paint used for all of the facility is highly graffiti-resistant and easy to clean.

One challenge the designers didn't totally anticipate was the attraction that the open-aired portion of the facility would have for birds such as pigeons and starlings. Once it became evident how many birds were nesting and resting within the beams of the vaulted roof, the facility managers placed netting to cover virtually every open space within the beams. Remarkably, if it is not pointed out, this netting is unnoticeable to the casual observer and does not detract at all from the pleasing design. The netting has proved extremely effective in denying birds opportunities to nest and cause the problems they otherwise would to passengers and facility maintenance personnel.

A bus transfer center that is somewhat sizeable and requires more than one island to accommodate a large number of buses presents challenges in ensuring passenger/pedestrian safety for those passengers changing from one bus to another. Knowledge of passenger transfer patterns between routes can help planners store buses in bus bays next to each other, and this helps to minimize cross-facility pedestrian activity. However, with such a strong radial pattern, 
virtually all transferring passengers must use this facility, and many passengers must cross in front of bus paths in order to catch their connecting route. There is really little that can be done to eliminate this conflict. Stairways or escalators to pedestrian bridges that would allow people to cross over the buses to get to a connecting bus would likely not be used by passengers who almost always look for the most direct path to walk to their connecting bus. Strictly enforcing a five mile-per-hour speed limit for buses has helped to prevent any serious bus-passenger accidents, but as 45,000 passengers utilize the facility daily, it is an ongoing concern.

One of the few design "flaws" is the fact that the adjoining pavilions have 22-foot high ceilings. These high ceilings add to a sense of spaciousness, but also add to the cost of air conditioning and heating. Property managers responsible for the budget of the facility advise that it is very important for those who will operate the facility to be a prominent contributor during the design phase of a transit center. They believe that such concerns would have been expressed, and the design and construction would have been altered to help reduce ongoing operating costs.

\section{Security, Management, and Operations}

The emphasis on security at the Charlotte Transportation Center can not be overemphasized, particularly from the point of view of the facility's acceptance in the downtown community. Any transportation facility that attracts tens of thousands of people a day presents opportunities for problems such as theft, property damage, loitering, panhandling, gangs, etc. This is often the image transit transfer facilities suffer from, and it is the possibility of these kinds of activities happening that contributes to making transit transfer centers unwelcome neighbors.

The private and public stakeholders of downtown Charlotte were very aware of this and designed the Transportation Center and supervise it accordingly. First, the interior areas under the roofs are all

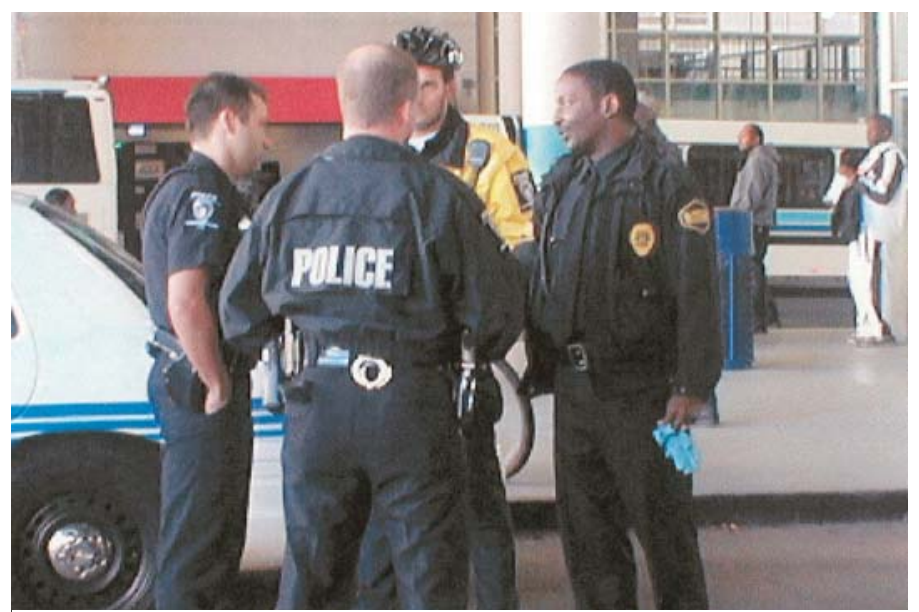

Charlotte Police and Transit Center Security Officers discuss the day's events. 
open and spacious, offering no real hiding places for those who might be intent on engaging in any unlawful activity to other persons or to the property. The lighting is more than sufficient during the day and evening, which is particularly important for a facility that operates from 5:30 am to 1:30 am daily. Second, the facility is equipped with 29 cameras, including a number of pan and zoom cameras, that can view virtually every public space in the facility and record the activities digitally. Third, there are always a minimum of four security personnel on duty, with as many as six to eight on duty during peak service hours. (This includes one security officer monitoring the cameras at all times). There is usually a very visible Charlotte police car parked inside the facility. Approximately $\$ 800,000$ is spent annually for security and off-duty police personnel. In addition to these dedicated security personnel, there are also transit supervisors within the facility, though they tend to stay within an office with large windows on one of the islands among the bus bays.

The facility is maintained immaculately. During the site visit there were two janitorial staff members keeping the facility as clean and litter-free as possible, and this attention to cleanliness goes on throughout the day and night. A fresh coat of paint is put on everything in the facility every year, and more often if required. The restrooms and other high-contact areas are covered with graffiti-resistant paint and/or ceramic tiles. If anything is broken or any graffiti appears, it is repaired or removed immediately. This philosophy of no-tolerance toward crime (i.e., the broken windows theory), combined with an extremely high standard of maintenance, helps to make this facility a good neighbor. Incidents of crime have doubled in the downtown from 1995 to

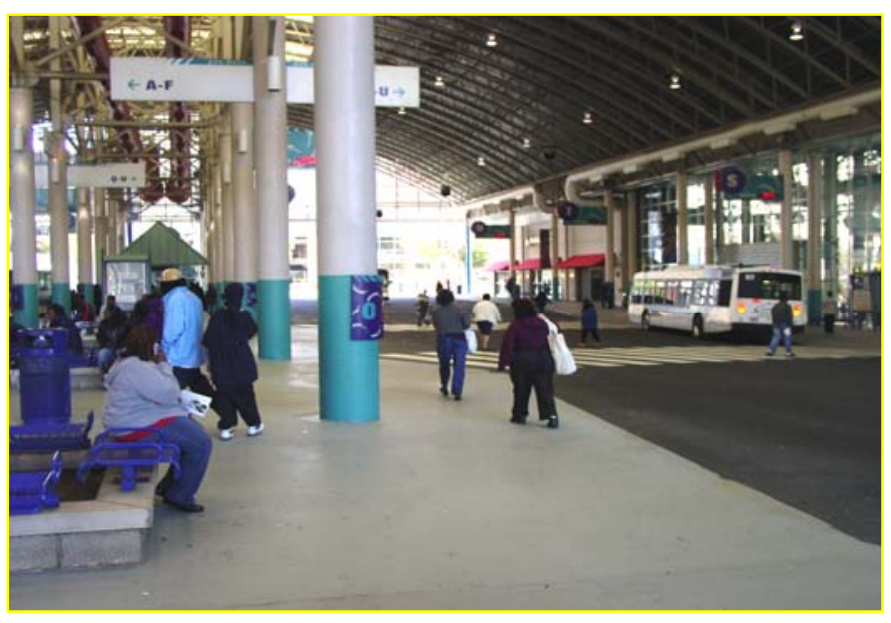

The CTC is bright, clean and maintained immaculately. 2004, but it is not likely the CTC is to blame since buses were already coming into downtown and transferring on Tryon Street prior to its construction. The increased crime is far more likely the result of tens of thousands of additional employees working in the downtown, in an area where many more events such as National Football League games and major festivals take place. 
No one interviewed by the principle investigators, including those who keep statistics for the Charlotte-Mecklenberg Police Department, believed the transit center is a significant contributing factor to crime in the downtown area. It is generally believed that crime is relatively constant in a community, but tends to be undertaken in areas of least resistance and will tend to avoid areas with a high level of security, such as the transit center, where apprehension is more likely.

Maintaining an orderly, clean, and safe environment was important from the very conception of the facility. The Charlotte Transportation Center is regarded as a private facility in spite of its very public purpose. City managers formed a partnership with the Bank of America to establish a private entity, known as Charlotte Transit Center, Inc., to govern and manage the transportation center. Its four-member board, comprised of two city representatives and two Bank of America representatives, approves the budget and sets priorities for the facility annually. A budget of \$2.2 million was established for managing, maintaining, and operating the facility in 2004. The Charlotte Area Transit System pays 75 percent of these costs, while the Bank of America pays the remaining 25 percent. Management of the facility is taken very seriously. Lincoln Harris, a property management firm that provides management services to Bank of America, provides such services to Charlotte Transit Center, Inc. on a pro bono basis, courtesy of Bank of America. This is not a trivial contribution, as a very experienced and skillful property manager spends approximately 75 percent of his time at the facility. In effect, Bank of America has become responsible for the risk and responsibility associated with the facility, but in return they wanted control of its operations.

This public-private partnership has worked very well in the ten years since the Transportation Center has been opened. There was a belief that if the facility was regarded as private property, the managers of the property would have a much easier time "banning" or removing those who were loitering or engaging in any undesirable behavior. It appears to have been a very successful model of management. Not only are the passengers pleased with the facility, but the surrounding business community is very accepting of the facility as well. Managers of the facility and members of the board of Charlotte Transit Center, Inc. all noted that crime rates in the immediate surrounding areas have gone down since the center was built, even though crime in the greater downtown area has increased. Moira Quinn, the Director of the Business Improvement District 
in which the Transportation Center is located, is very supportive of the center and noted that anything that might have happened at the center dealing with gangs was a community issue, not a transit center issue. The Center City Public Safety Council meets once a month and has never cited the Transportation Center as a problem. Surveys of passengers have shown they feel safe at the facility. It appears the only concession made to dangerous behavior is that the bathrooms are closed after 8 pm on Fridays and Saturdays.

Tough security has resulted in positive relationships with the surrounding business community. In addition to the hard side of security, the property managers have also relied on clever tactics that have proven to be very effective. There was a time when large numbers of teenagers would gather at the Transportation Center to hang out. Even though the anti-loitering rules were in effect, it was not always easy to determine just who was loitering and who was possibly waiting for a bus. To discourage the loitering teens, the property managers played classical music through the loudspeakers of the facility. The managers absolutely believe that this music was what discouraged the teens from staying at the Transportation Center. There have been no such gatherings of teens since this practice was instituted.

\section{Services Available at the Transportation Center}

The visionaries who conceived of the Charlotte Transportation Center, including the city managers, Bank of America representatives, and the architect all believed that the transit transfer center should be more than just a place for people to transfer from bus to bus. They wanted more people to use transit to get to downtown Charlotte. The new transportation center was intended for multiple purposes that would help attract and benefit passengers. In this fashion, the Transportation Center would help relieve traffic congestion and bring more people into the downtown area. Focus groups of bus passengers were conducted prior to the final design of the

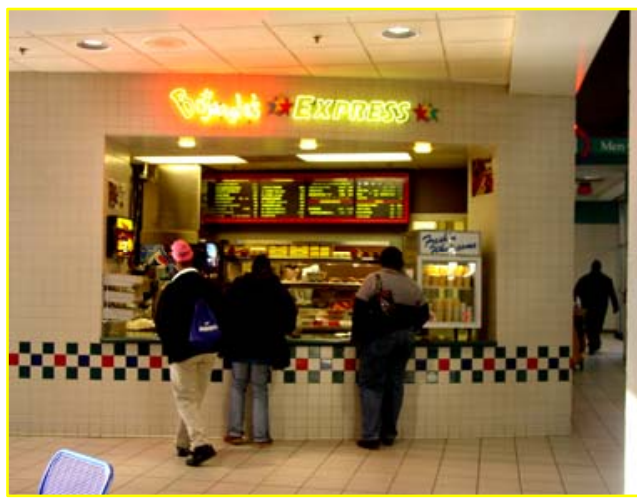

One of six fast food restaurants in Pavilion A of the CTC. Transportation Center to get input on what types of services would be welcome and helpful in such a facility. 
There are two pavilions that flank the bus transfer bays in the middle of the facility. Pavilion A is leased out entirely for retail purposes There are six different fast food eateries in Pavilion A ranging from national chains such as Burger King and Bojangles to much smaller individual stores offering soft drinks and snacks. The seating inside Pavilion A is quite generous and is offered on two floors under a single 22-foot high ceiling. Also included in Pavilion A is a small US Postal Service office, and two offices where Charlotte area residents can walk up to pay their utility and phone bills. Most of the retail businesses in Pavilion A close at 7 p.m., with the exception of Burger King which stays open until 9 p.m. Pavilion A also includes approximately 3,000 square feet of offices for the Carolina Medical Group that offered clinic-type medical services to walk in patients. The demand for medical services at the Transportation Center decreased to the

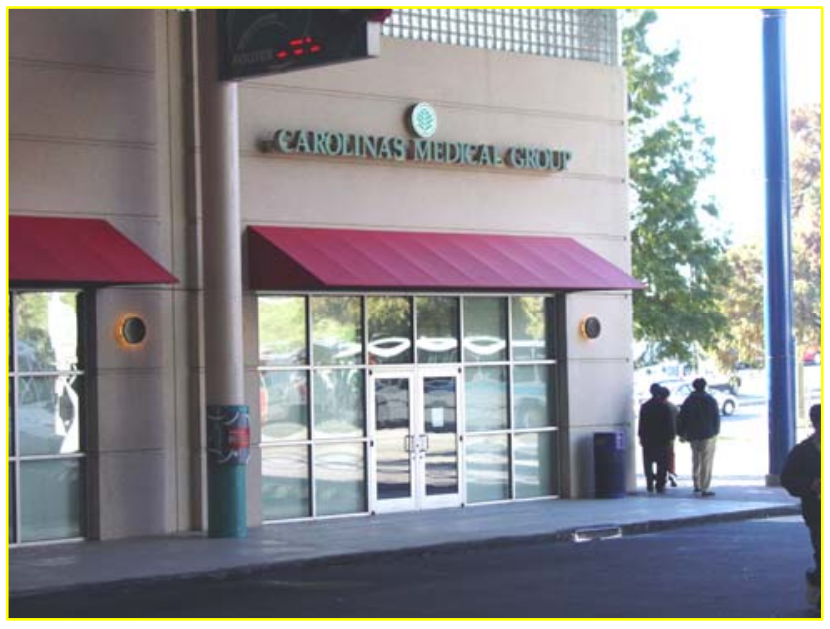

The Carolina Medical Group Health Clinic was an original tenant of the CTC. point where those services were discontinued.

This was not due to any inappropriateness in being located at the Transportation Center. According to property manager Mark Thorson, the services were discontinued at this location due to the fact that the Carolina Medical Group has recently built a number of new clinics nearer residential communities that many bus passengers found more convenient to visit. CATS intends to use this now-vacant space for administrative office purposes.

Pavilion B includes a very pleasant CATS customer information and service area where passes can be purchased and information on the transit system can be obtained. Next to the customer service area are restrooms, a bus operators' lounge, and a security office containing multiple closed circuit video screens broadcasting images captured by 29 cameras located throughout the facility. Also in Pavilion B is

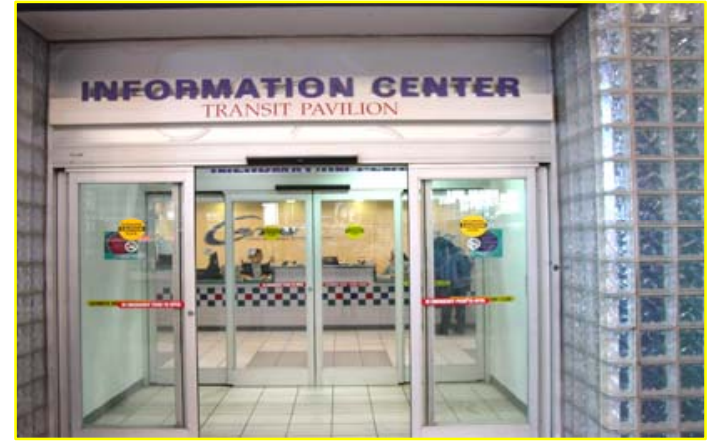

Passengers can purchase passes and receive maps and schedules at the CATS Information Center. 
"Plaza Sundries" where passengers or passersby can obtain all sorts of convenience items. This store is open until 8 p.m. There is a full service Bank of America branch office in Pavilion B as well as a 400 square foot community meeting room that has been used for a variety of purposes, though it is primarily used for meetings with tenants of the facility. In addition, the CharlotteMecklenburg School Board uses an office that is designed to have counselors meet with kids to encourage them to stay in school. Many times kids will be found at the Transportation Center who should be in school.

Mark Thorson, property manager for Lincoln Harris advised that the rents charged per square foot are competitive (between $\$ 15$ and $\$ 60$ per square feet).

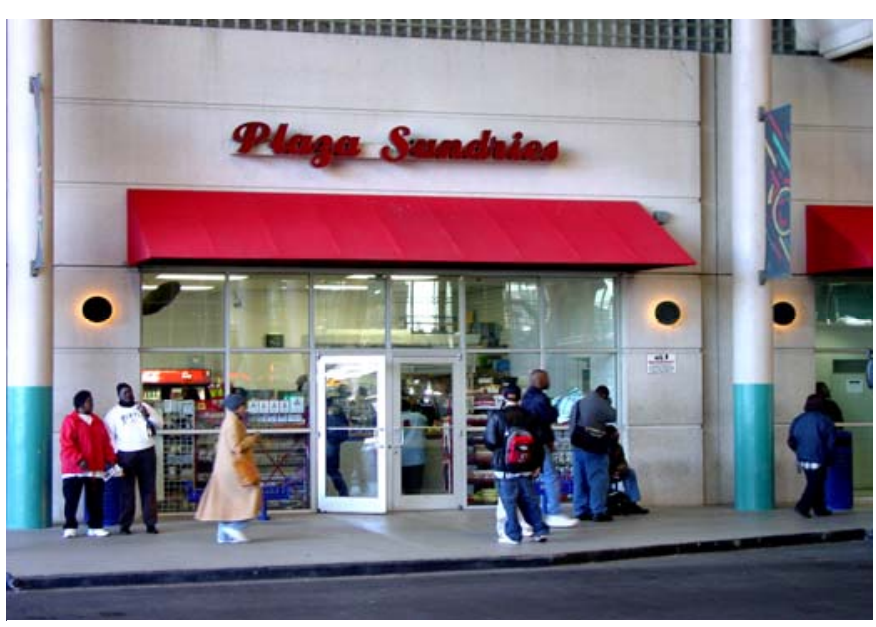

Plaza Sundries located within the Charlotte Transportation Center.

The revenues collected from the rents constitute only a small portion of the expenses of operating and maintaining the Transportation Center. Those revenues are placed into cash reserves and are used to help pay for any capital improvements needed at the facility. Mr. Thorson noted that many of the current tenants have been operating in the facility since the day it opened, and turnover among tenants is quite low. He also shared that he receives occasional unsolicited inquiries from small businesses interested in locating in one of the pavilions.

The businesses located in the Transportation Center do well enough to maintain themselves, but it is a fact that most of the purchases of products and services are completed by bus passengers versus others in the surrounding area. This might change when the new Arena and entertainment complex open in 2005. The businesses are hoping to receive a great deal of additional traffic as thousands of more people a day will be in the immediate vicinity as they attend events at the arena and visit the new Epicenter complex. 


\section{Contributions of the Transportation Center Toward Positive Community Development in the Surrounding Area.}

Some people fear that a bus transfer center will be an undesirable neighbor, and retard the development of land around it. That has not been the case in Charlotte. The city is building a new $\$ 250$ million dollar arena directly across the street from the center. The new arena will host over 180 events a year, bringing thousands of people in direct contact with the Transportation Center on an average of every other night. Clearly, the city is not concerned that the bus transfer center will discourage people from attending events at a new showcase for Charlotte. Perhaps more impressively, a new entertainment complex is being built adjacent to the north side of the Transportation Center. To be known as the Epicenter, this new complex will take the space once occupied by the old convention center in downtown Charlotte. Moira Quinn, Director of the Business Improvement District, advised that eight new high-rent residential towers with between 65 and 300 units are being built in various locations downtown, all no more than five blocks away from the Transportation Center. These new residential towers will contribute to a downtown residential base that already includes over 10,000 people. As Assistant to the City Manager Boyd Cauble stated, "No developers are steering away from the Transportation Center.” A new light rail line is being built through Charlotte and is scheduled to open in 2006. One of its stops will be at the Transportation Center which will only increase its use and importance to the entire transportation system in the Charlotte area, and to the successful development of downtown Charlotte.

\section{Summary}

As noted at the beginning of this chapter, there are some unique elements at play in Charlotte that are not likely to be duplicated in other cities. As John Sacclarides of Bank of America stated, "Bank of America's commitment to its center city is like no other in the United States." This growing and enormously successful financial services company has invested over \$2.5 billion dollars in downtown Charlotte in its own offices and in many other public facilities and neighborhoods in the immediate area. Contributing \$9.6 million to pay for the construction of the Transportation Center was not a major stretch for this corporate citizen that has demonstrated 
ongoing remarkable care and concern for the betterment of its home city. This company's generosity has also been extended to help pay a substantial portion of the ongoing expenses of managing and operating the Transportation Center. As Mr. Cauble noted, "If you have a great private partner, you are very lucky.”

While similar financing scenarios might not happen in many other cities, there are still lessons that other areas can learn from the Charlotte experience that will serve them well in the development of a transit transfer center. Perhaps the first lesson is to realize that the location of a transfer facility is extremely important to its acceptance in the community. In the case of Charlotte, it was important for everyone to

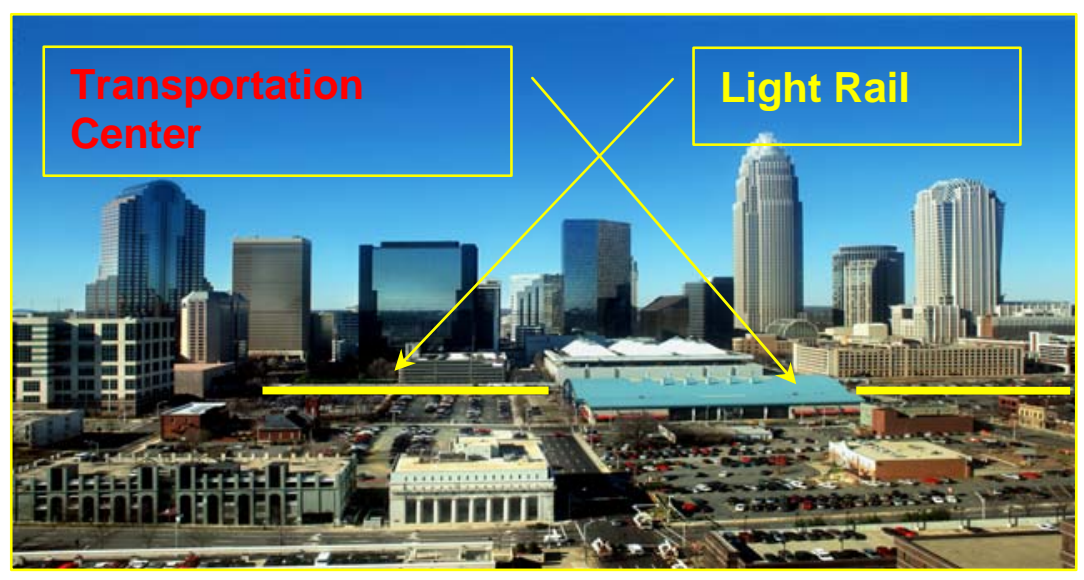

The CTC, visible from all points in the city, is strategically located within two blocks of the office towers and governmental buildings of downtown.

realize that having all buses meet along the main street of downtown Charlotte was not in the best interests of the city's development. While some might regard this as a rebuke of the importance of transit or as a class-based action, it was more important to recognize that the same function could be accomplished very close by in a way that would allow the main street to become all it could be. It also centralized all bus transfers in a place that was ultimately more convenient for the vast majority of passengers. Hence, the first question a transit agency might ask itself when siting its transfer center is "where will we do the most good for the entire community and not just for our passengers?” By moving its transfer function from Tryon Street to a location two blocks away, the transit function went from being a nuisance to being accepted and embraced by the broader community as a contributor to positive development.

Another lesson is the importance of tight security at the transfer center. Not too many other cities will be able to state that their centers are private property as they do in Charlotte, but they can be sure not to skimp on security equipment and personnel, and to design with safety and security of all people in mind. They should also adopt the philosophy of no tolerance for illegal 
behavior or property damage, and to keep the facility as clean as possible at all times. A high level of security in and around the transit center will encourage most people with criminal intent to go elsewhere, making the surrounding community actually appreciate the transfer center as a facility that helps to minimize crime.

Charlotte has been very fortunate to be in a growth mode economically, and the citizens of Mecklenburg County recognized the need to address this growth by supporting a half-cent general sales tax for transit improvements throughout the county. This has caused the budget for transit to increase from $\$ 16$ million dollars annually in the early 1990s to \$75 million in 2004, to go along with a major capital program which will include light rail, commuter rail, and bus rapid transit. Ridership and demand for transit services has increased accordingly. One lesson CATS learned is to plan for expanded service when designing a transit center. The Charlotte Transportation Center is a wonderful facility, but operates over capacity at the moment due to the expansion of transit services since 1998. A number of buses need to park on the street adjacent to the center due to insufficient bus bays within the facility. A new intermodal center is being built approximately a half-mile away that will accommodate commuter rail and Greyhound bus service, and will also be the transfer point for some of the routes that now use the existing Transportation Center. The new center will no doubt be an attractive facility, but it will require some passengers to transfer more than they might like in order to complete their transit trips. Had the Charlotte Transportation Center been made a bit larger in 1995, these transfers would not have been required. 


\section{Chapter Three}

\section{Corpus Christi Transit Stations/Centers}

\section{Introduction}

Corpus Christi (TX) is home to a number of transit centers that have helped bring positive impacts to the communities surrounding them. The Corpus Christi Regional Transportation Authority (CCRTA), as the provider of transit services in Corpus Christi, has been instrumental in developing the Staples Street Station and the Six Points Station as primary transit centers (or node points) in the local bus network. The Staples Street Station is CCRTA's award-winning example of a transit transfer center that improves its surrounding community by creating a sense of place within a business and government center environment. This has been accomplished primarily through its Spanish Mission architecture and community-based design as it provides a safe, pleasant, and efficient facility for bus transfer activities. It has also begun the process of connecting a nearby lower income community to the downtown it has been cut off from due to the construction of major highways. The Six Points Station represents a solid example of how a transit agency can use its Federal grants to become a welcome neighbor that can help redevelop an older commercial/residential area while also improving its transfer facilities for its passengers. CCRTA has developed fairly inexpensive transit transfer facilities with distinctive designs that are deliberately intended to improve the neighborhoods around them and incorporate significant public participation to help the community feel a sense of ownership and pride. In order to give each transfer center a more permanent sense of place, CCRTA calls their transfer centers "stations" as railroads with permanent tracks do. None of the bus stations visited by the principle investigators incorporate any other public or private services or agencies, nor do they offer any but the most minimal of conveniences at the facilities. Nonetheless, they provide benefits to bus passengers by offering safe and comfortable waiting areas, and they benefit the surrounding communities by being catalysts for other improvements. 


\section{Historical Background}

The City of Corpus Christi is located along the Gulf of Mexico, approximately 200 miles southwest of Houston, Texas. The city's population of 277,000 is 71 percent white, yet 54 percent of the residents claim to have Hispanic or Latino heritage according to the 2000 United States Census. Approximately seven percent of Corpus Christi households do not own a car and are therefore transit dependent.

CCRTA in 2004 provides fixed route transit with a peak hour pullout of 50 buses serving an area of approximately 850 square miles. Annual ridership in 2003 was estimated at 5.8 million unlinked trips, an excellent level of ridership for such a small system. The route design of CCRTA's operations follows a grid type network design to better serve an urban area characterized by considerable sprawl with a number of smaller economic centers throughout the service area. This spread of economic centers away from downtown Corpus Christi has resulted in CCRTA establishing five transit transfer centers in the city, namely:

- Staples Street Station

- Southside Station

- Flour Bluff Station

- Port Ayers Station

- Six Points Station

The transit system pattern is clearly more grid-like than radial. All bus routes use at least one of these transfer centers, but not all bus routes pass through the downtown transit center of Staples Street Station.

During the mid-1990s the Livable Communities Initiative (LCI) was established by the Federal Transit Administration (FTA). The challenge and opportunity of this initiative was, 'to strengthen the link between transit and communities by improving personal mobility, transportation system performance, and the quality of life' (Federal Transit Administration, 1999). The LCI provided relatively modest grants to selected cities to meet this challenge. Corpus Christi was selected as one of several cities to host LCI Demonstration Projects. The 
Project for Public Spaces (PPS) together with the CCRTA used the \$1.3 million FTA grant to assist three Corpus Christi communities through revitalized transfer centers:

- The Staples Street Station situated in downtown Corpus Christi;

- The Six Points Station in Corpus Christi's first urban commercial center outside of downtown; and

- The Port Ayers Station located in a retail strip development area at the intersection of Port Avenue and Ayers Street.

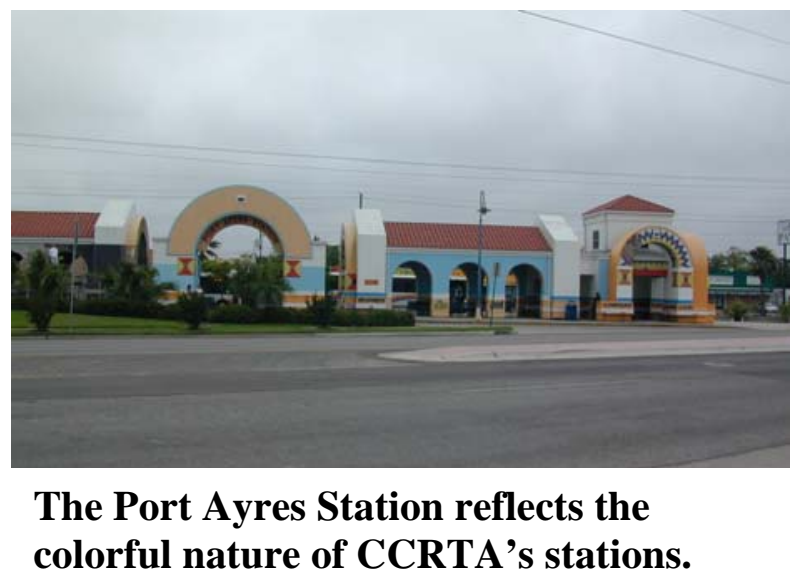

The remainder of this chapter will describe the history, design, and community benefits of the first two stations listed above.

\section{The Staples Street Station}

The Staples Street Station was the first modern transit center opened by CCRTA in 1995 and represents the largest transfer station in the CCRTA's network. Prior to its establishment, bus transfer activities had taken place on the street at the intersection of Leopard and Staple Streets. As was the case in many similar circumstances around the country, the local businesses on those streets were not pleased that their storefronts were often hidden by waiting bus passengers and that parking in front of their stores was reserved for buses. The area near the intersection of Leopard and Staple Streets was primarily used for governmental purposes and some small retail establishments. In between the various city, county, and school board buildings around Staples Street, there was an area of surface parking and underutilized retail stores that provided an opportunity for a dedicated transit transfer center within a block of where many bus routes intersected and numerous transit-supportive activities were present. The objectives to be met by establishing a new transfer center were to: 
- enhance pedestrian and traffic safety;

- improve transit operating efficiency;

- provide transit customers with high quality amenities;

- provide a safe facility to transfer between buses;

- enhance mobility options through the transfer center;

- create a sense of place and civic pride; and

- contribute to neighborhood economic development through a facility improving the 'livability' status of the immediate community.

To realize these objectives, extensive community involvement was initiated and maintained through the conception, design, and construction phases of the Staples Street Station. The idea for extensive community involvement was influenced in part from the LCI initiative which aimed to, 'strengthen the link between transit planning and community planning to ultimately provide physical assets that better meet community needs and make the transit facility a community facility.' (FTA, 1999) The CCRTA concurred with this approach and saw such processes as ways of gaining greater credibility in the community. Therefore, a number of Town Hall meetings and community workshops were held in the immediate and surrounding areas to consider community views on the proposed Staples Street Station.

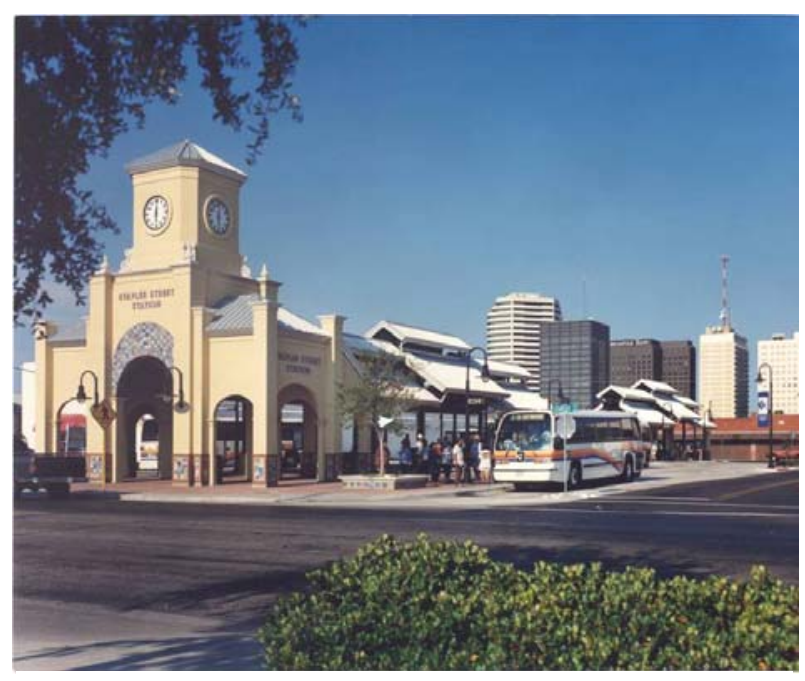

The Staples Street Station in Corpus Christi.

\section{Design Features at Staples Street Station}

The architect, John Wright, wanted to create a distinct 'sense of place' for the immediate environment in which the station would be built. Corpus Christi is a sprawling urban community that lacks a sense of centrality. There needed to be a design that would feel inviting and permanent, and that people would feel reflected their cultural backgrounds. The use of Spanish 
Mission style architecture reflects the city's heritage and is consistent with other historical buildings in the broader community, even though it was not necessarily consistent with the buildings immediately surrounding the transfer center. The buildings in the station do borrow a few features from the surrounding buildings such as the cast stone caps, scrolls, and roof angles. However, the combination of being

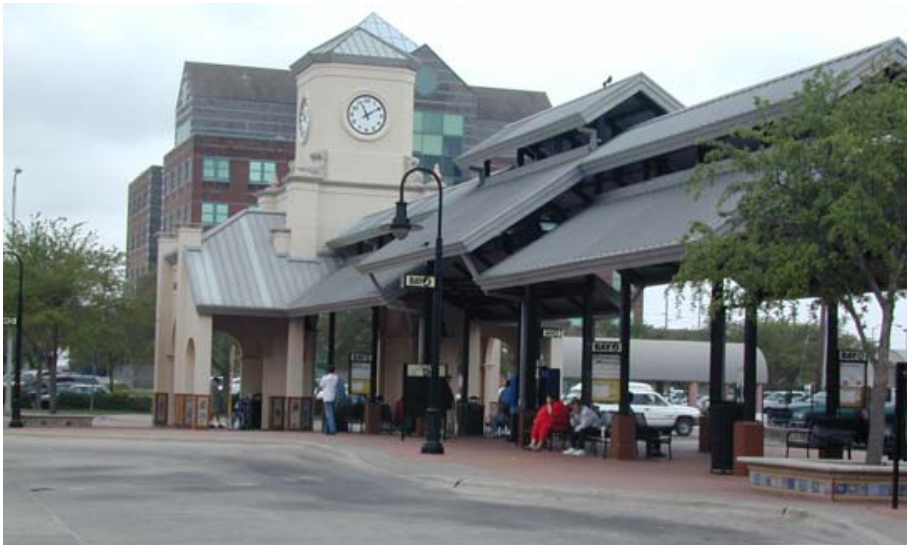

Design similarities of Staples Street Station and surrounding structures (note angles of clock tower and glass roof of City Hall).

fairly distinct in its immediate surroundings, but consistent with broader community themes, immediately makes it a positive landmark for the area. The architectural reflection of the area's history also helped to make the facility feel relatively timeless and permanent, which adds a certain gravitas to the site.

Mr. Wright also suggested incorporating a 'head house' into the buildings on the site. This head house is reminiscent of train station design, further enhancing the sense of history and permanence. The head house actually intrudes into the sidewalk of Staples Street by a few feet. This strategic positioning of the head house allows it to be seen by people traveling on Staples Street from a considerable distance, further increasing its presence in the area and establishes

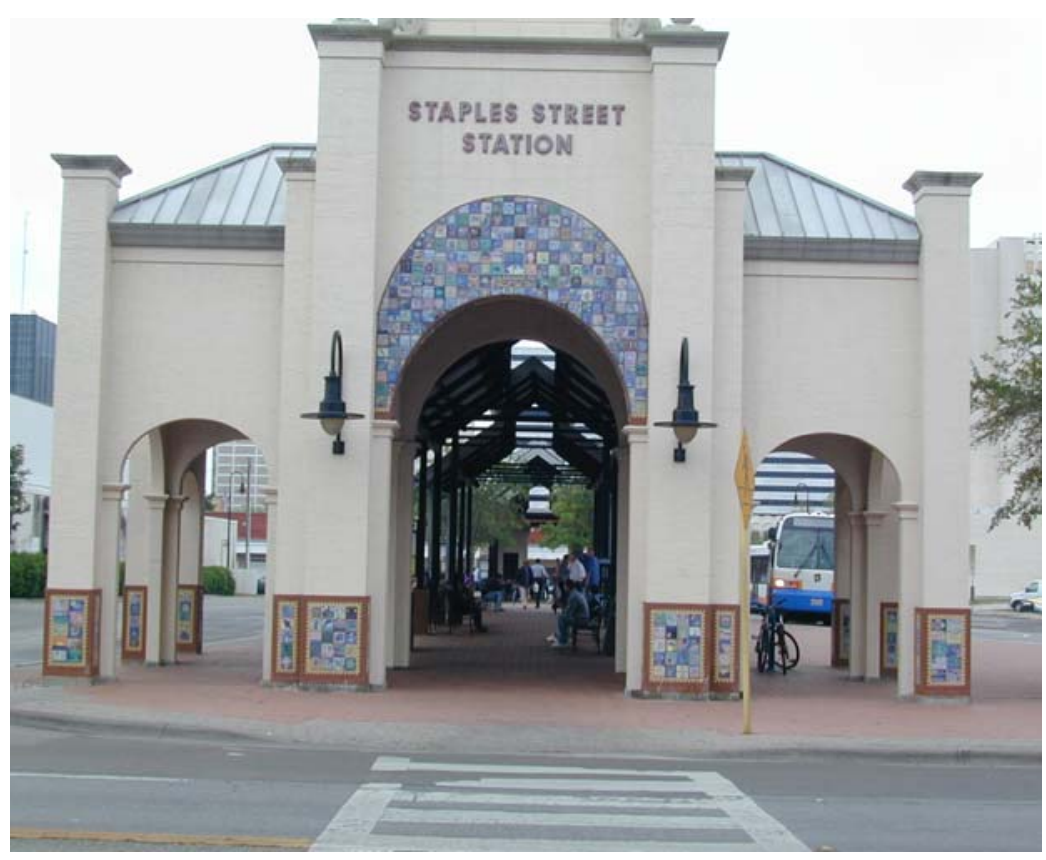

View of the Staples Street Station looking through the facility from the head house. it as a landmark in this area of the 
city. Crooked-armed streetlights reminding one of the early 1900s also imbues the site with a historic feel.

The Staples Street Station is comprised of two buildings and stands on a site of only .62 acres. Fifteen bus routes use the 10 bus bays at the site. Passengers wait under covered areas with structural metal roofs, with concrete pavers covering the floors. The overall height of the head house is 40 feet. The strong Hispanic heritage of Corpus Christi is reflected in the Spanish style clock tower and arched portals. The clock tower houses an anatomical clock, which is self correcting and always gives the correct time. There are no indoor waiting areas for passengers, but the weather conditions in Corpus Christi rarely justify the need for being in a heated shelter.

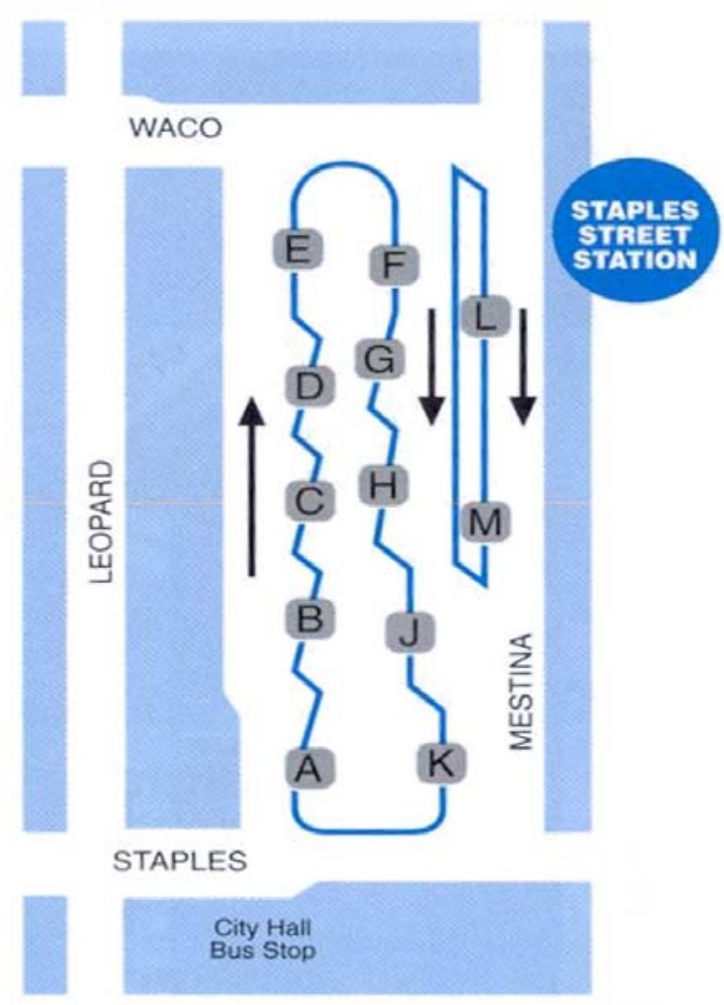

The Projects for Public Spaces, Inc., a New York City-based planning and consulting firm, was included as a consultant for this project. The PPS/John Wright design team searched for other ways to make this facility more of a truly public place that the community could feel ownership of. They hit upon a brilliant idea that was inexpensive, yet powerfully effective. They decided to incorporate ceramic tiles produced by residents of Corpus Christi into the walls of the buildings on the site. Incorporating these hand made tiles into the design of the Staples Street Station established the location as a place of public art. The Creative Arts Center and Aloe Tile Works in Corpus Christi were tasked to manage and coordinate the design and production of 1,700 ceramic tiles that were placed on the facility's vertical surfaces. Hundreds of local residents assisted in the design of the tiles. Contributors came from senior homes, local schools, and community centers of differing ages and socio-economic backgrounds. This innovative approach of community involvement culminated in a marked sense of community ownership of 


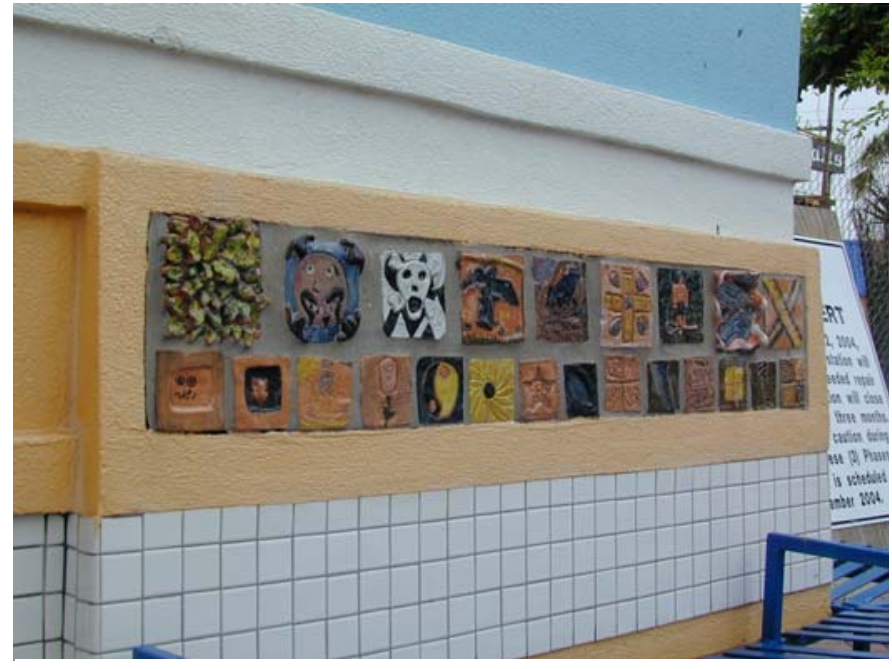

Hand made ceramic tiles created and made by the Corpus Christi community located at CCRTA transit stations. the Staples Street Station. The designs on the tiles often incorporate local scenes, bringing a greater sense of community identity to the facility.

The unique design features at the Staples Street Station have resulted in numerous awards including the Federal Design Achievement Award through the National Endowment for the Arts Presidential Design Awards Program.

\section{Security, Management, and Operations at Staples Street Station}

This facility is very open air in nature, with virtually no opportunities for someone to hide or assault anyone without being seen or heard. Passengers wait under pleasant covered areas with benches, planters, and trees. The CCRTA uses off-duty police officers to provide security at all of its transit stations. The officers do not provide oversight on a 24-7 basis, but they are a frequent presence at these facilities and oversee the facilities with unpredictable schedules. A CCRTA supervisor is often at the site as well to provide assistance to passengers and operators. The police officers also get out of their cars to be a presence among the passengers, to help provide information, and to discourage transients from staying in the facility or bothering any other passengers. There are no security cameras at the facility. There have been very few occurrences of property damage or danger for passengers since its opening in 1994. This part of Corpus Christi has historically not been subject to a high level of crime.

The decision to use ceramic tiles designed by members of the community on the vertical surfaces of the facility helps enhance security at the station in two ways. First, community production and ownership of artwork helps minimize the chance of damage or graffiti. A cleaner facility translates into a safer feeling facility. Secondly, being surrounded by the familiar settings often 
reflected in the tiles helps make passengers feel more safe and secure. The principle investigators were told that benches, poles, and trash cans are painted in black so that any graffiti can be easily and quickly spray painted out. It might be fair to surmise that the Spanish mission style of architecture also contributes to a greater ambience of peace and respect.

There are no customer service personnel at the Staples Street Station. This is partially a reflection of the tight budget of CCRTA. Approximately 4,000 passengers per day go through the facility, but they buy their passes at the Regional Transportation Authority's

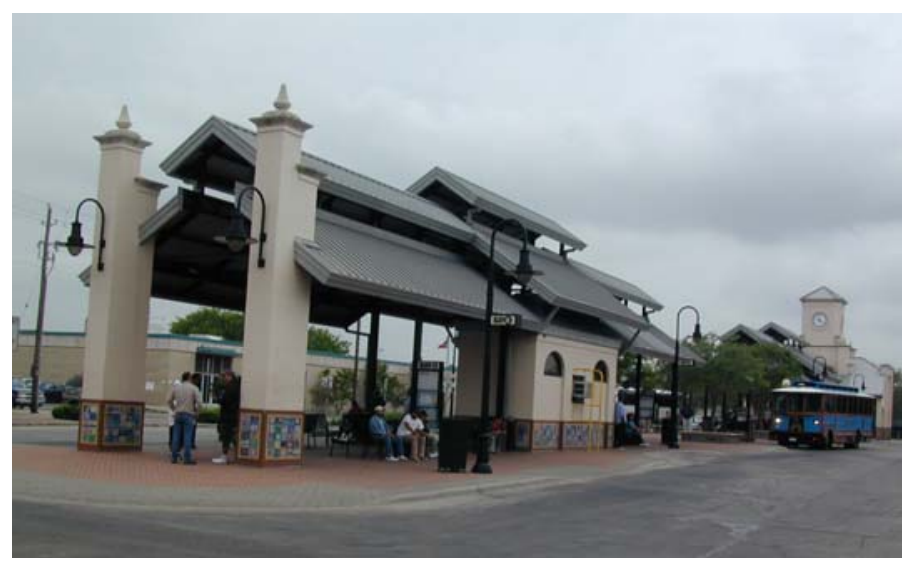

Passenger waiting areas at the Staples Street Station.

Customer Service Center near the Six Points Station a couple of miles away. The ten bus bays at the Staple Street Station all surround a single island, minimizing any conflicts between buses and pedestrians. The restrooms at the site are available only for bus operators and supervisors. There is a small building in the rear of the facility that operators can spend breaks in.

There are no vending machines at the site at this time, but the head house was built with the electrical infrastructure to allow such machines or kiosks if the CCRTA decides to incorporate such services in the future. In spite of this lack of conveniences, the passengers interviewed by the authors of this report spoke very highly of the facility and were grateful for it.

\section{Contributions of the Transportation Center toward Positive Community Development in the Surrounding Area}

The Staples Street Station is a facility that is well appreciated by bus passengers. The businesses along Staples Street and Leopard Street were also grateful to have the bus transfer area removed from the front of their buildings. As so often happens, bus passengers might be quite innocent of any wrongdoing, but many people feel uncomfortable having to go past strangers to get into a store or business. Moving the bus transfer function from the street to the transfer station also provided additional parking in front of the stores and offices along those streets. It would be 
saying too much to imply that business has dramatically improved in the immediate area around the Staples Street Station. Most of the uses are institutional and governmental. Nonetheless, those in the area are much more pleased with the current situation than they were with the former transfer operation. The improved architecture brings a great deal more class to the neighborhood than was there before. The image of transit has clearly improved within the community.

The relative openness of the station's design also helps provide more visual unity to the city offices that are located on one side of the station and the county and state offices that are located on the other side of the station. There is now a more natural spatial flow between these governmental buildings. Aesthetically pleasing pathways connect the Station with surrounding government offices, medical facilities, and a community service center. The pathways in and around Staples Street provide a safe and secure walking environment for all pedestrians, not just transit users. Curb cuts were made to make the entire area easier to navigate for the disabled. Improving the pedestrian environment through pathway design in and around transit stations has positively influenced the attractiveness of transit to Corpus Christi residents while improving the general ambience of surrounding communities.

A number of people commented on the fact that many hundreds of people participated in the planning and design of the facility. Numerous meetings were held with surrounding businesses and governmental agencies, as well as bus passengers and operators, to gain input on what the station should have and how the station should look. People who designed the ceramic tiles still come to the site to find their small contribution to the facility. There is clearly a sense that this is a community-based facility that is recognized as a point of pride. The CCRTA's image has been boosted as a positive collaborator in the community. A major part of the reason that there have never been major problems with graffiti or damage to property at the station is that it is regarded as a true community facility because so many people were part of the planning process.

The Staples Street Station was built with traditional funding sources from the state and Federal government, as well as the local match provided by the CCRTA. In addition, the CCRTA is utilizing an LCI grant to build a connecting walkway from the transit center to a low income minority community (Northside) that had been cut off from the downtown area by a major highway that divides the community from the governmental services around the Staples Street 
Station. The LCI grant provides the funds to help convert a local overpass for vehicles into a landscaped vehicle-free pedestrian pathway that links Northside and the downtown area where a number of services from the city and county are available. The design theme of the Staples Street Station is extended over the pedestrian pathway to the community center a few hundred yards away. LCI funds have already been used to provide bus stop signs and shelters in Northside that reflect the Staples Street Station theme. The CCRTA also helped improve the area around the Oveal Williams Senior Community Center with better sidewalks, planters, and tiled signage. These improvements have been welcome, and they do provide safer access to public services for those who live in the community, but it has not led to major changes in the community to this point. A transit agency can only do so much in that regard. The CCRTA has been a partner with the city in encouraging residents to attend job training and workforce development programs that are now located in the Northside area. Perhaps over time there will be a stronger association between the job development training and the accessibility that CCRTA provides to multiple job

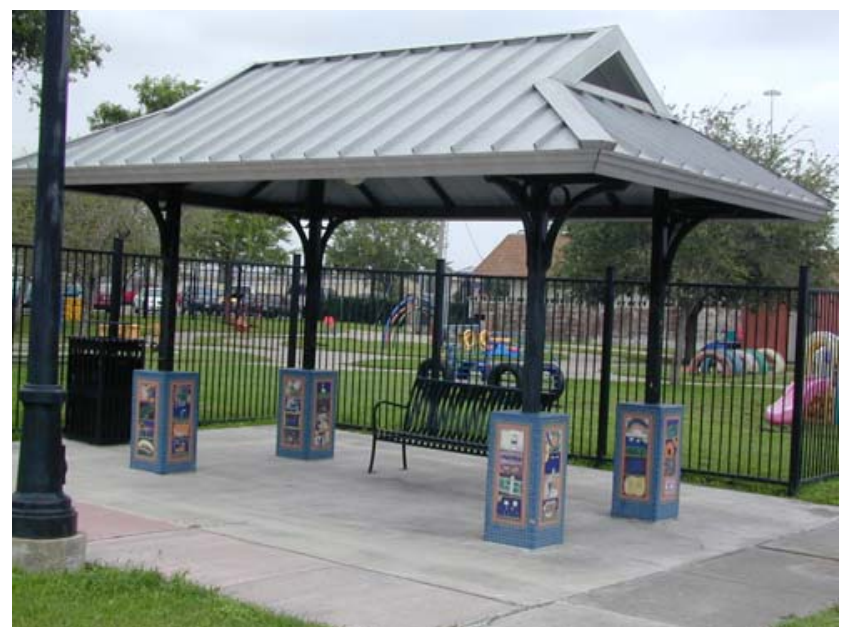

LCI Grant Funded Community Improvements at Oveal Williams Senior Community Center, Northside, incorporating Staples Street Station design themes. opportunities that may result in greater income to the residents of Northside, with consequent higher investment in that community.

\section{The Six Points Station}

The Six Points area of Corpus Christi was one of the first satellite business areas to be established outside of downtown Corpus Christi back in the 1940s. It had been in a state of decline for a number of years as newer development located further outside the downtown along major highways. By the 1970s, the core of the business area in Six Points was mostly derelict. The area had become characterized by empty and/or poorly maintained buildings, including a vacant bank building, a run-down empty movie theater occupied by homeless people, drug 
dealers and prostitutes, and many other shuttered businesses. According to community leader Dorothy Spann, an Eckerd's pharmacy was barely hanging on and wanted to move out of the community. The only other viable concerns were a small mom and pop bakery and the Democratic Party headquarters for Nueces County. The transit transfer station at "The Triangle" in Six Points was also decrepit, being managed by a city-owned transit system that had insufficient funds to maintain its various facilities.

In 1985, Corpus Christi passed a referendum with a number of elements, including a halfcent general sales tax dedicated for mass transit, and money to make multiple improvements to roads and drainage, particularly in flood prone areas. This gave the Six Points area some hope that help might be on the way. With the new general sales tax, the CCRTA was established as a separate agency from the city with considerably more money for transit service and improvements than had been available before. The CCRTA

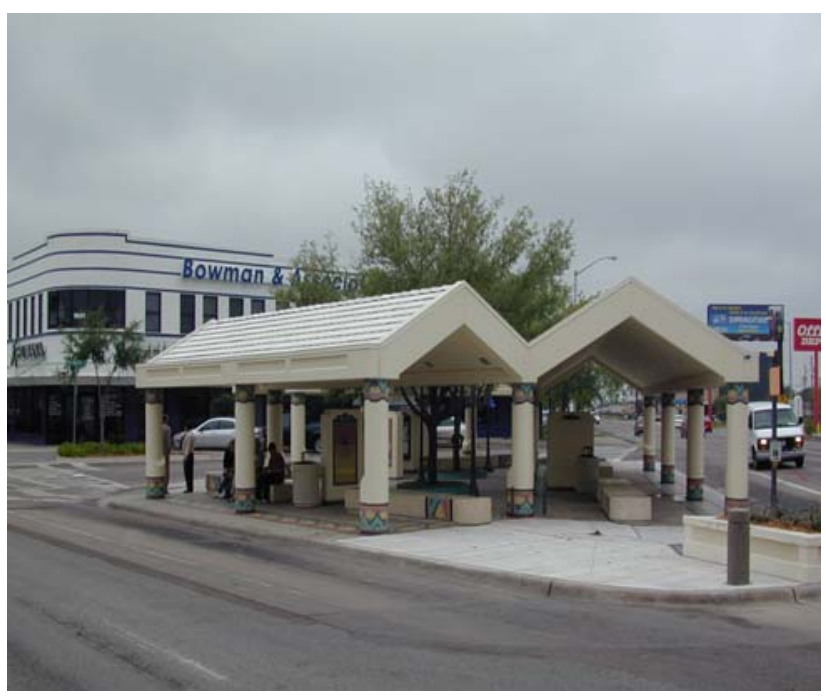

The Six Points Station (with Humana Insurance Office in the Background). tore down the decrepit transfer station at The Triangle, and replaced it with a simple but very attractive waiting area for passengers on the many routes that traveled past Six Points. In addition, the expanding RTA was looking for more administrative office space and was attracted to the vacant bank building at Six Points. The building had good size and plenty of parking, and was affordable, given the nature of the neighborhood. These two actions by the CCRTA helped bring a bit of life to the surrounding community. There was also hope

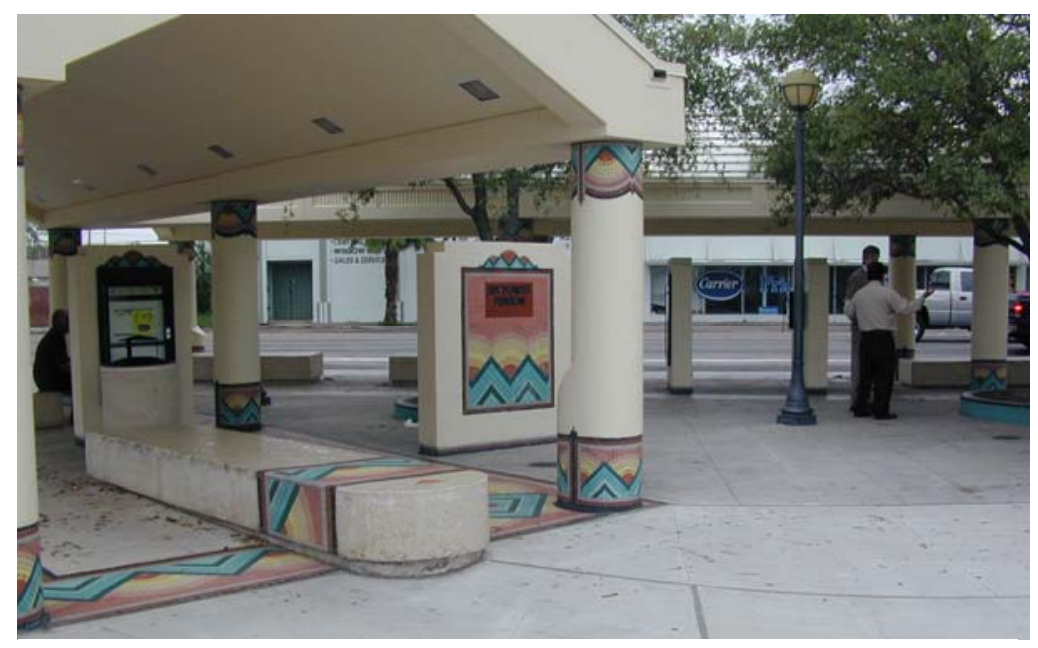

Simple but cheerful interior of Six Points Station. 
that improved streets and drainage made possible through the 1985 referendum would make the area a bit more attractive as well.

Six Points was a community desperate for improvements. It had a number of positive factors going for it in terms of good location in relation to a number of things in the city, and it was located on one of the highest points in the city in terms of flood protection. However, property values had been stagnant for years, and the lack of investment in both the business and residential communities reflected that. Now that its administrative offices were located in the neighborhood, the CCRTA became more aware of and involved in other issues in the community. Investors had expressed an interest in building a free-standing Office Depot in the area. However, the property they owned did not have enough parking spaces to allow the development of such a store. The CCRTA stepped in and made some of the spaces it had in its building available for use by the proposed Office Depot. This allowed the developer to gain the parking variance needed to proceed with the project. Things were starting to go in a positive direction, but more was

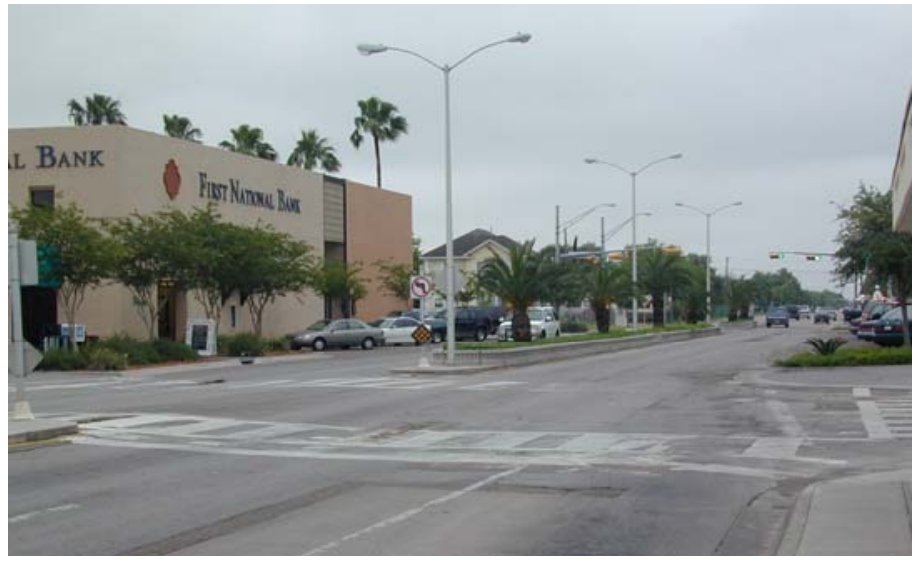

Landscaping, lighting, and pedestrian improvements near the Six Points Station funded through the Livable Communities Initiative Grant.

needed. CCRTA Director Tom Niskala and members of his board actively pursued a Livable Communities Initiative grant from FTA, and sought community input on where such funds could best be applied. It didn’t take long for their neighbors in the Del Mar Neighborhood Association to put together a list of improvements around the Six Point Transit Station for funding through the grant.

The community requested improved sidewalks, landscaped medians (which incorporated access management principles), street lighting, marked crosswalks, and angled parking instead of parallel parking in front of the businesses near the transit station. The improvements were included in the CCRTA's grant application to FTA which was approved, and the projects were put into place in 1999. From that point the neighborhood began to experience continued positive 
growth. The Eckerd's pharmacy that wanted to leave the community did leave its building, but moved to a better location in the Six Points area. An accountant purchased and renovated the second floor of an old building near the transit transfer facility and started a successful accounting business from that location. A Humana Insurance office that was used by many clients who used mass transit was established across the street from the transit station. The CCRTA sold the old bank building it had been occupying to a banking company that started its successful operations from that location. While the CCRTA moved the bulk of its staff to a new operations and administrative center outside of town, it retained its customer service center there in Six Points. The mom and pop bakery was replaced by an upscale restaurant.

The CCRTA played a major role in this community's turnaround. While the improvements it made to Six Points Station were hardly solely responsible, the Federal dollars that were made available for improvements through the LCI grant only came to the city through the linkage to the transit station. The $\$ 600,000$ facelift to the Triangle was a highly visible statement that this was a neighborhood on the way up. Business interests were willing to take a risk on investing in this community again. As is often the case, success breeds success. As each new business established itself in the area, more businesses were attracted to do the same. The owners of the derelict movie theater at least realized that their property might now be worth something, so they tore the old building down to make it ready for future development. Even though the site is not yet developed, there was an addition to the neighborhood through the subtraction of the old theater.

Essentially the CCRTA was filling a void that the City of Corpus Christi had left in terms of paying attention to opportunities for redevelopment. With its Federal grants and newly available general sales tax revenue, the RTA was in a position to be a player in the redevelopment of communities that wanted to partner with the agency. The Del Mar Neighborhood Association proved to be a consistent and solid partner with the CCRTA. Each side grew to respect the other due to the honesty and integrity each party displayed at all times. Regardless of changes in the leadership of either party, each honored what had been agreed to before and stayed on a steady course of neighborhood improvements. The neighborhood is now a much more desirable place to live and do business in, as evidenced by higher property valuations and more rapid turnover of properties as investors buy and sell in an improving market. 


\section{Summary}

The Corpus Christi Regional Transportation Authority elevated itself from being just a provider of mobility to also being a partner in economic development. Their ability to receive Federal grants designed to improve the livability of communities helped them leverage other public and private investment. The CCRTA has come to realize that it will prosper as its community prospers, and they actively seek opportunities to promote positive community development. While some of the results might seem small in a larger regional perspective, they can have meaningful impacts in smaller local communities. This in turn helps improve the image of transit in the service area.

As in a number of other areas, the CCRTA accepted that not everyone wants a bus transfer center in front of their businesses. Rather than resist this, they looked for positive alternatives that led to much better results for passengers and the surrounding community. The results have been that passengers have safer and more convenient facilities at which they can make their transfers, while communities have benefited from the award-winning transit centers that replaced run down properties.

The CCRTA also actively pursues total community participation in the planning and design of the improvements they can make. None of their plans are made behind closed doors with small teams of designers. They encourage hundreds of people to actively participate because they truly believe these are community facilities that can dramatically affect surrounding neighborhoods. The more participation there is on the part of the public, the more people will feel the facility is their own. In turn, the facility will be a safer place that will be respected and better maintained by those who use it. 


\section{Chapter Four}

\section{The Cedar Rapids Ground Transportation Center}

\section{Introduction}

As in many communities in the United States, public transportation does not carry a large percentage of all trips in Cedar Rapids, Iowa, nor is it expected to in the near future. In spite of this, the Ground Transportation Center developed by the Five Seasons Parking and Transportation agency has been a major factor in the positive development of downtown Cedar Rapids. The somewhat rare circumstances of having the transit function and the parking function combined in one organizational entity has helped those in charge of transit to be active players in the improvements for a midwestern city that had a significant need for a catalyst for growth and redevelopment. The Ground Transportation Center is an unusual example of mixed uses that coexist peacefully, while they have helped generate support for investment in a part of the downtown that had been extremely underutilized. The center is also a tribute to public-private partnerships, patience, persistence, flexibility, and creativity. The Ground Transportation Center did not reach its current state as a result of a single plan that was executed over a year or two of design and construction. This facility took almost 20 years

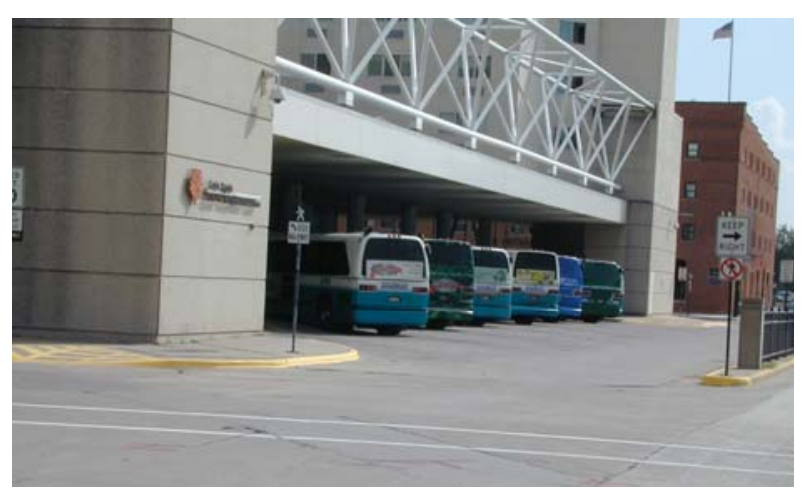

Buses parked in angled bus bays next to the passenger waiting area at the Cedar Rapids Ground Transportation Center. to attain its current functions.

\section{Historical Background}

Cedar Rapids is a mid-sized city with a population of 120,000, located in central-eastern Iowa, approximately 200 miles due west of Chicago, Illinois. It is the second largest city in the state and serves as the manufacturing, trade, and distribution center of eastern Iowa. Firms such as 
Quaker Oats, General Mills, Amana, Siemens, and Ford have been major employers in the area. The railroad industry has always been a major factor in Cedar Rapids, providing employment and transportation of agricultural and manufactured goods produced in the region. Nine different railroad lines criss-cross the roads within the city.

In the 1960s and 1970s, downtown Cedar Rapids started to decline noticeably due to the same sort of decentralization that was occurring in most urban areas around the country. People who once lived in and very near downtown were moving out to the suburbs. Retail businesses that had flourished in the downtown environment started to move to the suburbs as well to be closer to their customers. Two of the railroads that had rail yards in the city went bankrupt. A slow national economy burdened by extremely high interest rates made new investment very expensive and difficult. Cedar Rapids was suffering from these forces and was clearly at a turning point in its strategic positioning.

Through the 1970s, the transit agency in the city had no dedicated downtown transfer center. All the buses were timed to meet to transfer passengers around the intersection of $3^{\text {rd }}$ Avenue and $2^{\text {nd }}$ Street, considered the heart of downtown. There were no more than a few bus shelters to provide protection from the worst of the weather. The convergence of these buses took up valuable parking spaces in front of stores and businesses, and bus passengers often waited in front of the businesses on the street which made the retail function even more difficult downtown. Intercity bus terminals for services such as Greyhound and Trailways were not located where the intracity buses converged.

Fortunately, Cedar Rapids’23-year Mayor Donald Canney was a visionary, great facilitator, and a man with timely connections. He clearly saw the benefits of an off-street bus transfer center with indoor facilities that would benefit both passengers and businesses that would be relieved of bus passengers standing in front of their doors. In the larger picture, the Mayor understood the forces that were changing the downtown area, and recognized the need for Cedar Rapid's downtown to change its emphasis from retail functions to become an office, government, and cultural center. In the mid-70s the city focused its redevelopment in the northern portion of the downtown and was successful in office tower development and hotel investment, much of which occurred with air rights over public buildings such as new community centers, and on land 


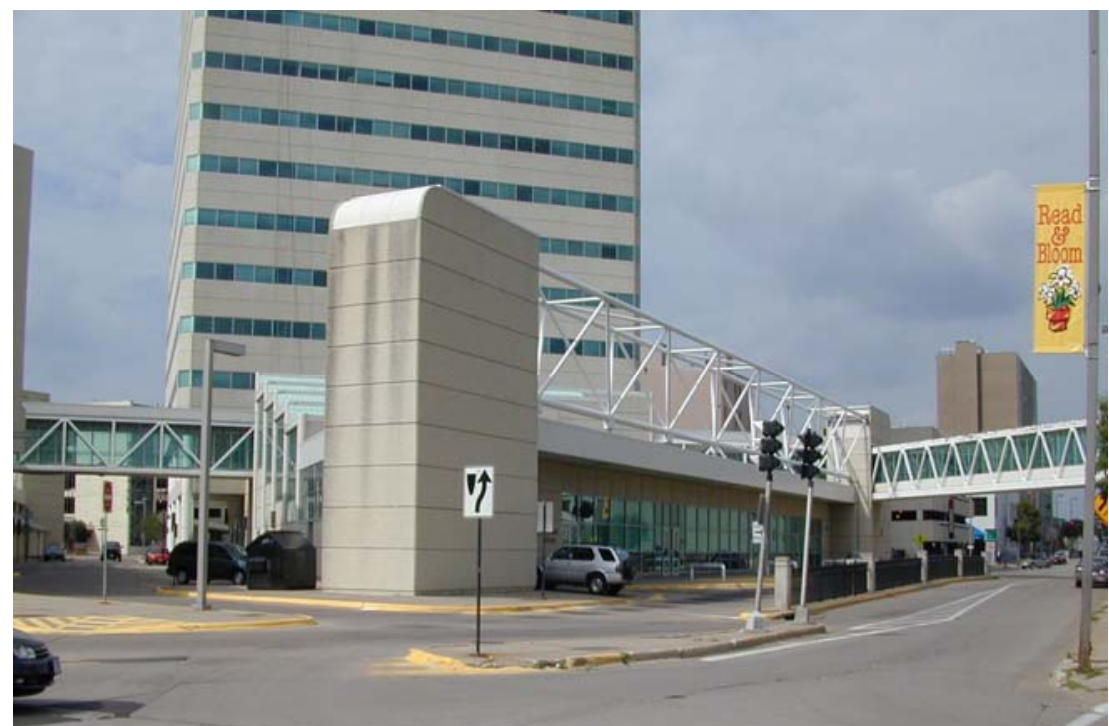

The GTC features private development in public air rights connected by skywalks to the rest of downtown. owned by the city. Cedar Rapids also started the construction of second-story enclosed pedestrian skywalks that helped connect the various buildings downtown. While these developments were very encouraging, much of the city remained underdeveloped.

The next best opportunities for redevelopment were toward the south end of the city where there were underutilized warehousing and storage yards. Fourth Avenue was seen as a barrier, south of which no one felt comfortable in investing. Mayor Canney saw the bankrupt railroad yards and other underdeveloped properties not so much as eyesores, but as opportunities for redevelopment. What was lacking was local public capital in a slow-growth city in a highinterest rate economy. The Mayor helped promote the idea that a ground transportation center could serve as the link between the redeveloping north portion of the city and the underdeveloped southern portion of downtown Cedar Rapids. This would provide a demonstration that the city was supporting development in the southern half of the city to help convince private stakeholders that investing in that portion of the city was a good business decision. However, there were insufficient local funds to pay for the costs of such a transportation center, and a transit function by itself would not be persuasive enough to encourage more investment in the south half of the city.

In 1976, as in all presidential election years for many decades, the Iowa caucuses were regarded as an extremely important opportunity for little known candidates to establish a reputation as a political winner early in the party primary season. Mayor Canney had been an early and active supporter of presidential candidate Jimmy Carter and came to know him on a first name basis. Of course, Mr. Carter was successful in the presidential election and took office in 1977. 
President Carter, who was familiar with urban issues from his time in helping to establish the Metropolitan Atlanta Rapid Transit Authority, had his administration develop urban policies that were designed to help strengthen inner cities through comprehensive approaches dealing with transportation, housing, and business development. The Carter Administration's Urban Initiatives Program set out to establish partnerships with localities that wanted to address their downtown challenges comprehensively. Cedar Rapids had already had experience with publicprivate partnerships through its redevelopment projects on the north side of the city. Hence, incorporating private partners into a ground transportation center was not a new concept or daunting task to the Mayor or City Council.

While consolidating transportation services at one location would be beneficial to both riders and businesses downtown, it must be appreciated that the city was looking to do much more than build just a transportation center. The greater vision was to encourage joint private development at the transportation center that would pay taxes that would accumulate in a Tax Increment Finance fund. Those funds could then be used to help pay for additional public improvements in the southern portion of the city to encourage even more private investment. Hence, the transportation center, to be made possible with Federal grants and private investment, would serve as the catalyst for a major redevelopment of downtown Cedar Rapids. The city hired Cannon Design, Inc. to prepare the concept for such a facility, based on that firm's experience in designing a similar transportation facility in Buffalo, New York.

From the start, the intent was to establish a center with mixed uses for a variety of reasons. First, such a development would satisfy the criteria of the Urban Initiative Grants that the Carter Administration was in position to award to applicants. Second, as noted above, the city fully intended to use property taxes paid by the private owners at the transportation center to help pay for further public improvements on the south side of the city. Third, the city wanted this development to integrate smoothly with the nature of the north side of the city so that there would be a natural blending with redevelopment that was taking place. A site with approximately 100,000 square feet was found at Fourth Avenue and Second Street that was already partially owned by the city. The site included a bankrupt railroad building that paid no property taxes, an old gas station with underground tanks that created a brownfield, and a hide and fur tanning operation. In all, the site contained small warehousing and retail businesses with 
about 75 employees that would receive relocation assistance once the properties were purchased by the city.

Cannon Design, Inc. managed the complex design process by developing a matrix that included the needs to satisfy various requirements for transportation (city buses, intercity buses, taxis, pedestrians, and paratransit), retail uses, office space, and housing. Architects worked with city development staff, city and intercity bus system managers, and interested developers in forums to develop various configurations for how to incorporate all the different uses on the site. During the summer of 1979, the city advertised for and received bids from private developers expressing interest in building over the air rights of the Ground Transportation Center (GTC). Although this type of development was a bit unorthodox, it was nonetheless attractive to a number of developers due to the fact that there was no cost for the land, and the site's infrastructure, as well as the foundation for the office tower, would be prepared by the city. The plan for the GTC called for a second story of retail that would be accessed through skywalks extended from the north half of the city. In addition, an eight to twelve story office tower and a ten to twelve story 200-unit apartment complex were proposed to be built over the retail space.

On its merits, the city's application clearly met the criteria of the Carter Administration's Urban Initiative Program. The project would require approximately \$5 million dollars in Federal funds, but if built as planned, the project would leverage almost $\$ 24$ million in private investment on the site of the GTC, and would hopefully spur other development in the area. These were the types of results the Carter Administration was looking to achieve. The Mayor's professional and personal affiliation with President Carter, spawned during the Iowa primary caucuses in 1976, certainly helped clinch the city's successful bid for Federal funds which were awarded to the city in December of 1979.

What the Federal government approved was a strong concept with many letters of intent from the city and a number of developers. However, economic conditions in the early 1980s caused the original private firms that had proposed retail and housing at the site to withdraw from the GTC project. Architectural plans for the site were consequently put on hold. The office developer also had to reconsider how it would stay with the project. Through much negotiation, an electrical contracting company agreed to develop the apartment complex if it could also develop 
the office tower as a means of making the financial numbers work for its investment. The original office tower developer agreed to this if his firm could retain ownership of one of the floors of the building. This led to further creativity in how the office tower would be built and managed. The electrical contractor decided to develop the office tower as a condominium, selling it floor by floor rather than renting out all of the square footage to various tenants. Owners of each floor could occupy the floor or rent it out, but they would all pay taxes to the city just as if they were on the ground floor.

The City of Cedar Rapids helped the electrical contractor by issuing industrial revenue bonds at approximately $10 \%$, much lower than the regular interest rates that were ranging as high as $22 \%$. The electrical contractor could sell these bonds and pass on this much more attractive rate to prospective buyers of the floors of the office tower. With these arrangements in place, the final design for the GTC could start. Groundbreaking for the facility took place in June 1982, almost three years after the initial plans for the center were developed. The center's grand opening occurred on November 7, 1983. Changes in occupancy have occurred at the center since its grand opening. However, more than 20 years later, the Cedar Rapids GTC remains a testament to how public transit can be a major contributor to its community through means other than just its transportation service.

\section{Features of the Center}

\section{Design}

This report has already given general information on the types of uses that were planned for the GTC, and more about the current uses will be included later in the report. From a design perspective, the Cannon Design group developed clear objectives for the center. Perhaps the most significant departure from other transit transfer centers was the fact that this center was designed first and foremost for people. Many transit center designs seem to be much more focused on efficient bus movements and storage. The Cedar Rapids GTC was designed to create a pleasant, efficient, and comfortable space for passengers to wait and easily see buses as they came into their 12 bus bays. The guiding principles behind the design of the entire center were: 
- The project must reflect the spirit of the City of Cedar Rapids. As a major gateway to the city that is known as the "City of Five Seasons", the center had to be an inviting, active public place in the spring, summer, fall, and winter;

- The GTC had to be a credit to the community and a source of civic pride;

- The GTC had to enhance the surface transportation experience and differ dramatically from the traditional bus terminal image of the past;

- The facility needed to project a sense of safety whereby all users would feel secure through the design of clear, unobstructed, highly visible spaces;

- The GTC must be safe and convenient by establishing easily understood and separated pedestrian and vehicular movement patterns;

- The GTC needed to be energy efficient, reflecting the energy efficiency goals of public transportation;

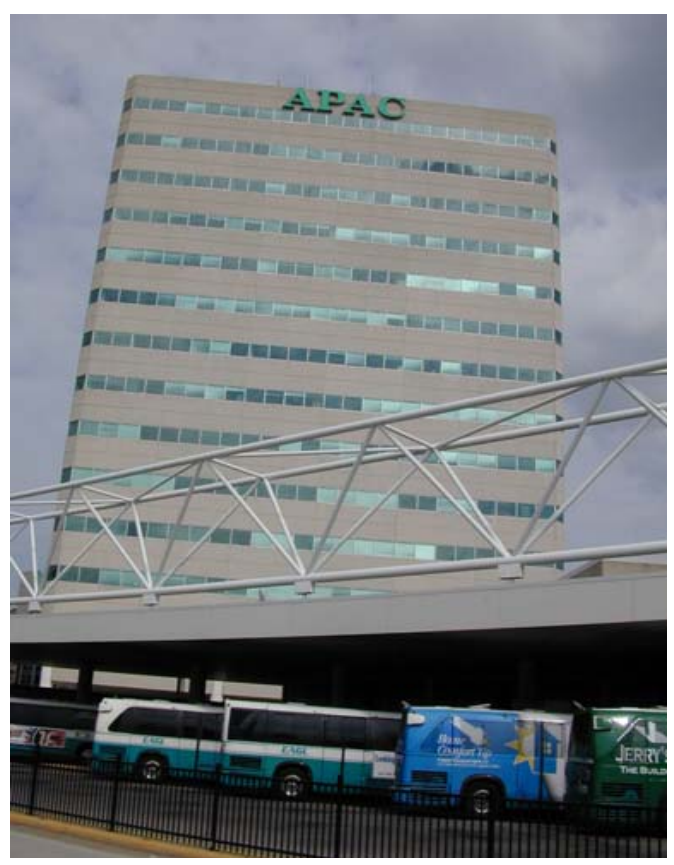

The APAC Office Tower with the GTC in the foreground.

- The GTC must totally integrate the relationships between private and public sector components of the facility.

The rectangular 15-story office tower is built at a 45-degree angle to the streets of the block in which the GTC is located, making it the only such building oriented in such a fashion downtown. This building's unique orientation gives the entire center a certain distinction within the downtown. It also opens up the GTC to the blocks around it and allows more ground area to be used for pedestrian purposes, including a public plaza that invites people from both sides of the block to enter. There is a very attractive walkway with wooden benches around flowers and trees. A significant metal sculpture representing running water (symbolic of rapids) dominates 
this plaza, where the Cedar Rapids Symphony Orchestra has held noon concerts during the summers.

The materials for all the buildings within the GTC are complementary to each other, to enhance a sense of integration among the various uses. There is a generous use of green-tinted glass panels

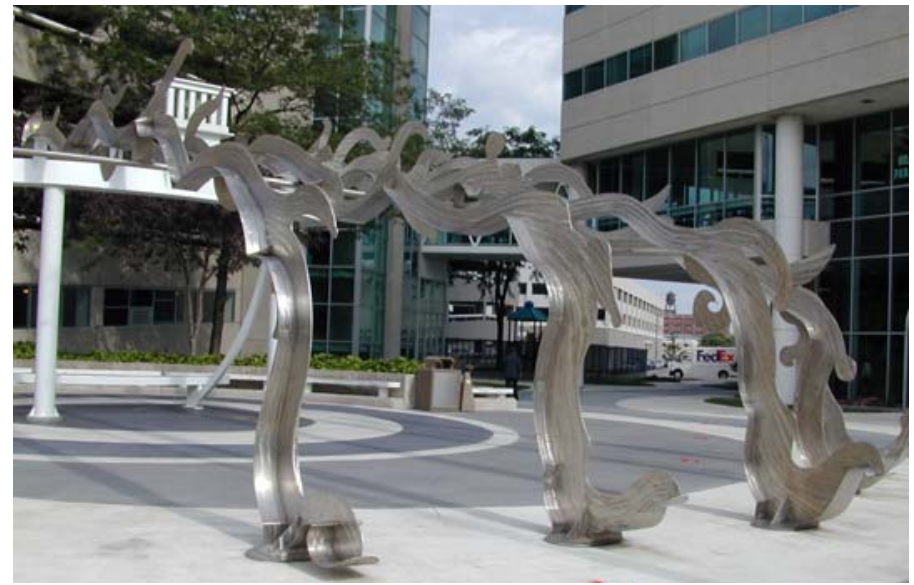

Public art representing river rapids situated outside the APAC Building. throughout the buildings that are designed to provide good visibility for security purposes, and also to provide a greater sense of warmth and friendliness than dark glass ordinarily would. The design of the glass panels over the passenger waiting area again reflect a cascading action, evoking a sense of motion as well as another reference to rapids. It was originally thought that the greater amount of natural light entering the buildings would also decrease utility bills due to less need for artificial light. While this strategy did work to reduce light bills, the glass was not the best material to hold heat in during the cold Iowa winters. Since the construction of the facility, the transit portion of the GTC has changed its heating system from electric to steam, saving a considerable amount of money on utilities.

The design of the bus bays for the city buses at the GTC is somewhat of a surprise to the first time visitor. The buses pull in at an angle to the curb parallel to the enclosed passenger waiting area. The buses are very visible to the waiting passengers and easy to access, but the buses must back up out of their angled parking bay to leave the facility. Although this method of

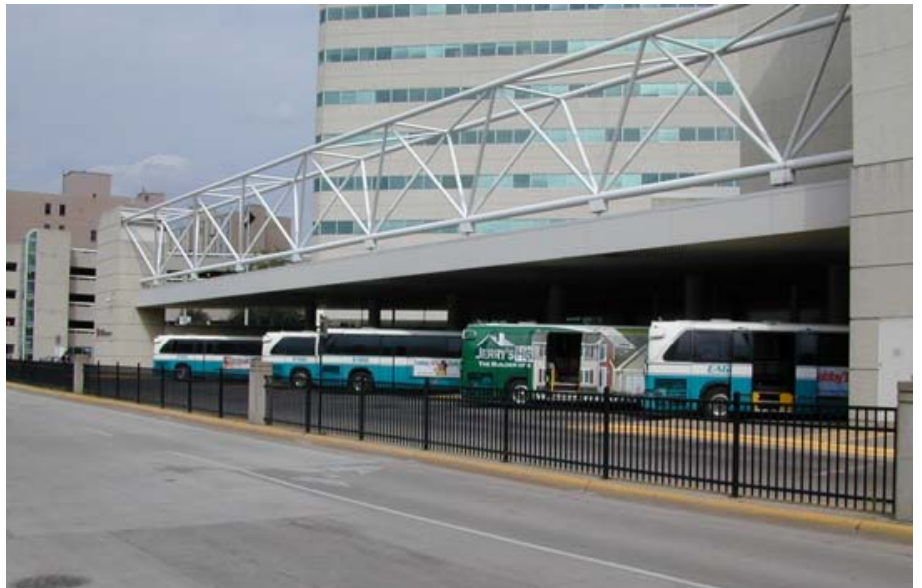

Angled bus bays at the GTC. 
parking buses helped ensure that passengers would not be running through any bus passageways to catch a bus, the likely cause for this design was the relatively tight space on a site trying to accommodate so many uses. The GTC is designed in such a way that the buses do not back up

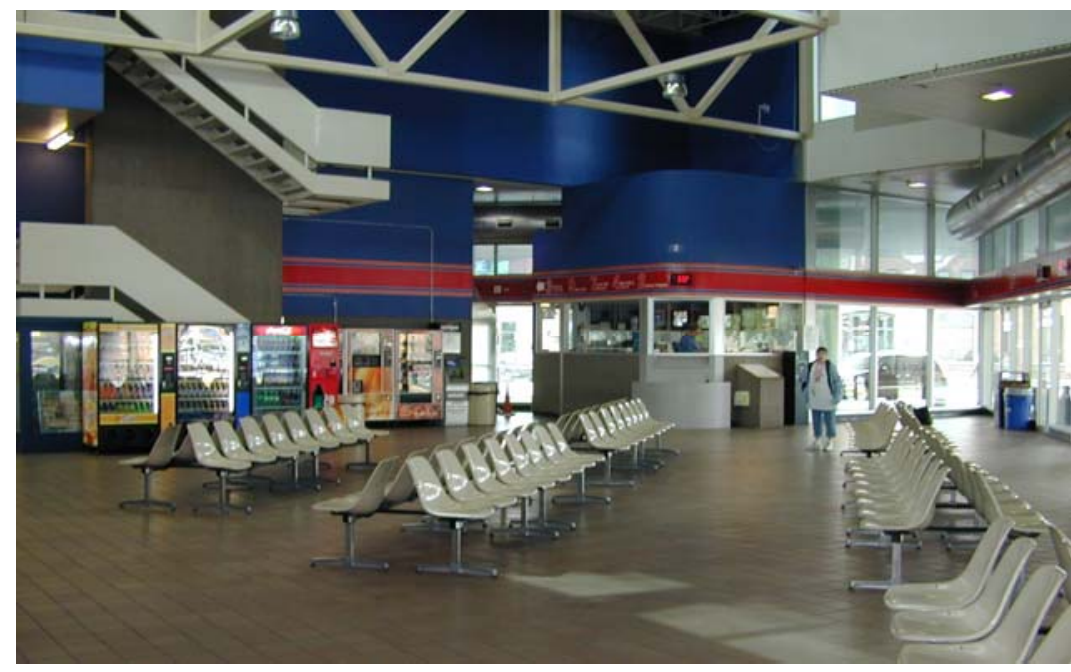

The GTC passenger waiting area is spacious, clean and comfortable with vending machines and customer information services available to customers. into any city traffic, so the danger of accidents with other vehicles is minimal. There is no good reason for any passenger to ever be behind one of the buses, and a traffic control supervisor in the GTC has cameras that can view the areas all around the buses. This supervisor controls the departures of the buses through activating green or red lights that tell the bus when to go and

when to stay where they are. There have been no vehicular or pedestrian accidents in over 20 years of operations, but all new bus operators are carefully taught how to back a bus out of the angle spaces.

The interior of the passenger waiting area is quite spacious with over 4,000 square feet and no support columns to block mobility or visibility once inside.

The relatively open floor plan is even more important to the many disabled people that use the transit system in Linn County. The ceilings are 22-feet high, providing an even greater sense of space. Some people claim it reminds them of an airport terminal as their vision is expanded through the high ceilings and cascading glass panels. The sense of international travel evoked by an airport is enhanced by a sixfoot diameter, rotating globe surrounded by a brass rail carved with the signs of the zodiac. The primary beige color of the inside of the terminal is livened by rich blue and red

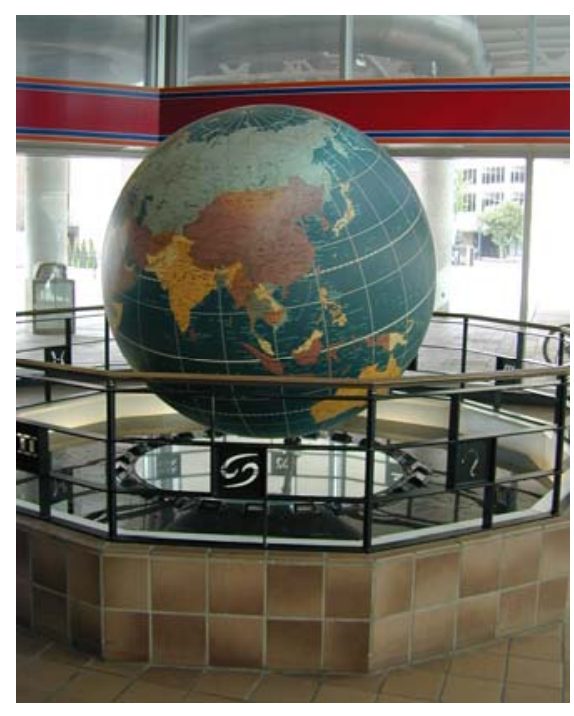


accents. The passenger waiting areas for intercity bus passengers is much smaller and more modest, but those passengers are welcome to wait in the intracity bus waiting area if they wish. The bays for the intercity buses are located in a separate portion of the GTC, though just a short walk away.

\section{Security, Management, and Operations}

The Cedar Rapids Ground Transportation Center is the focal point of the transit system in the city. Twelve routes converge in extraordinary precision each half hour at the center, allowing easy transfers for people making trips that require more than one route to complete. The GTC is rapidly becoming the center of the redeveloped downtown of Cedar Rapids, and bus passengers can access most immediate areas of the downtown via surface streets or through the pedestrian skywalks from the bus center. Given its high visibility and relatively high usage by passengers, Five Seasons Parking and Transportation takes substantial measures to keep this system landmark clean and safe. Though it was over 20 years old when the authors of this

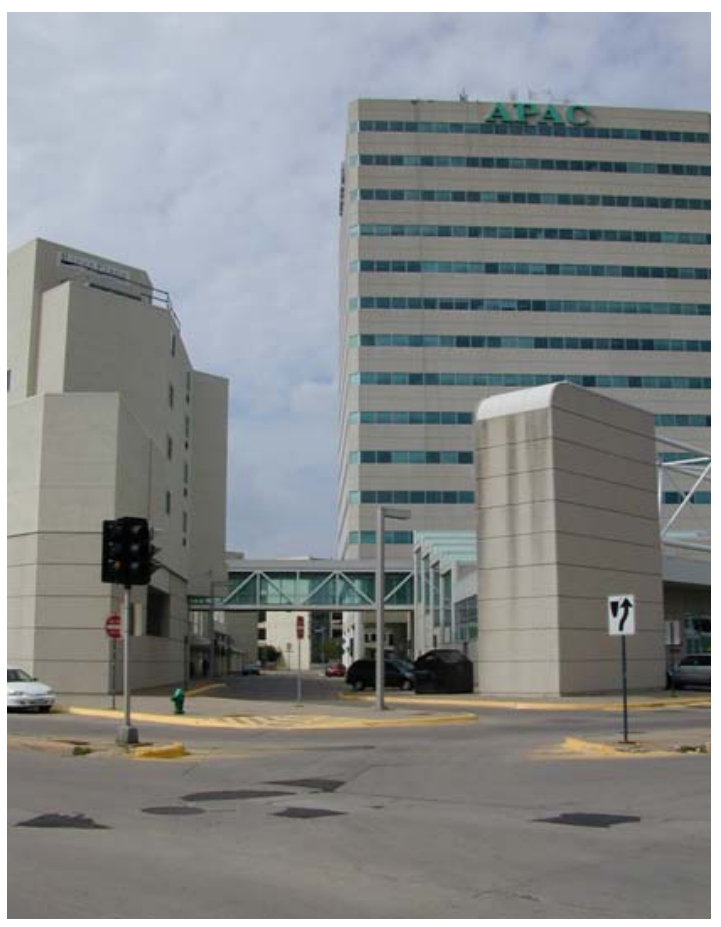

Entrance to intercity bus station adjacent to GTC/APAC. report visited the center, one would never know that it wasn't relatively new. The facility is kept very clean on an hourly basis, and it is repainted frequently to keep everything fresh, clean, and bright. One unusual and positive aspect of the bus system in Cedar Rapids is that all the buses run on alternative fuels. Though there are twelve buses idling when all transfers are being made, there is virtually no odor of diesel fuel coming from the buses. More remarkably, the average age of buses in the fleet for Cedar Rapids is 25 years, with most buses having over 900,000 miles of service. The city was the third transit property in the country to purchase RTS buses in the late 1970s, and they have made it a point of pride to maintain this fleet in top shape. This record of efficiency helps their image in the community as an agency that is being run in an efficient, business-like fashion. 
There is a security guard on the grounds 24 hours a day, seven days a week. There are a number of security cameras that view the inside and the outside of the all buildings at the Ground Transportation Center. The cameras focusing on the transit portion of the facility are continually viewed by a station supervisor. A chief supervisor for bus operations has his office at the facility and is there to oversee bus operators and to assist passengers, and adds another level of oversight for security. A passenger information booth is also positioned to see everything going on in the passenger waiting area.

As noted earlier, the center is characterized by substantial glass panels that provide clear visibility throughout the facility. There are no evident hiding places where criminal intent might be carried out undetected. There is good natural lighting during the day, and sufficient lighting at night to help discourage any nefarious activities.

The bus transfer portion of the GTC is managed and operated by the Five Seasons Parking and Transportation agency, a division of city government in Cedar Rapids. The office building, known as the APAC building after its primary user (the All-State Promotional Advertising Company) is managed separately by the Center Owners Association comprised of the various owners of the 13 floors of offices. The housing portion of the GTC is managed by yet a separate entity. Crime does not seem to be a major issue in and around the GTC. According to Bill Hoekstra, director of the Five Seasons Parking and Transportation agency, crime has gone down in the area around the GTC since 1983. The property manager for the APAC building stated

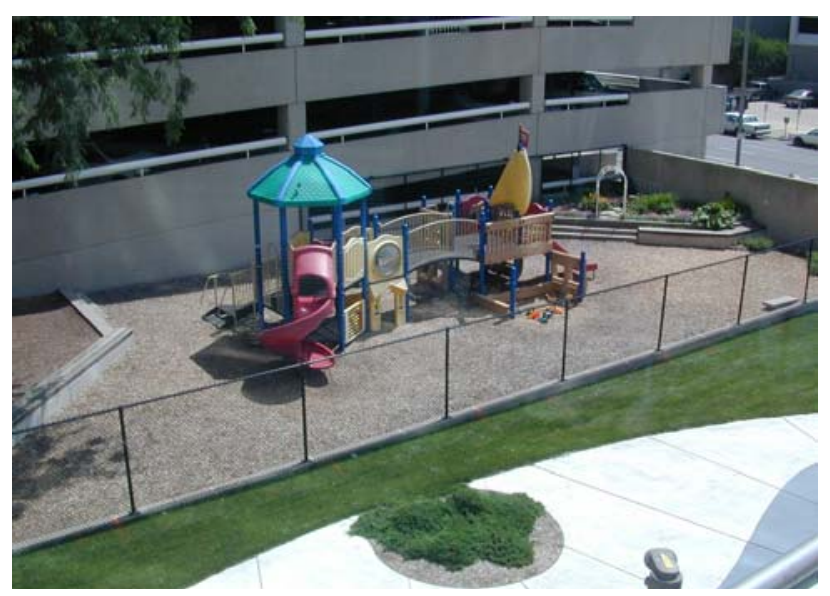

The play area of the Montessori School located at the GTC. there are occasions when a drunk might be found sleeping in the stairwells. There was a time that the bus waiting area started to become a hang-out for teenagers. As in Charlotte, North Carolina, the transit agency started playing classical music and big band music in the waiting area, and this made the area less attractive for groups of teenagers to hang out in. The city also passed ordinances making loitering illegal in the facility, 
giving security and operations supervisors the right to ask people who have been there more than 30 minutes to move on.

One of the more unusual elements of the GTC that was not originally planned for is a Montessori School for children from the ages of two and six. The space that the Cedar Valley Montessori School occupies is in the first floor area of the office tower and was originally planned as space for passenger waiting areas and storage for intercity bus companies. Nine bus bays had been provided for intercity buses, the most prominent being Greyhound and Trailways and that company's affiliates. By the 1990s, intercity bus service was falling on very hard times. Greyhound suffered strikes and downsizing while some other smaller companies went out of business permanently. By the late 1990s, only nine intercity buses a day were using the GTC. The intercity bus function no longer needed the entire space that was originally built for it.

At the same time, the Cedar Valley Montessori School, located in the suburbs, was facing an expiring lease and looking for a new location. The city of Cedar Rapids was actively trying to attract a school into the downtown as a further strategy for making office development more attractive and offered a \$50,000 grant as an incentive. The Montessori School conducted a capital campaign and raised an additional \$100,000 to help remodel three-quarters of the space originally designed for the intercity bus function. While there were some skeptics who questioned whether an elitist school

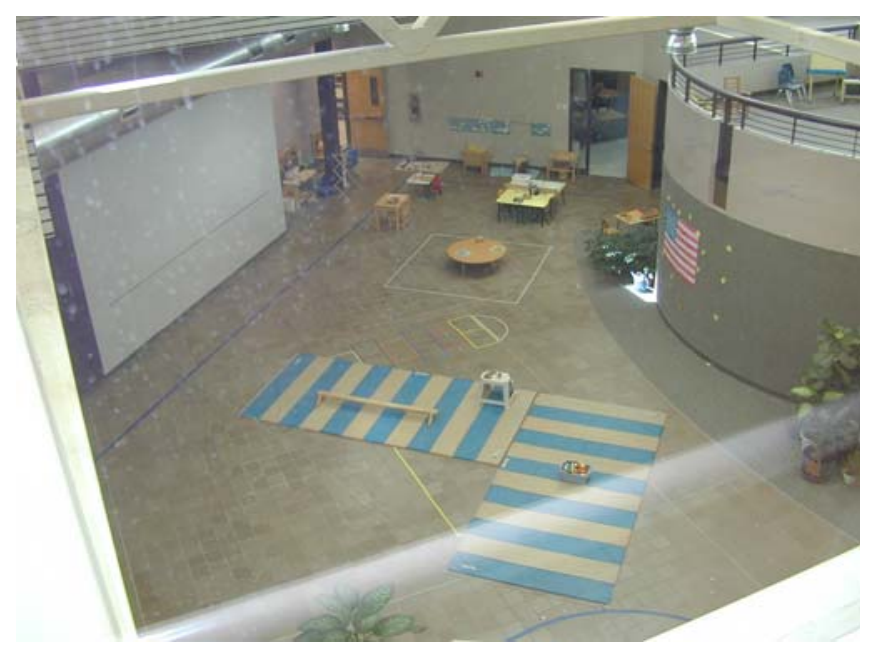

Interior shot of the Cedar Valley Montessori School at the GTC that was originally used as intercity bus waiting area. should be allowed to operate on what was public property, the school signed a ten-year lease in 1997 to operate from the GTC. Classes at the school operate from 8:30 a.m. to 11:30 a.m. and from 12:30 p.m. to 2:30 p.m. The facility offers daycare services from 7:30 a.m. to 5:30 a.m. 
Security is a major priority for a school with young children. There were clearly nervous parents who questioned whether a school on the grounds of a bus transfer center made sense. The image of transients that often characterizes bus transfer centers was prominent in the fears of concerned parents. Ultimately, not a single child attending the school when it was in the suburbs left the school when it moved to the Ground Transportation Center. The Cedar Valley Montessori School paid for and utilizes many cameras, shares the cost of security guards with the office tower managers, and strictly limits the entry ways to the school space. No one gets into the school building without being seen and greeted. The school representatives claim the majority of parents are very happy with the central location of the school, being closer to where many people work downtown. The only downside is the relatively small area outside the building at the GTC that is protected by a fence and set aside as a playground.

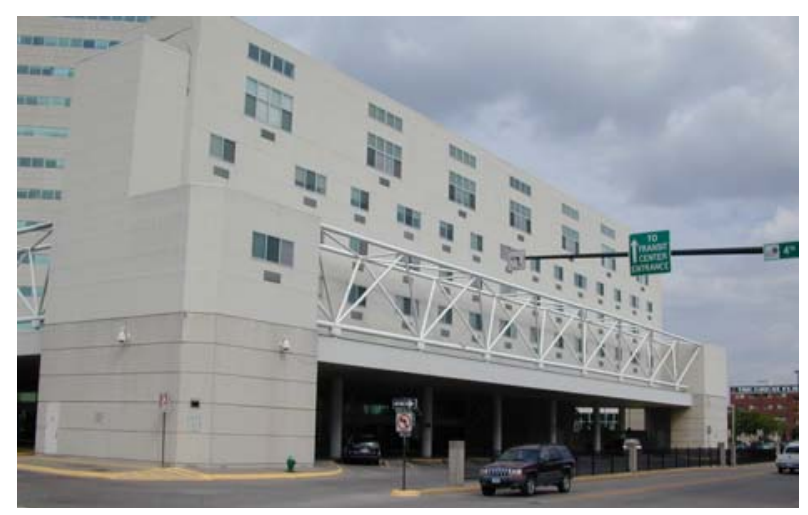

Rental housing above the GTC.

The housing apartments at the GTC were originally intended to be Federally subsidized housing for the elderly, with a certain percentage available to low income people. When plans changed during the middle 1980s, the rents were targeted for middle income renters. Over time the housing provided at the center has been more attractive to modest income households. It is not regarded as the most successful element of the GTC, but it was an honest effort on the part of the city to provide affordable housing to those who work in the city, and to attract more people who would support the retail businesses in the downtown. Most tenants now tend to be younger families and single parent households.

The APAC office tower was 85 percent occupied when the principle investigators for this report visited the site. According to the property manager for the APAC building, the average occupancy rate for office buildings in downtown Cedar Rapids is approximately 60 percent. Hence, the office tower at the GTC was doing quite well in terms of attracting and retaining occupants. Those occupying the floors of the APAC building included an advertising firm, an insurance company, and a number of Federal agencies including the FBI, the IRS, and the United 
States Bankruptcy Court. APAC is a telemarketing company that occupies 50 percent of the building. The office space is well located within the city, but some occupants regard some of the other uses at the GTC as a nuisance. They find that when classes change at the Montessori School there is a "beehive" of Hummers and Explorers occupied by parents waiting to pick up their children. This makes it difficult for visitors to the office building to find convenient parking at the street level when these class changes happen. The taxis that wait along the curbs to pick up intercity bus passengers also take up curb space that visitors to the office tower might otherwise use. The office occupants are also mildly concerned with the occasional panhandlers that sometimes approach those who walk through the GTC to get to work. It appears that none of the aggravations noted above are critical, but it does point out that any new facilities built with similar activities can learn from some of the minor conflicts that occur with this set of users at the GTC.

Five Seasons Parking and Transportation collects rent from all of the different users at the GTC. It collects $\$ 60,000$ annually from the Montessori School, \$48,000 annually from the office tower based on a charge of $\$ .15$ per square foot of space, \$20,000 from the rental apartments based on a rate of $\$ .10$ a foot, and $\$ 25,400$ a year from the intercity buses that operate at the GTC. These rents almost cover the $\$ 170,000$ annual costs of maintaining, supervising, and securing the facility.

The intercity bus function takes a relatively small portion of the GTC. Being jointly located with other transportation modes is beneficial to the intercity bus passengers, and is a better arrangement for the intercity bus companies than owning, maintaining, and paying taxes on their own bus stations in another part of town that was often unattractive. Five Seasons Parking and Transportation wants to see the intercity bus companies succeed, since they are renters at the GTC and help feed passengers to their local buses. Hence, the level of partnership has been very positive and appreciated by both sides. The city uses Trailways as their charter bus agent, and helps the company with Federal grants to make the intercity buses more accessible to the disabled and more secure for all passengers. Ron Moore, president of the local Trailways' affiliate stated that he wished the GTC had dump stations for the intercity buses that stay overnight, which would allow them to clean the restrooms of their coaches during their overnight 
stays. Other than that, he is delighted with the arrangement of being a part of the GTC, and is most appreciative of the city’s sincere efforts to work with them on a number of issues.

\section{Services Available at the Center}

Although there are a number of different tenants at the facility, the Ground Transportation Center does not offer a great variety of services that are that meaningful to the everyday transit passengers. The office tower contains the types of businesses and agencies that might be found in any typical office tower in a downtown area, with a mix of private businesses and Federal agencies. The Montessori School is private and expensive, and while School Supervisor Linda Waldman noted that some scholarships are offered, she doesn't believe that any of the students or their parents use the local buses to get to the school. The students are young children, and virtually every one of them is dropped off and picked up by their parents. The intercity bus services are a convenience for the relatively rare occasion that a Cedar Rapids person might need to use one to get to another city, but there is not a prominent flow of people from one facility to the other. Some of the households that live in the moderate housing on the site use the transit service, but other passengers certainly do not use the housing in any fashion.

The interior of the bus waiting area contains food vending machines for the convenience of waiting passengers. In addition, on the second floor of the office tower there is an affordable cafeteria-style restaurant that is available to the passengers as well as any other member of the general public or anyone else that works at the GTC. Cedar Rapids is a relatively small city where only three percent of all trips to the downtown are made by transit. With a daily passenger flow of just a few thousand, there is not a sufficient market among passengers to support more substantial business activity.

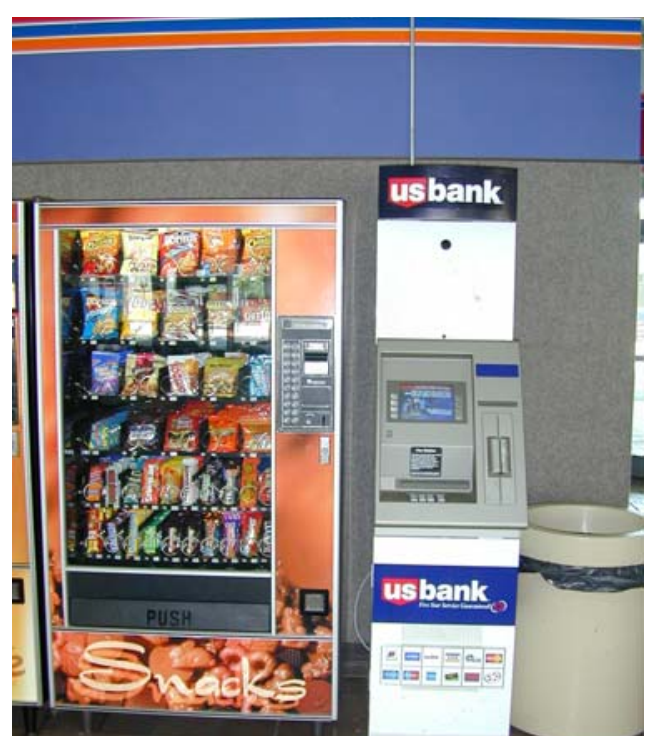

Vending machine and ATM inside the GTC.

The passenger waiting area also includes passenger information that is made available through a customer service agent located in an office that 
oversees the entire waiting area. This agent sells tickets and fare media from that office. One interesting feature of the passenger waiting area is the real-time bus information that is available to passengers. One might not ordinarily expect to see such a service in a small transit system. However, Rockwell-Siemens, a defense and transportation systems contractor, is a major employer in the area that has produced products for the military and for transportation interests. Five Seasons Parking and Transportation worked with Siemens as a test site to develop and perfect an Automated Vehicle Location system. Consequently, at low cost, the transit agency in Cedar Rapids became one of the first transit agencies in the country to operate such a system which is beneficial to transit supervisors and to waiting passengers who can monitor when the next bus is going to arrive.

There are restrooms in the passenger waiting areas, and a very spacious room for bus operators to take breaks in. Transit Supervisors also have offices in rooms adjacent to the passenger waiting area that is separated by walls and windows, allowing supervisors and drivers to observe any activities going on within the common areas.

\section{Contributions of the Ground Transportation Center Toward Positive Community Development in the Surrounding Area}

As noted above, the GTC in downtown Cedar Rapids does not offer a great variety of services to the everyday passengers who use it as the focal point of the city's transit system. It does offer comfortable shelter from the weather in a pleasant, safe, and well maintained environment with passenger information, restrooms, and some limited options for food if desired. There are no other frequently used local governmental or public services that are otherwise available on the site. While the limited services offered to passengers are very important to them, the real story behind the GTC is the value it has brought to positive development in the City of Cedar Rapids.

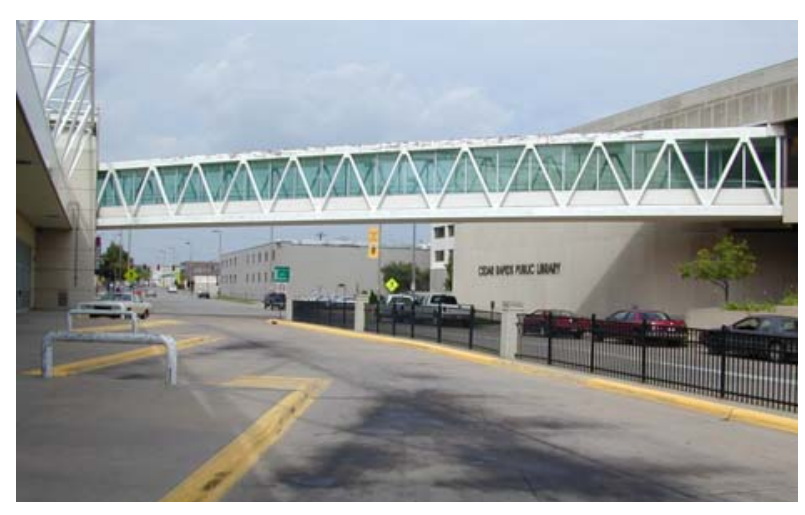

An example of an enclosed pedestrian skywalk connecting the GTC and the Cedar Rapids Public Library. 
All of the local stakeholders credited the GTC as being the catalyst for redevelopment in the northern half of the downtown area of Cedar Rapids. At a time when public and private capital for construction was hard to come by due to a slow economy and very high interest rates, the GTC provided a platform for the city to attain Federal funds that helped build a multi-use center that included a prominent office tower in a part of downtown that had suffered disinvestment for years. The office developer was attracted to invest in the site due to the fact that were no land costs to assume, and the foundation for the building was paid for through the Federal grant. In addition to the reduced costs of construction, industrial revenue bonds issued by the city offered interest rates that were half the rate of borrowing money in the private market.

This development helped to convince all investors that the city was clearly supportive of continued redevelopment in the southern portion of the downtown area. With this demonstration of investment, the city was then able to attract mostly private donations from large and small contributors to build a new municipal library across the street from the GTC. This library was linked via skywalks to the GTC, and helped to solidify the transit center's importance and provide further evidence that the trend in development downtown was to move further south. Over an eight year time period the city collected $\$ 2.4$ million in taxes from the private developments at the GTC. This money was placed into a Tax Increment Financing fund, the proceeds of which were used to help finance other public improvements south of the GTC such as a riverwalk park, a science station at a refurbished historic firehouse, and an IMAX theater. The library and the science museum are very complementary uses to the Montessori School. These public investments in turn

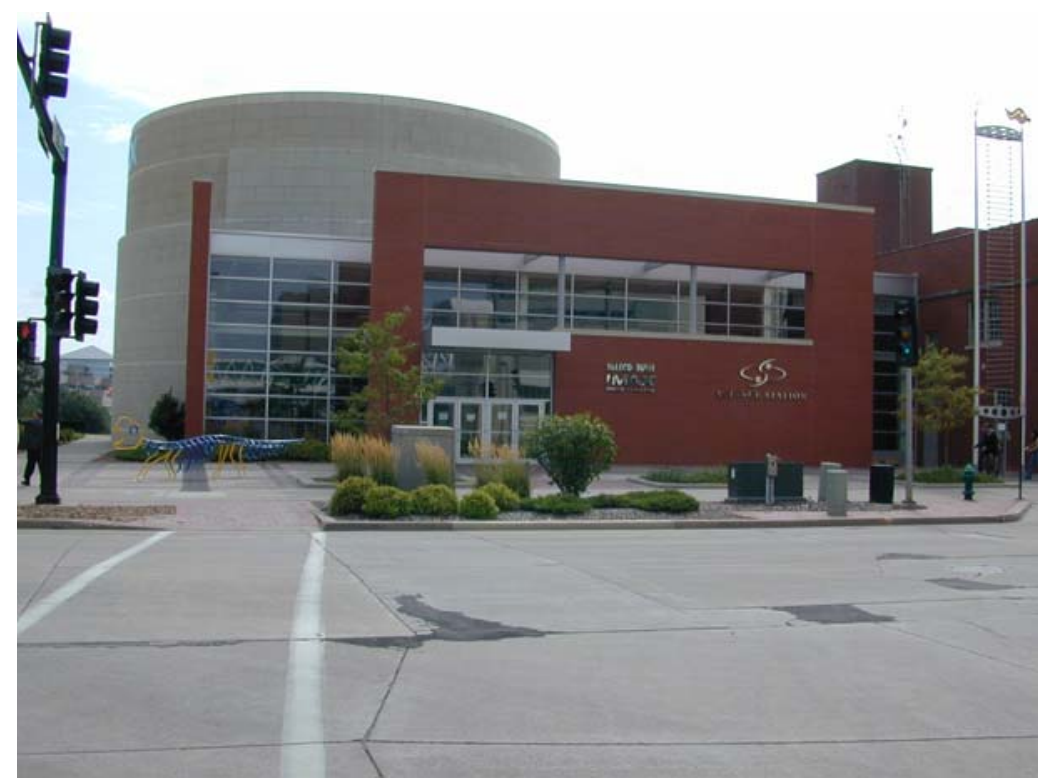

IMAX Theater built on land made available through tax increment funds generated by the private development at the GTC. 
made the south end of the city that much more attractive for further private investment.

The location of a Montessori School at the GTC provides no direct benefits to bus passengers, but having such a school downtown makes the downtown a more attractive place for employers and employees. Those who work downtown have a convenient place to take their children to school as part of their commute to work, and they can easily visit their children during the day if they wish. There

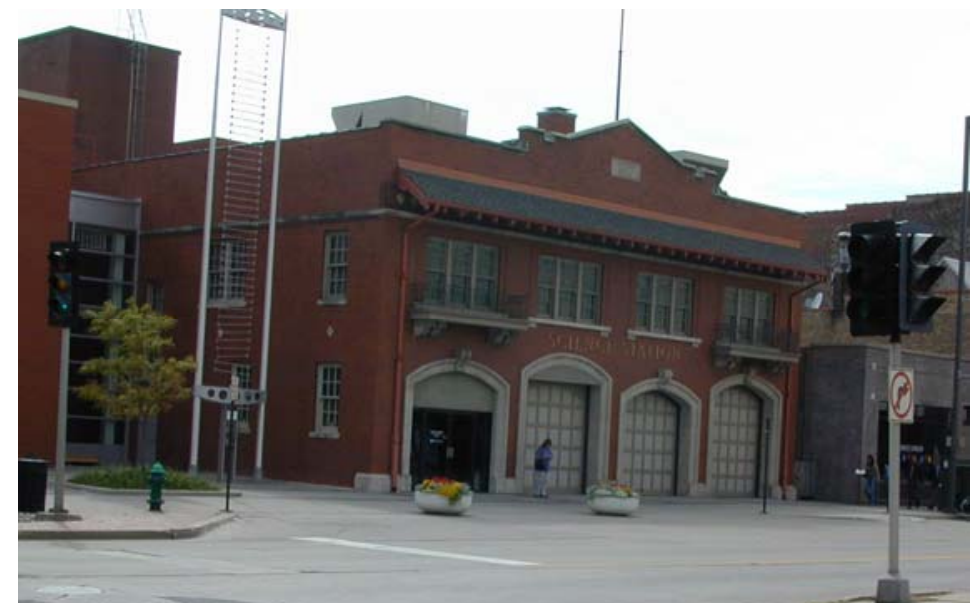

Renovated Fire Station and Museum funded through tax increment financing generated by the private development at the GTC. is now a waiting list for openings at the Cedar Valley Montessori School through 2007. This convenience for office workers helps to make the downtown area a more attractive and competitive place for office development.

A new center for the developmentally challenged will be opening within a block of the GTC. Having the transit transfer function nearby will assist these clients by learning the life skills necessary to use the transit system as they transition from the center to the work world.

Moving the transit transfer function from the intersection of $3^{\text {rd }}$ Street and $2^{\text {nd }}$ Avenue was a benefit to the businesses at that prominent downtown location. It helped create more parking opportunities in front of their businesses, and it removed the nuisance of having bus passengers waiting in front of their doors as they waited for a bus. The GTC provided a much more pleasant facility for bus passengers in a location only a block away, connected by skywalks to all of the rest of the downtown. This proved to be a win-win situation for the passengers and businesses downtown. Sarah Else, Director of the Downtown Business Association, does not regard the GTC as a place with any stigma at all. She regards it as a part of the vibrancy of a downtown, and as a facility that helps to make everyone feel welcome and wanted in the downtown area. 
All stakeholders visited by the principle investigators for this report firmly believed that the GTC was the catalyst for new developments in the south end of the city including the Great America Building (another office complex), Intermec (a computer technology manufacturer), a new YMCA, and a new Federal courthouse. All of this development saw its genesis in the construction of the GTC. The GTC did not have a

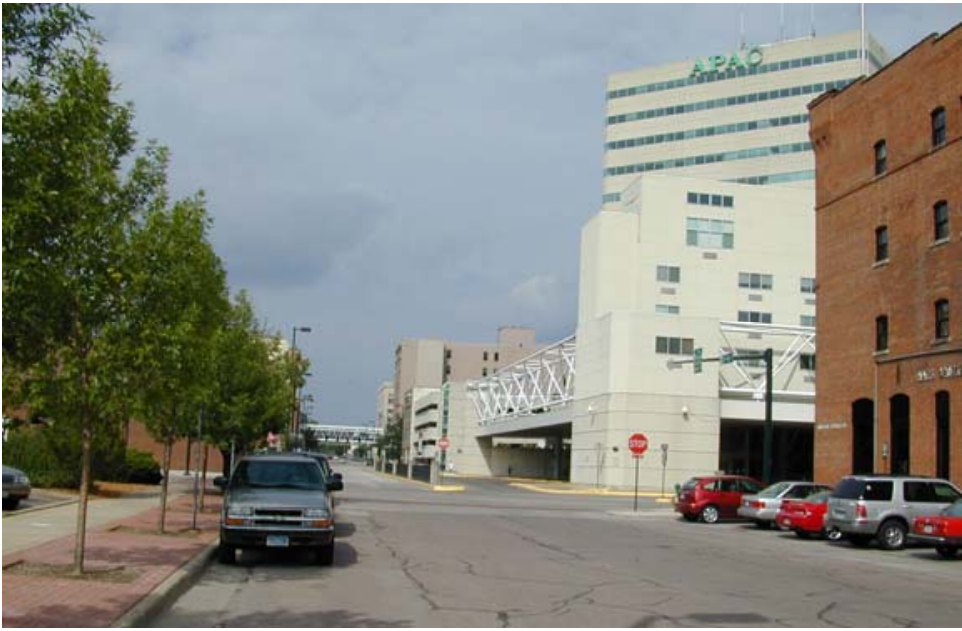

Tax Increment Funds generated by the GTC helped pay for new sidewalks, curbs and landscaping that helped attract new investment in the southern half of the city. dramatic effect on transit ridership, but it had a major impact on the development of the city. People in Cedar Rapids regard it as a point of pride. The business community thinks highly of the transit system because it is run very efficiently and its facilities are well maintained. Five Seasons Parking and Transportation is not regarded as just a public service provider: it is regarded as an economic development partner. Its success is co-dependent on the success of the local community. As hoped, the GTC has become the center of downtown Cedar Rapids, and is well recognized by residents, businesses, and community agencies. 


\section{Chapter Five}

\section{The Transit Centers of Columbus, Ohio}

\section{Introduction}

Most of the transit transfer centers described in this report are located in downtown areas. The Central Ohio Transit Authority (COTA) is taking the tact of building a number of transit transfer facilities in low and moderate income areas outside of the immediate downtown but still in the inner city as a means of generating ridership, and to facilitate neighborhood redevelopment. COTA has been alert to opportunities to work with public and private partners that provide local match for Federal funds available through the Livable Communities Initiative of FTA. The many activities at the transfer centers generate sufficient revenue to pay for the cost of operating the facility, and contribute toward the cost of neighborhood circulator transit services that help bring people to the centers. Another twist is that the transfer facilities in Columbus are primarily buildings that provide space for services of importance to neighborhood residents, and do very little to accommodate new bus movements. Most bus service at the centers is already provided on the streets next to the new centers. COTA has been able to achieve the goals of stimulating neighborhood improvements, increasing transit utilization, and enhancing the relevance of transit not only to the surrounding neighborhoods, but to the region at large through their creative approach to developing transit transfer centers.

\section{Historical Background}

COTA is headquartered in Columbus, Ohio, an area with over 1 million residents that enjoys arguing with Cleveland over which is the largest city in the state. Columbus serves as the state capital and the home of the Ohio State University, one of the two largest universities in the United States. COTA is a mid-size transit system with over 300 buses that carries over 65,000 passengers daily, with hopes and plans for light rail in the near future. 
The economy in Ohio has gone from robust prior to 2001 to stagnant since that time. Low income communities did not enjoy all the benefits of a growing economy prior to 2001, and have felt the sting of a slow economy more than others since that time. Part of the problem for these communities is that most of the new economic growth in the Columbus area has been taking place in the suburbs around the I-270 outer belt, approximately eight miles from the downtown. Residents of low income communities, many of whom have no cars, have been somewhat isolated from these opportunities in the suburbs.

COTA has been very aware of the need to provide mobility opportunities for low income residents of inner city neighborhoods to access the 43,000+ expected jobs that are becoming available at such large new developments as Easton and Polaris, and in areas such as Westerville. Express buses in the form of reverse commute services have provided mobility for many people. The managers of Easton, a major mixed-use development financed by The Limited located on the outskirts of Columbus, also decided to assist in this effort. The developers realized that it needed service employees at the many new businesses opening in this enormous upscale complex. Working with COTA, The Limited (a large clothing retailer headquartered in Columbus) donated 2.6 acres of land worth over a million dollars to serve as the site of a new bus transfer station and a day care center at the Easton site. COTA used the value of this donated land as the local match for an FTA Livable Communities Initiative grant that was originally intended to be used not only for the transfer station and the day care center, but also for a number of electric buses to circulate in the Easton development.

Shortly after the grant application was sent to the FTA, David Baker, President of the Columbus Urban Growth Corporation, a non-profit real estate development corporation supportive of urban infill projects, approached COTA. He wanted to see if there might be an opportunity to make an even greater impact for a low income community through the use of LCI funds. The Urban Growth Corporation had been assembling land in an area known as Four Corners in a minority community called Linden in the inner city area of Columbus. Mr. Baker agreed that the planned transfer center at Easton was a good thing, but he suggested that even more could be accomplished if a transfer facility with multiple uses targeted for the 4,500 lower-income residents of the Linden community could be provided at Four Corners. The concept was to 
provide a one-stop facility where good bus service already was in place where residents could access day care, health services, job training, postal services, banking services, and transit service all in one community-based center. Providing such a center could help the residents of Linden get most of the services they needed to become more job-ready and attractive to employers. The bus service already in place could get them to multiple places of employment, but the residents, many of whom were on welfare or coming off welfare, needed these concentrated complementary services in order to become fully prepared to take advantage of the job opportunities. Mr. Baker also believed the development of a transit center at Four Corners could be a catalyst for further development in the community.

COTA ultimately agreed that this was a concept that they would like to be a part of. Transit agency representatives discussed the possibilities with the Mayor of Columbus and with representatives of The Limited, who would need to accept modifications to the grant for the

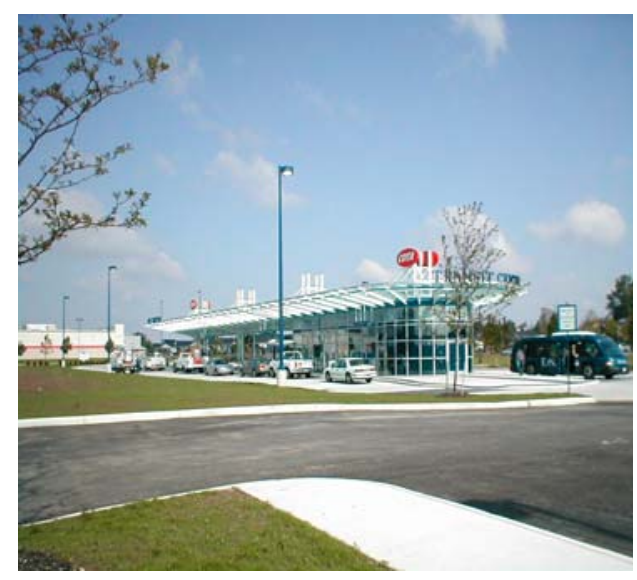

A view of the Easton Transit Center in the major mixed use development in the suburbs of Columbus.

Easton Transit Center in order to help provide funds for the proposed transit center in Linden. According to Mr. Baker, The Limited saw the benefits of the Linden proposal immediately, and agreed that the Federal Transit Administration should be asked to permit changes to the grant application for the Easton Center to allow the transfer of some funds to the proposed Linden center. The proposal for electric buses at Easton was thus eliminated, making available $\$ 2.1$ million dollars in Livable Communities Initiative funds for the Linden proposal. The value of the land donated by The Limited for the transfer center at Easton helped serve as some of the local match for Linden as well, combined with funds from the City of Columbus, the Ohio Department of Transportation, and COTA. The City of Columbus indicated it could take other steps to help protect such an investment in the Linden community, where no private or public investment of any significance had been made for over 40 years. The various community benefits that have sprung from this project will be described later in this chapter. The FTA agreed to modify its LCI grant to COTA by including a transit transfer center for the Linden community. Shortly thereafter, another low-income, inner-city, minority 
community (Near East) determined that the model of development at Linden would be well suited for them as well. The FTA has since approved another grant for another transit transfer center in the Near East community for which property is being purchased and plans are being finalized.

\section{Features of the Linden Transit Center}

\section{Design, Security, Maintenance, and Operations}

The Linden Transit Center is a 17,000 square foot, two-story facility located at the intersection of

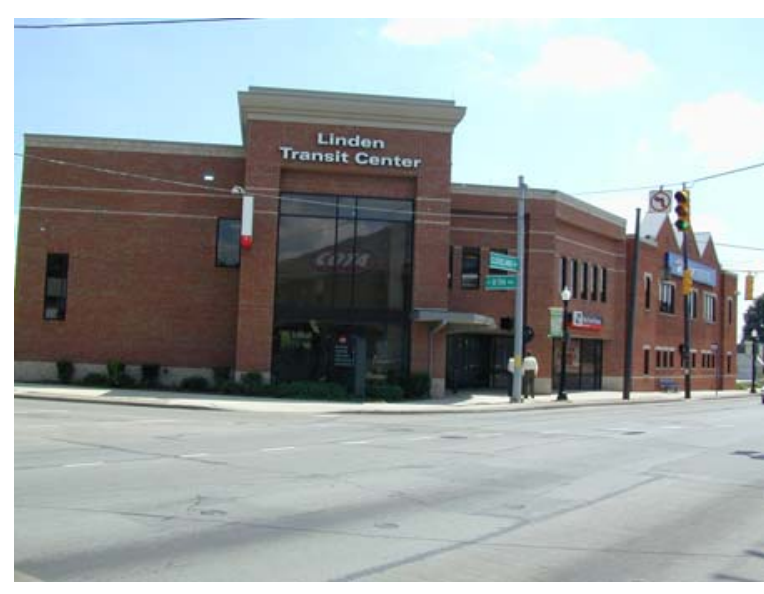

The Linden Transit Center located at the intersection of Cleveland and $11^{\text {th }}$ Avenues.
Cleveland and $11^{\text {th }}$ Avenues on a little over an acre of land. It is located approximately two miles from the center of downtown Columbus. It is a handsome, fully enclosed brick building that is oriented to Cleveland Avenue where the majority of bus service arrives and departs at stops in front of the building. The brick construction materials of the building help to make the center blend with many other brick buildings in the area, and gives it an aura of substance and permanence.

The Linden Transit Center provides space for a number of different agencies. The building and grounds are managed by COTA. The annual costs (approximately $\$ 200,000$ ) of maintaining, operating, and repairing the facility are covered by the market-rate rents collected from the agencies that operate there. Though there is no full time building manager on site, the center has suffered very little vandalism or graffiti since it was built. There are a number of factors that contribute to this record. First, there is a Columbus Police substation directly across the street. This clearly heightens the perception and reality of security. Second, there are security cameras located at a number of strategic points inside and outside of the facility. There is a 24 hour security guard on weekends and holidays, and from 8:00 p.m. to 8:00 a.m. on weekdays. But perhaps equally or even more important is the fact that the transit center is seen as a true 
community-based facility that houses multiple services that benefit hundreds if not thousands of residents of the Linden community. There is a sense of pride and ownership among members of the community. Consequently, there are even more "eyes and ears" that maintain a watch over this facility at all times.

There is parking for only 28 cars behind the facility. COTA hopes to add additional parking spaces due to the nature of the use of the center by the community, which will be further described in the next section.

Perhaps the most distinctive aspect of the design of the Linden Transit Center that separates it from all other centers reviewed in this report is that is has minimal provisions for off-street bus bays. There is only one neighborhood circulator bus that comes onto the property purchased for this center. All other COTA buses continue to provide service as they have for years on Cleveland and $11^{\text {th }}$ Avenues.

All passengers wishing to access COTA's local and express buses wait underneath the canopies of the building as it faces Cleveland Avenue. Given the cold weather that Ohio experiences in the winter, it might

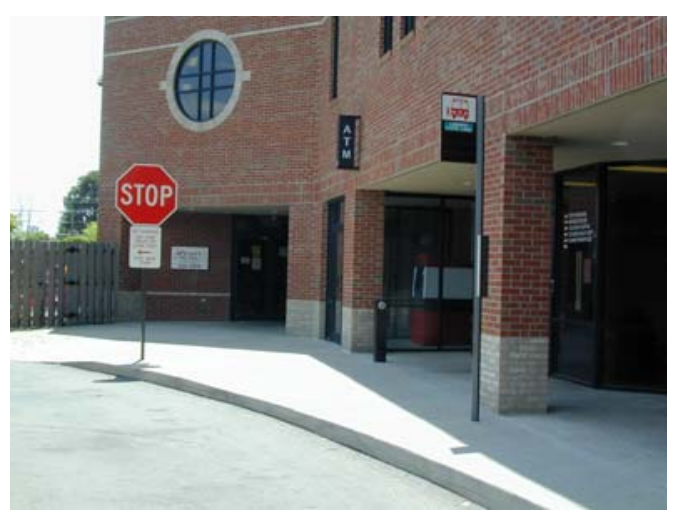

Pull in area for the Linden Link, the neighborhood circulator that provides 30 minute service to the transit center. have been advantageous for waiting passengers to have better vision of oncoming buses from within the center's lobby. A real-time electronic bus information sign should help to minimize this minor inconvenience in the future.

This is not a typical transit transfer center designed with bus bays and turning radii for multiple buses. It has been built to take advantage of the multiple routes that already operate on the streets adjacent to the center. These buses do not deviate from their routes to enter the facility. From COTA's point of view, bus schedules are not degraded by needing to add time to routes to enter and leave an off-street transit facility. 
COTA's long range plan calls for establishing as many as 17 new transit centers as it changes its focus from a purely radial system to one that offers more cross-town services and neighborhood circulators. The agency uses the following "Transit Center Site Selection Criteria" when considering where to place new central city transfer facilities:

- Size of site adequate to support proposed program of uses;

- Availability and reasonable cost of land;

- Safe pedestrian and bicycle access;

- High visibility (i.e., adjacent to major arterial street);

- Compatibility with surrounding land uses;

- Located adjacent to existing transit routes;

- Safe and convenient vehicular access for both automobiles and small circulator buses;

- Sited in areas where the transit center can be a catalyst for economic development;

- Located in close proximity to key social service providers.

The Linden Transit Center complies with all of the criteria listed above. Not much land was needed since it would not require space for large bus turning movements. The land to build the center was not very expensive, since it was formerly occupied by an after hours, slum-like motorcycle club. The site was visible on a prominent avenue. The uses at the site would be supportive of the surrounding community. There were nine bus routes that went past the Four Corners intersection. Vehicular access was sufficient, located on a corner with space for parking in the rear. The real strength of the Linden Center proposal was how it satisfied the last two criteria. As noted earlier, the Linden community had suffered neglect for decades and was in need of some sort of catalyst to inspire new investment and development. The transit center itself would serve as the site for the social services that COTA's criteria called for.

\section{Services Available at the Center}

The vast majority of the square footage within the Linden Transit Center is used by agencies that provide a variety of vital human services to an area that had long been without them. The Columbus Urban Growth Corporation, working extensively with community groups, was the coordinating force behind finding the initial set of tenants for the center. Mother's Helper Day Care is a privately-owned business that occupies approximately 6,000 square feet of space on the 
first floor, providing day care for 104 children on an 18-hour-a-day basis. Day care was identified early on by the community as a service that would be needed, particularly for those mothers who were coming off of welfare and joining the workforce for the first time in many years.

Also on the first floor is a branch office of the Fifth Third Bank, a local banking business with branches throughout the city. The 300 square feet of space for the bank is not intended to provide full banking services. The immediate market in Linden was deemed too small to justify establishing a full branch at the center. However, residents and customers can visit with a bank representative at the office to set up loans and accounts. An Automated Teller Machine (ATM) is also available in the building, to allow people automated access to their funds.

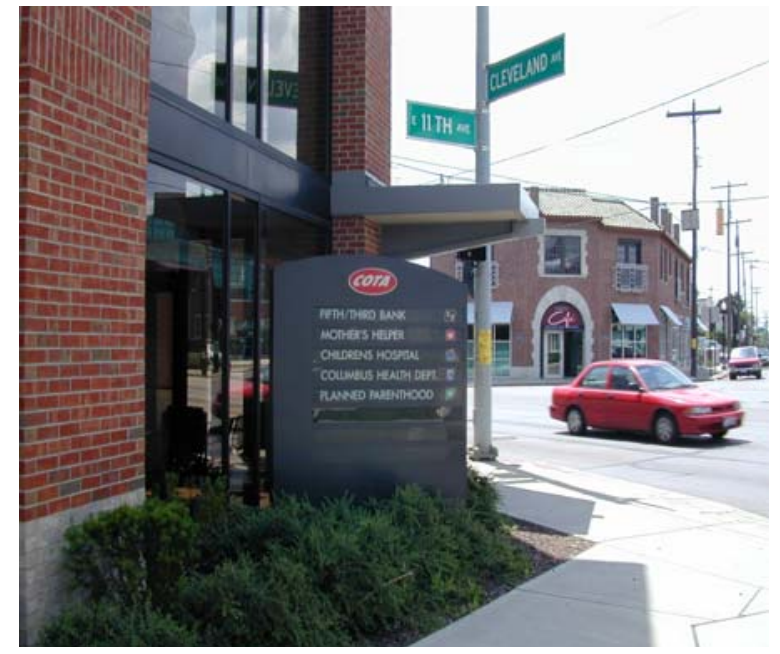

Signage showing the occupants of the Linden Transit Center, with the Linden Café across the street.

COTA provides almost 400 square feet for transit functions including an office where passes are sold and transit information is provided to passengers through bus route schedules and maps, and through COTA personnel. When a COTA representative is not present, there is a telephone available for customers to directly contact the transit agency's customer service office. The remainder of the area for COTA's direct use is available as a waiting area for passengers. As noted earlier, while the enclosed waiting area provides warm and dry shelter for passengers, the oncoming buses are not easily seen from a distance within the waiting area. Hence, passengers need to go outside the building for the final few minutes before their bus is scheduled to arrive to be sure to catch their bus. However, a future automated vehicle location system should provide real-time information for waiting passengers, allowing them to know when a bus is just a minute away. The waiting area has served as a site for job fairs. It is also used as a voting precinct for the community, and as a space to hold community meetings. There are fully accessible restrooms on the first floor of the building as well. 
The second floor of the transit center is primarily dedicated to the Childrens' Hospital satellite pediatric clinic and to the Columbus Health Department. The pediatric clinic was at first hesitant to occupy space in the building thinking that there were not enough people in the immediate neighborhood to make the investment worthwhile. However, the many bus routes that lead to the center make the location more attractive since residents from many other nearby communities can access the clinic by bus. Representatives of the clinic now regard the services at the Linden Transit Center to be among their best situated in the County. The County Health Department provides services including Planned Parenthood and general health screening. Also on the second floor are offices for St. Stevens Community Homes, a non-profit housing program that helps lower income and first-time home purchasers secure a house with payment plans that they can afford.

Last, but certainly not least, are the various bus routes provided by COTA that serve the transit center. As noted many times earlier, most of the bus services were already in place, but there were no provisions for passengers to wait other than in bus shelters on the street. Two local COTA routes provide service at Cleveland and $11^{\text {th }}$ Avenues, in addition to six express routes and a reverse commute route. An important additional transit service, added as a condition of building the transit center, is a 30 -foot neighborhood circulator bus that provides 30 minute service throughout the day through the Linden

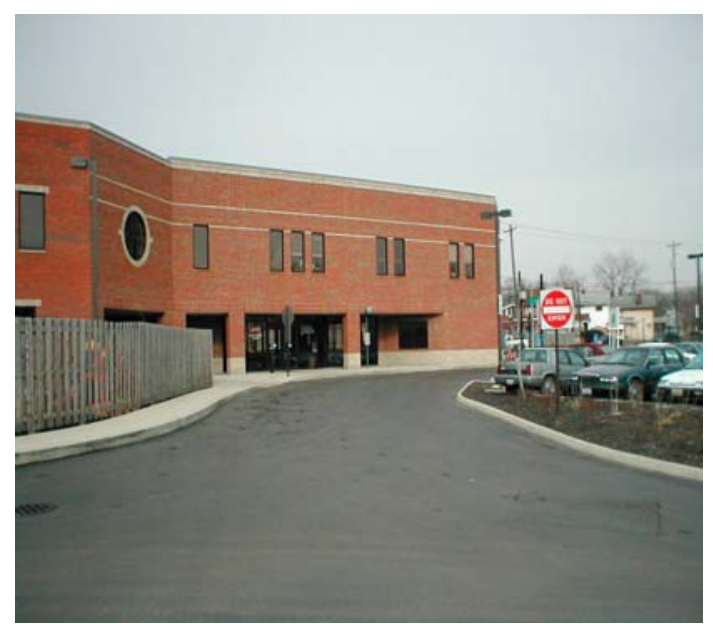

The local circulator uses space in the rear of the building near the parking area where there are $\mathbf{2 8}$ spaces available. community. This service (the \#74 Linden Link) not only provides convenient access to the Linden Transit Center, but also allows residents to get to other community facilities such as the local park, the recreation center, and the library. The only off-street bus bay on the transit center property is dedicated for a dropoff - pickup space for the local circulator at the back door of the center in the parking lot area of the property. 


\section{Contributions of the Transit Center Toward Positive Community Development}

The Linden Transit Center is an outstanding example of how a facility normally associated only with the provision of public transit services can actually be the catalyst behind the rejuvenation of a community. According to Boyce Safford of the Columbus Mayor's Office, The Linden Transit Center was the linchpin that not only helped provide access to jobs, but also served as the catalyst for urban revitalization.

Reverse commute services have been established in a number of cities throughout the United States, usually providing an express service for people located in the inner city to get to jobs that are located in the suburbs. The Linden Transit Center serves as a site for such services that reach out to the new developments on the fringe of Columbus. More importantly, the center has consolidated a number of the services people need to help complement their ability to access new jobs. For many people, particularly single parents, they can not hope to participate in the workforce unless they have reliable, affordable day care services to tend to their children while they are at work. The neighborhood circulator allows them to access the services at the day care center without needing a car, which also enhances the value of the transit center to the community.

The unemployment rate among households in the Linden community was over 33 percent in the 2000 census. Any facilities and services that can help residents of this community secure employment are going to ultimately have a beneficial impact on the neighborhoods. More income translates into better economic conditions for each household and for opportunities to improve properties. One of the primary reasons for building the Linden Transit Center was to help link the residents of an area with high unemployment to areas primarily outside the downtown where most new employment opportunities were occurring. A major function of this center was to provide fundamentally important human services (health, day care, and family planning) and guidance in matters of financing and housing to help people plan for and live a more upwardly mobile, stable, and productive life. More than eight job fairs have been held at the transit center, where 15 major employers have attended to advise the over 800 attendees of the employment opportunities that exist with their companies. It will take years to determine just 
how much impact the Linden Transit Center has had in improving incomes and quality of life, but no one questions the basic approach or potential benefit to the community.

One of the benefits of planning for such a facility is that it helps bring the community together as they identify the various needs within their area. There were dozens of meetings held within the community to receive input on what people wanted to see in the facility, and what improvements they thought were needed in the community in general. While COTA provided the bulk of the local match for the Federal grant for the facility, some of the local match was also provided by the City of Columbus through its Urban Infrastructure Recovery Fund program. These funds were used on capital projects that community representatives said would be important around the facility, including better sidewalks, lighting, curbs, trees, and street crossing markings. The Linden community also noted that police services needed to be bolstered in their neighborhood. It is not surprising, then, that the city built a two-story police substation directly across the street from the Linden Transit Center as a result of input received at the meetings for planning the transit center. In addition, the city has been using neighborhood policing techniques that emphasize more personal approaches for police officers to use when patrolling a community. According to David Baker of the Columbus Urban Growth Corporation, crime rates in the community have gone down since these practices started.

A school that was going to be closed is now going to stay open. The community will also be getting a new fire station and a branch library.

The Linden community was also a full partner in determining what services would be available at the transit center. When the community plays such a strong role in the planning of a facility, and the facility is then built as planned, there are much better relations built between the community and the policy bodies and operating agencies involved in the project.

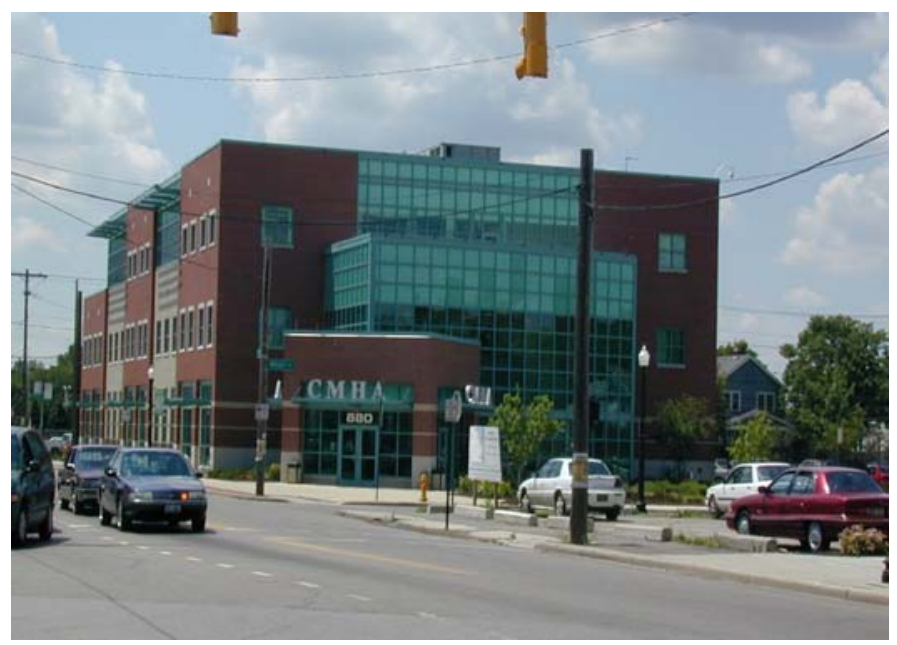

The headquarters of the Columbus Metropolitan Housing Authority as viewed from the front door of the Linden Transit Center. 
The city gains some political capital, particularly in areas where many promises may have been broken before. The operating agency gains the benefit of having the community accept the facility as truly part of their neighborhood, resulting in better protection from vandalism and theft.

There is no doubt in anyone's mind that the building of the Linden Transit Center served as the catalyst for more development in the Four Corners area. No substantial investment of either a public or private nature had taken place in Linden in over 40 years. According to George Tabit of the Columbus Compact Corporation, once you get a new building in an area where absolutely nothing has been happening for decades, people get the sense that the neighborhood is coming back. It is clearly a great morale booster for the community. The demonstration of public investment helps to tip the balance for private companies that might have been reluctant to invest in the area. Within two years of the completion of the Linden Transit Center, the Police Substation was built and the Columbus Metropolitan Housing Authority completed their new administrative headquarters a half block from the center, bringing its 150 employees into the immediate area. A State Farm claims office has also moved to the Four Corners intersection. In the cases of the Linden Transit Center, the Police Substation, and the Housing Authority, older low-quality buildings were being replaced by new modern buildings. Only one older building at Four Corners was retained and was rented to tenants providing a restaurant, a barber shop, and small offices. While these businesses are not thriving, they are still in business and in hopes that more development that will soon take place on another of the corners of the intersection will bring more supportive critical mass to the area. That last corner will soon be the site of a twostory, 14,500 square foot building known as the Clarence D. Lumpkin Point of Pride

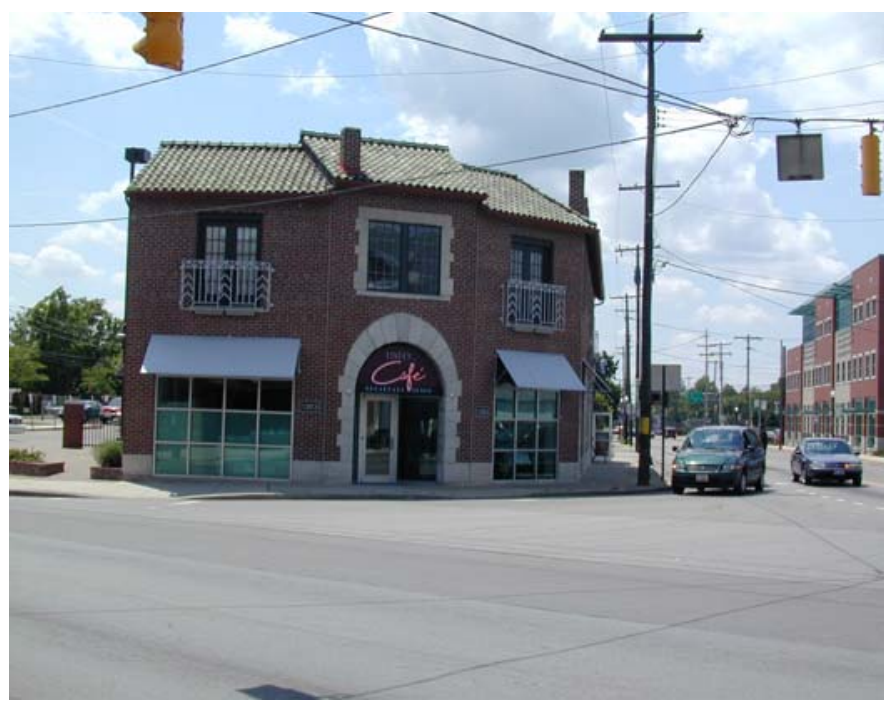

The Linden Café building that also hosts a barber shop and offices located directly across the street from the Linden Transit Center. 
Building which will house the Greater Linden Corporation offices as well as other small retail functions.

One final and notable improvement that has taken place at Four Corners is the development of seven market-rate single family townhouses within a block of the transit center. These are the first new houses to be built in the Linden community in many years. They are designed to be purchased by households buying their first homes and cost approximately $\$ 100,000$. According

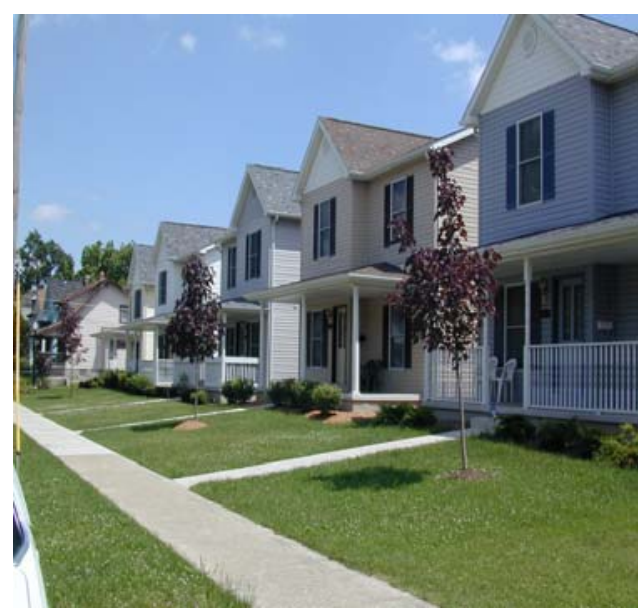

New townhouses that were built within two blocks of the Linden Transit Center. to community representatives, there is a market for better housing for those who wish to stay within the communities they grew up in.

In total, the Four Corners area has witnessed almost $\$ 10$ million in new and renovated buildings housing 400 jobs since the transit center was built in 1999, with the Point of Pride Building yet to come. The Linden community has a renewed sense of hope for continued investment, better local transit service, better police service, and an excellent relationship with the City of Columbus and COTA. According to COTA, transit ridership has not significantly increased as a result of the Linden Transit Center. One reason is that the economy in Ohio, a subject of national interest during the 2004 Presidential Election, has not done well since 2001. Another reason that is of some mild irritation to COTA as expressed by Planning Director Michael Greene is that once people improve themselves economically through getting a job, one of the first things they often do is purchase an automobile for personal travel. However, COTA can take some of the credit for their improved financial conditions, all of which ultimately help raise a community's quality of life.

One other result of the Linden Transit Center is that other communities in Columbus wish to emulate the model that was used for improving the Linden neighborhood through the development of the transit center. The Near East community, another lower-income area with a high percentage of unemployment and disinvestment in the older part of Columbus, wants to use the same basic process to help rejuvenate its neighborhood. COTA, working once again with 
multiple partners and closely with the local community, was able to secure another Livable Communities Initiative grant from the FTA, and has been very careful in the planning process to ensure the facility will have what the community supports.

The transit center will be built on less than an acre of land that will accommodate approximately 40 parking spaces and a two-story, 12,000 square foot brick building located at the intersection of major transit routes on E. Main Street and Champion Avenue. As is the case with the Linden Transit Center, bus services will not be routed onto the site of the transfer center itself. Buses will remain on E. Main Street and Champion Avenue, where they are among the most heavily used in the COTA system. At least one neighborhood circulator is proposed to help get people to and from the transit center.

The facility is in the final planning stages, but is expected to house COTA passenger information services, medical care and banking services, day care services, and possibly a small restaurant. As is the case in Linden, it is expected that the center will become a voting precinct to help solidify its prominence within the community and be available for use as a community meeting place. There are also likely to be some postal services available at the site. Fortunately, a police station and the County Health Department are already located within a block of the proposed Near East Transit Center. Walter Cates, President of the Main Street Business Association and unofficial "Mayor of Main Street", has been the local representative that has maintained a steadfast purpose of seeing the new transit center built. He noted that someone in the local community must be the 'touchstone' who knows the political process and holds local officials accountable to deliver on promises that are made when such facilities are planned. While he would like to see more retail activity at the site if possible, it is not a critical matter to him. He is a firm believer that activity of any positive nature draws interest from businesses who might be considering investing in the area. He believes that 95\% of peoples' impressions of an area are based on what the corridor looks like as they drive through it. A new building can only improve the impression of an area that has been stagnant for decades.

There is already a growing critical mass of approximately 700 employees among the police department, the health department, and the Arts Council nearby. Just as in the case of the Linden Transit Center, Mr. Cates sees the transit center in Near East as a linchpin between his area of 
high unemployment and areas where new jobs are being created. He anticipates holding many job fairs there. He also sees the new transit center as one more demonstration of investment in a community where absentee landlords have been reluctant to improve their properties.

It would be inappropriate to say anymore about the Near East Transit Center since it is not yet built. However, it is using the blueprint of success of the Linden Transit Center and hopes are high that there might be similar types of positive spin offs from its development.

\section{Summary}

Not every community is anxious to have a bus transfer center located near them. They can rightly object to the additional bus traffic, noise, exhaust fumes, and they might understandably feel uncomfortable about the presence of strangers that a bus transfer facility can bring. The facility in the new development of Easton on the outskirts of Columbus is an example of a transit center that serves its purpose as a place for people to transfer from one bus to another and to get on to local shuttles. However, the facility has been politely shuffled off from the main view of most people who enter the Easton development.

COTA has been able to find locations within the inner city to build the types of transit centers that are regarded not as nuisances, but as beneficial facilities for the surrounding neighborhood. The transit agency, through its access to Federal grants, has decided to build facilities for passengers and for community purposes at places where prominent transit service already exists. In these communities, transit is seen as a way to access opportunities, not as a nuisance. Transit is now also associated with positive community services that improve the lives of residents in surrounding neighborhoods. It is thought of as the catalyst that helped improve other community services such as police, fire, and recreation. On a broader basis, transit is better appreciated by the regional economy that is often looking for entry-level employees who often come from communities with high unemployment. The services at the transit center help make these unemployed people more available for entry-level jobs. Some have suggested that it would be

appropriate to rent space that might come available at the transit center to a job placement agency as a further way of helping bring more income into the community. 
COTA has demonstrated that it can be a full partner with other community development agencies in Columbus by using Federal grants to build transit centers that serve as catalysts for considerably more positive growth in areas that have suffered disinvestment.

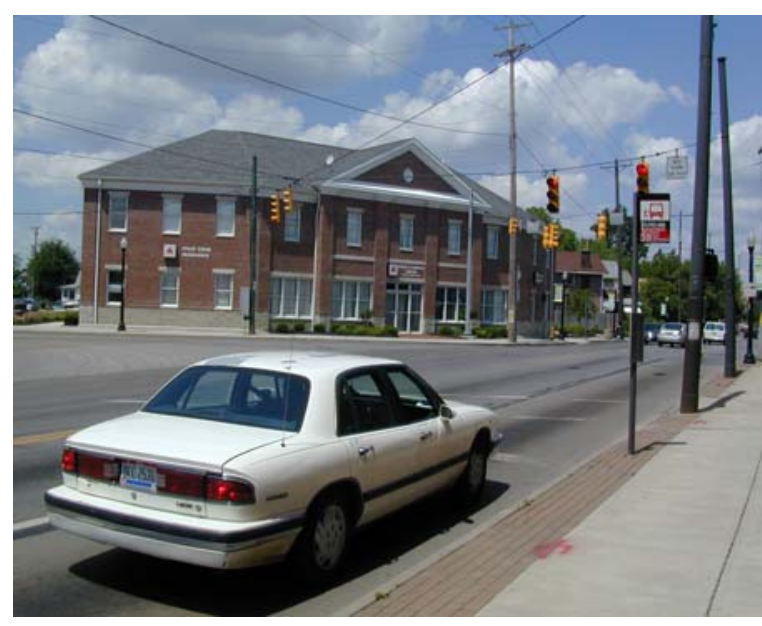

The new State Farm Insurance building located diagonally across the intersection from the Linden Transit Center.
The growth that has occurred in the Linden community was being facilitated by other community agencies with missions to foster in-fill development. However, those agencies still need a catalyst to start the process of investment in the community. The Linden Transit Center served that purpose of bringing a new building to the area. Once people see that improvements are being made, whether it is being done by the public or private sector, there is an increase in the morale of the community and in the attractiveness of the area for additional investment. 


\section{Chapter Six}

\section{Summary of Best Practices}

Richard Cromwell III, former director of Sunline Transit in Palm Springs, California once said, "I have done the math. Less than 10 percent of the people in my community use the transit system, but all of them pay for it. I need to make my transit system relevant to the rest of the community as well”. One way for transit agencies to accomplish the goal of increasing its community relevance and acceptance is by building transit centers that are community assets. In the majority of cases, surrounding areas are not initially excited by the prospects of having a bus transfer center as a neighbor. It is understandable that people might object to large buses that are too often loud, exhaust-spewing vehicles that take up space on the street and bring loads of unfamiliar people to an area.

This report reviewed four examples of transit systems that have been successful in developing bus transfer centers that have contributed positively to their surrounding areas and to the community at large. While this report is based on only four site visits to six different bus transfer centers, there were many lessons learned and best practices that are transferable to other agencies that they should consider as they go about developing such facilities in their communities:

Transit managers need to expand their own self-image. It has been a struggle for some transit managers to grow from being providers of bus service to becoming full mobility managers. However, they can be even more than that. They can become facilitators and enablers of positive community development. Grants that only they can secure from the Federal Transit Administration can provide the financing that can help build not only a new transit transfer center, but can also provide the funds necessary for other improvements that will lead to more investment in the surrounding area. In addition to providing the best transit service possible, transit managers need to be very open to the possibilities of participating as full partners in the development of facilities in ways that help transform communities. In Cedar Rapids, an Urban Mass Transit Administration (now known as the Federal Transit Administration) grant of $\$ 5$ million for a transit center resulted in over \$32 million dollars in private investment at the site. 
In Columbus, an FTA grant of \$2.1 million dollars helped build a facility that served as a catalyst for over \$10 million in public and private investment in the neighboring blocks in an area where no investment occurred in decades. These are rare opportunities that require transit managers to think differently and work with non-traditional partners. The development that can occur as the result of strategic investments in transit transfer centers can renew hope for an entire community. The services that are provided at bus transfer centers such as day care and health services can help low-income residents become more job ready, which will result in more income flowing into the community for more investment. It starts first with the managers of the transit agency being open to the new possibilities that a new self-image can provide.

Make the bus transfer facility consistent with a comprehensive plan for the area. Bus transfer facilities will be more easily accepted and welcomed if they focus on more than just transit buses' and passengers' needs. As Richard Cromwell noted, a relatively small percentage of a community's population uses buses. However, if the transit facility helps the community reach some of its broader community development goals, then the transit function becomes much more appreciated and supported. In Cedar Rapids, the city wanted to attract redevelopment to the southern half of its downtown. The development of the Ground Transportation Center with office, retail, and residential uses on site was the critical project that spurred growth in that sector of the city. The $\$ 2.4$ million in taxes generated by the joint development at the Ground Transportation Center were used for other public improvements that encouraged more private investment in the surrounding area. The Montessori School operating in one of the buildings at the Ground Transportation Center helped make the downtown more attractive for office development, which was the strategic direction the city wanted to take.

Fundamentally, the transit agencies reviewed in this report expanded their role from being mobility managers to being key collaborators and facilitators of positive community development. Smart transit managers understand that what is good for their community is ultimately good for the transit agency. Similar results were obtained in Corpus Christi where the investment made to the Six Points transfer center and the surrounding blocks through Livable Community Initiative funding from FTA caused substantial spin-off benefits to the immediate neighborhood in the form of private investment that has helped that community come back to life. It was the redevelopment of the area that the transit agency was most interested in, 
consistent with plans that had been developed by the community and the city. The Linden Transit Center in Columbus helped spur other public and private investments in an area that had seen no investment in over 40 years. This was consistent with the Mayor's objective of revitalizing inner city neighborhoods. Moving the bus transfer function off of Tryon Street and to the Charlotte Transportation Center allowed Tryon to become the major center of office and retail functions that the city envisioned it to be. In short, the transit agency in all cases asked the question 'What are the major goals of our community and how can we help our community succeed in accomplishing them'? In essence, they followed an old paradoxical axiom that notes, 'To get ahead, put others first'.

Private partners can play a prominent role. In public transit agencies, the normal partnerships that are formed include local, state, and Federal agencies that contribute to the financing of a new facility. Every community will have its own unique circumstances and opportunities, but they should not discount the possibilities of partnering with the private sector to help build and possibly maintain their transfer center. In Charlotte, the Bank of America provided 100 percent of the funds needed to build the Transportation Center, and that company contributes approximately 25 percent of the cost of maintaining the center. In Columbus, the value of land donated by The Limited served as the capital match for the Easton Transit Center. That company also agreed to modify the grant proposal for the Easton Center to free up funds to build the Linden Transit Center in inner-city Columbus. In Cedar Rapids, the office tower and housing units at the site were built and financed by private investors. It is more possible to secure private partners when the transit transfer center is part of a larger community development plan.

Community involvement in planning the facility is critical. As has been noted many times, communities are often not thrilled with the idea that a bus transfer center might become their neighbor. That is why it is critically important to involve the community in its design and in the determination of what activities and services will be offered there. This will help the community buy in to the facility, and will help ensure that the facility will be providing services or activities that are beneficial to the surrounding area. In Corpus Christi, hundreds of citizens actually helped produce hundreds of customized ceramic tiles to decorate the vertical spaces in the facility. In addition, surrounding community members participated in multiple design charettes 
before a final design for the facility was completed. In Columbus, dozens of meetings were held with community organizations to determine what human services would be most important to include at the Linden Transit Center. The community determined that a day care center, health care services, and a pediatric clinic were among the most important services for their community, and that is why they are located at the Linden Transit Center. The full inclusion of the community in the planning process helps in many ways. It helps create a sense of acceptance of the facility by the community since it includes what they believed was important for the community. It also creates a sense of ownership, which results in a facility that is watched over by the community, enhancing its security.

The act of planning for a new transit transfer center, when approached from a community development point of view instead of just from the transit operating point of view, can help a community come together and plan for other improvements in their neighborhood such as parks, libraries, streetlights, landscaping, etc. These plans stand a good chance of being supported and funded by city officials who will recognize the positive trend going on in the community and will want to build their political capital with the residents. The community should recognize that these additional positive improvements were made possible by transit's expanded role as a partner in community development.

\section{Provide opportunities for the facility to house activities that further identify the center with the} community. Transit agencies would be wise to follow the example set by Columbus, where the waiting area of the Linden Transit Center is also used as a neighborhood voting precinct, a space for community meetings, and as a place for job fairs. Even non-transit users appreciate the facility more and support its place in the community. Cedar Rapids has used the grounds of its Transportation Center as a place for philharmonic concerts. Being associated with such positive activities can only help improve transit's image in the community and make it easier to place future transit centers where they are best suited.

Become part of the solution instead of a nuisance. Bus transfer activities are not appropriate in every area, and transit agencies and passengers should not take this personally or as a form of prejudice, even if it might initially appear to be. In Cedar Rapids, Corpus Christi, and Charlotte, it was evident that the transit mall concept, where buses transferred passengers on their main 
downtown street, was not contributing to positive downtown development. Buses transferring passengers on a street with heavy traffic can add to congestion. Businesses on streets used as transit malls don't appreciate their entrances being blocked by waiting bus passengers, or the fact that spaces that could be used for parking for customers are being used by buses. The general public who wish to enter those buildings often feel they are walking through a gauntlet when going by waiting bus passengers and are less likely to use the services located in those buildings. Finding a nearby off-street location for bus transfers ends up being a win-win-win situation for the passengers, the existing businesses, and for the growth of the business area. In this fashion, the transit transfer function changes from being a community nuisance to being part of the process of building a stronger community.

It helps to put a new bus transfer center on a site that is a current eye-sore. In Columbus, Cedar Rapids, and Corpus Christi, bus transfer centers replaced buildings that were generally run down and that detracted from the surrounding neighborhood. It is always easier to gain community support for a transit center when you are proposing to place it where it will rid the area of existing buildings that are undesirable.

Design matters. Transit agencies should try to inspire the community with the bus transfer facility through design, and not just build it as a utilitarian functional place for buses and passengers. It should be a place designed for people first. The Charlotte Transportation Center evokes images of world famous train stations. In Cedar Rapids, one gets the feeling of being in an airport terminal, producing a greater sense of adventure. In Corpus Christi, the elegant Spanish missionary style head house is not only beautiful, but is deliberately designed to jut into the Staples Street corridor so that it serves as a visible landmark from a distance. Great design causes the bus transfer center to be more easily accepted by a community, especially when compared to the blight it might replace. A bus transfer station should also be regarded as a gateway into the surrounding community through which many people pass, and as such it deserves to leave a powerful impression as a matter of civic pride. That impression can be enhanced with art incorporated into the design of the facility.

Convey a sense of permanence. In addition to designing an inspiring building, the transfer center should also convey a sense that the facility has been there a long time and belongs there. 
As noted earlier, Charlotte's Transportation Center looks similar to train stations built in the $19^{\text {th }}$ century and suggests to the passerby that this is a prominent facility. Corpus Christi's Spanish missionary architecture helps make the transit center feel as if it is part of the history of the community, even though it has only been there for a few years. The Linden Transit Center in Columbus is a brick building that blends in with the community and other historic structures in the city. In Corpus Christi, they refer to their bus transfer centers as 'stations', providing a further sense of permanence. This is particularly important for bus services, which ordinarily lack the sense of permanence that train stations enjoy. Surrounding communities appreciate facilities that look like they belong and appear to contribute to the historical continuity of the community.

Non-transit related functions can coexist at a bus transfer center and still result in success for the surrounding community. The Cedar Rapids Ground Transportation Center has a peculiar mix of uses. The Montessori School located at the site must be one of the most unusual activities in any transit center in the United States. The school itself does not generate any additional ridership for transit from students or parents. However, it helps make the downtown a more attractive place to work in for people with young children who desire day care services near where they work. Through this non-traditional partnership, the bus transfer center has contributed to positive community development in ways that should make other cities take note of the large range of possibilities available to them in their communities.

Thorough security is absolutely essential. One of the fears people have about transit centers is that they will possibly raise the level of crime in the immediate area. CUTR's white paper synthesis produced in 1999 found only isolated cases where this had happened for a short time before measures to improve security were taken. However, it is an image that is hard for transit to shake. It is also a fact that transfer centers can attract large numbers of teenagers with a lot of energy that worry surrounding neighbors. All of the transfer centers reviewed in this report make security a top priority. The managers of the Charlotte Transportation Center, where 45,000 passengers go through the facility daily, take substantial measures through uniformed police officers and dozens of cameras to ensure that order is maintained in the facility. All of the other centers also use cameras and/or police officers or security guards at their sites as well to a lesser degree due to a much smaller number of people using their facilities on a daily basis. The 
Linden Transit Center in Columbus has a police substation located across the street. All of these steps to enhance security at or near the facility are an acknowledgment on the part of the transit agencies that there is potential for criminal activities whenever large numbers of people are moving through an area. The transit agencies are also recognizing the concerns of their neighbors and are being responsive to them. This responsiveness builds trust between the transit agency and the surrounding community, which leads to more acceptance of the facility by the community. While those who are intent on criminal activity are attracted by opportunities presented by masses of people, they are also reluctant to engage in this activity if there is a strong likelihood of being apprehended. As one transit manager put it, crime doesn't increase or decrease greatly in the broader community, it just flows toward areas of least resistance. The various officials from all four cities interviewed as part of this project all believed that there has been no substantial increase in crime right around any of the transit centers in their cities. Investment in the surrounding blocks has clearly not been discouraged.

Thorough maintenance is also essential. Almost equal in importance to security is the need to keep transit transfer facilities as clean as possible. All of the centers visited for this project were absolutely clean and graffiti-free, with no signs of vandalism. Representatives of the transit agencies believe that once a facility starts to look shabby, the sense of safety and security is degraded. Fewer people will use it and the surrounding neighborhood will start to fear it. The transit agencies in this report operate under a 'no tolerance' policy toward graffiti, vandalism, and crime. Giving priority to maintenance might be expensive, but it must be a priority for the center if it is to continue being accepted by the community and if it is to continue to contribute to positive growth in the immediate area.

Plan for growth. Transit systems need to be positive in their forecasts for transit demand and plan their bus transfer centers accordingly. In Charlotte, the Transportation Center's 20 bus bays were outgrown in just a few years and a new transfer center will be needed to handle the overflow. Cedar Rapids is also looking at building additional capacity at a site just a block away. Corpus Christi operates at maximum capacity during peak hours. It is helpful to prevent bus transfer activity from spilling out into the adjacent streets to maintain the community's high regard for the facility. 
If possible, use alternative fuel in the buses serving the transit transfer center. Of the four transit agencies visited, only Cedar Rapids used alternative fuel in its bus fleet. It was very noticeable while at the Ground Transportation Center in Cedar Rapids that there was virtually no odor coming from the exhausts of the buses. This is one reason housing can be located at the site without complaints from the residents. While not many other transit transfer centers will include housing on the grounds, it is important to note that communities often resist having transit centers as neighbors due to the exhaust fumes. Using alternative fuels can help eliminate that reason for objection, and it would be another way for the transit agency to demonstrate that it is being responsive to the surrounding community's concerns. Ultimately the use of hybrid-electric vehicles will reduce the noise associated with arriving and departing buses as well.

\section{Concluding Thoughts}

The transit transfer centers described in this report provide excellent examples of how transit agencies can work with surrounding communities to contribute to positive community development. This can take place in cities of any size. Transit managers need to be open to seeing themselves as more than just providers of mobility, and then remain alert to the opportunities to work with new partners for broad community objectives. The Federal grants that transit agencies have access to can serve as the catalyst for many other improvements in the areas around transit centers. While this might be additional work to place on transit agencies that are often understaffed, the results can turn communities around and the image of transit can be transformed in the process. It is hoped that the lessons learned from the transit agencies reviewed in this report will be used by many other transit agencies around the nation to generate more positive growth in their communities. 


\section{Addendum}

\section{Literature Review}

\section{Introduction}

Transit agencies around the country are trying to improve or build new transfer centers, primarily for their passengers' convenience. Transit transfer centers are often regarded as "undesirable neighbors." This report is designed to provide transit agencies throughout the country with information that should ease the process of having transit transfer centers approved, while also enhancing the transit system's image in the eyes of the community. Many transit agencies are elevating the relevance and acceptance of transit in their service areas by making their transfer centers true community assets. Bus transfer facilities can accommodate other activities and facilities that contribute positively to surrounding communities, and possibly create revenue streams for the transit agency. This report offers lessons gained from site visits to four transit agencies that have built transit transfer centers that have been well accepted in their communities and have contributed to positive development in the surrounding area.

The literature available on transit centers tends to emphasize the transit function and the physical features of such centers. There has not been a great deal written on the subject emphasized in this report. For the purpose of providing a foundation for understanding the basic purposes of transfer centers, the literature review will provide summaries of many of the reports that focus on transit functions and physical features. It will also summarize the relatively few references found of reports that cover the effect of bus transfer centers on the surrounding communities.

\section{Historical Overview}

Research reports developed prior to the early 1990s focused primarily on bus transfer centers' physical design to accommodate bus movements and transferring passengers. The specific shortcomings of the then existing literature on bus transfer facilities gave rise to an Institute of Transportation Engineers (ITE) Informational Report in 1992 entitled 'The Location and Design of Bus Transfer Facilities.' As emphasized in the ITE informational report, 'transfer efficiency 
and convenience are critical to the overall serviceability and attractiveness of public transportation.' (ITE, 1992). Nevertheless, this report did not adequately address the potential impacts and interrelationships between bus transfer centers and the communities where they were located. Such issues came to the fore during the mid- to late 1990s. Identifying the potential complimentary relationship between the bus transfer facility and its immediate community, the late 1990s saw the consolidation of this linkage through the 'Building Livable Communities with Transit’ campaign of the Federal Transit Administration. (FTA, 1999)

\section{Definitions}

The varied definitions of the bus transfer center illustrate the migration from the purely 'physical' structure to that of a facility with community 'presence' and 'value.' Definitions of transfer centers are given below and the photo illustrates a typical contemporary example.

A transfer center as described in the

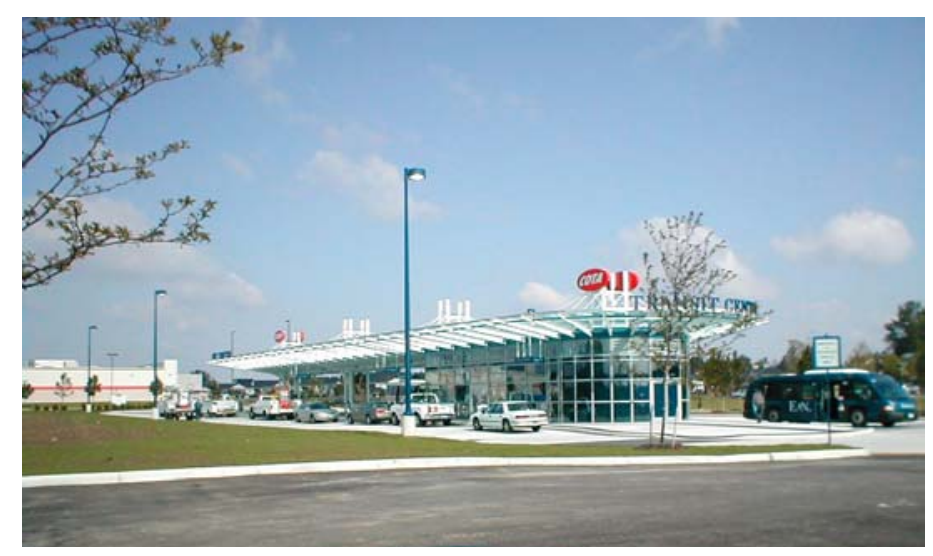

A contemporary example of a Bus Transfer Center.

Public Transportation Fact Book 2003 of the American Public Transportation Association (APTA), "is a fixed location where passengers interchange from one route or vehicle [of the same or a different mode] to another that has significant infrastructure such as a waiting room, benches, restrooms, sales outlet, ticket or pass vending machines, and/or other services.” (APTA, 2003) Gray and Hoel (1979) define a transfer center as, "a point where several routes converge with coordinated 'timed' schedules to improve connections with a minimum of waiting time.”

It is apparent from both definitions that a transit center is usually regarded as a 'functional' place for buses and passengers that doesn't need a substantial physical structure. At such a location, "the primary function of the facility is to accommodate [passenger] transfers between local buses and in larger areas, between various modes of transportation.” (Bates, 1978) The emphasis on 'time' in the latter definition by Gray and Hoel may imply a simultaneous and perceptible improvement in transit service provision in tandem with the establishment of the transfer center. 


\section{Transferring and Bus Transfer Centers}

The concept of the bus transfer facility has evolved over the years from simply a 'structure' with corresponding physical and/or geometric design characteristics to a functional 'place,' with associated environmental and community impacts. The need for some type of facility to permit the transfer of transit passengers is clarified by Nelson (Nelson et al, 1982), where he states that, "under ideal circumstances, transit would carry all users directly from their origins to their destinations without requiring a change of vehicles [or modes]. However, given the geographic and temporal distribution of trips, such direct service is of course uneconomical for transit to provide. Therefore, operators must undertake some set of actions (i.e. a transfer policy) to accommodate transferring riders.”

An alternative basis defining the need to 'transfer' is put forward by Stern, where transferring is subject to at least one of two conditions being fulfilled: firstly, "single point-to-point transit service is not available to all locations required by the ridership," and/or secondly, "different modes of transit are required to go from the point of origin to the destination”. (Stern, 1999) Other transfer policy objectives (determined by identified needs) with respect to the establishment of a bus transfer facility are indicated in Table 1 and start to suggest other broader community purposes behind bus transfer facilities. 
Table 1 - Policy Objectives of Bus Transfer Centers

\begin{tabular}{|c|c|}
\hline Operators & Users \\
\hline $\begin{array}{l}\text { - Provide vehicle operators with a rest area } \\
\text { - Enhance the image of public transportation } \\
\text { - Provide a civic facility for which the } \\
\text { community can be proud } \\
\text { - Aid downtown [and immediate locality] } \\
\text { - } \text { development and revitalization } \\
\text { Improve [and/or sustain] transit ridership }\end{array}$ & $\begin{array}{l}\text { - Provide weather protection and a secure } \\
\text { waiting area for passengers } \\
\text { - Reduce the potential for accidents between } \\
\text { buses, pedestrians and other vehicles } \\
\text { - Passenger convenience }\end{array}$ \\
\hline
\end{tabular}

Source: Hocking, 1990

The importance of the 'convenience' factor of bus transfer facilities with respect to transit ridership should not be underestimated as, "market studies have documented that passengers don't like having to change vehicles unless the connecting service provides a higher level of service than they could get with a single-vehicle ride.” (Stern, 1996) Furthermore, Stern goes on to state that, "from a passenger's point of view the most onerous part of transferring is waiting for the connecting bus.” (Stern, 1996) The type of activities incurred in the transfer experience may be described by the, "time and cost required for transferring, added trip planning, the possibility of a missed connection, the uncertainty of arrival time at destination, exposure to weather and crowding, the need to find the next vehicle and waiting in unfamiliar or hostile surroundings.” (Horowitz \& Thompson, 1994) These statements may imply that transfers involving bus transit may be seen as a disincentive to travel to the traveler, especially when comparing other types of transfers involving other modes, e.g. commuter rail to subway. Thus,

Stern's and Horowitz's reasoning supports the case that the level of functionality and convenience of the bus transfer center can positively influence the overall traveling experience of potential and existing passengers.

\section{Bus transfer facility type}

The ITE Information Report (ITE, 1992) categorized bus transit centers into two generalized categories, namely: on-street and off-street. With respect to on-street facilities, this is where 
buses operate in mixed vehicular traffic; on the other hand, off-street defines bus operations in restricted or exclusive transit-only streets or centers. In this particular project, the focus was on the community impact of the bus transfer facility, with respect to its physical and aesthetic characteristics. Thus, other types of transfer centers which lacked a unified physical structure, e.g. bus stops (with shelters) located on the corners of a four-way intersection, were not interpreted as a transfer center as part of this study.

\section{Facility amenities}

Table 2 indicates what Stern's study identified as the amenities provided at transfer centers studied as part of his research. Amenities ranged from basic provisions such as a covered waiting area, to high end facilities including video passenger information. The Figure on the next page illustrates amenities provided in the Easton Mall (Columbus, $\mathrm{OH}$ ) transfer center.

Table 2 - Amenities at Bus Transfer Centers

\begin{tabular}{|l|ll|}
\hline Basic & High End & \\
\hline Covered waiting area & Real-time next bus arrival & Video passenger \\
Off street loading and & Ticket-pass vending machine & information \\
unloading & Vending machine (non ticket) & Ticket-pass sales office \\
Passenger information & Concession sales space & Next bus arrival \\
Lighting & Park 'n Ride Facility & information \\
& & Restrooms \\
& & Enclosed area (heated, A/C) \\
\hline
\end{tabular}

Source: Stern, 1997 


\section{Easton Transit Center Passenger Amenities}

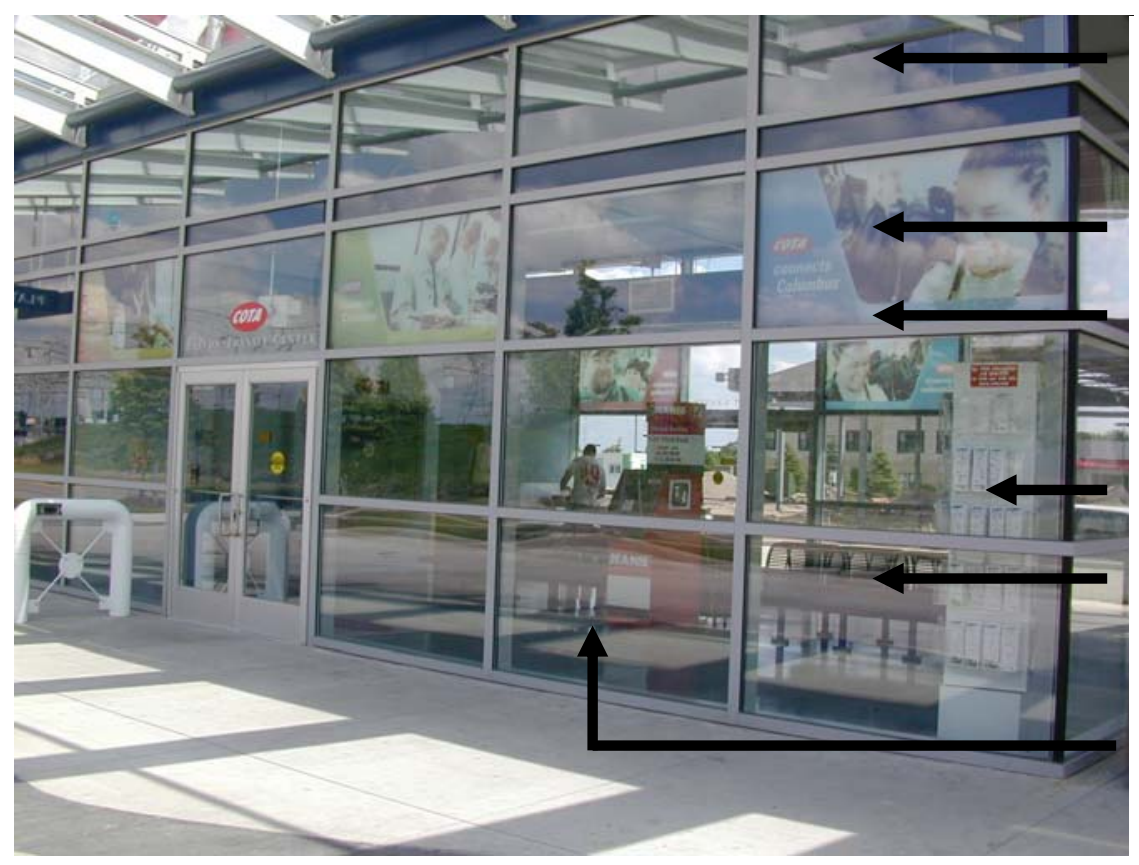

Natural and artificial lighting

Covered waiting area

Air conditioned/heated environment

Transparent materials (promoting passenger security)

Passenger information benches

Automatic teller machine

\section{Bus Transfer Center Location}

Early studies with respect to the location of transit centers noted that such centers were, "outside of the Central Business District (CBD) activity centers." (Robinowitz et al, 1989) Accessibility of transfer centers was the hallmark of their existence and locations close to the CBD were favored (subject to land values and accessibility levels). In recent years, however, transit centers have migrated to locate at urban 'activity centers,' whether they be within the CBD or situated at locations peripheral to it, such as the suburbs or at major highway intersections. Activity centers may take the form of major shopping centers, universities and medical centers; all of which independently generate a high degree of 'people' activity. The advantage of these new locations is that they may offer higher levels of accessibility and connectivity, accepting that bus transit uses the highway network.

Stern's research on passenger transfer systems indicated that few of the transfer properties surveyed had marketing programs promoting transfers (i.e. the process of 
transferring during a trip). Furthermore, "the promotion of the actual transfer location was not considered viable in transit." (Stern, 1999) Research conducted in this study identified a case where the opposite was true. The Staples Street transfer center in Corpus Christi exemplified bus transfer best practice where the community became involved through the making of tiles which were then used in the transfer center. Community members, e.g. school children and senior citizens, would travel to the Staples Street transfer center as a destination in its own right to locate their tiles and reinforce their community's ownership and pride of the facility.

Stern found from his research that only 33 percent of transit property respondents had formal service standards that were used for locating transfer facilities. Important indicators for transfer facility location were the number of passengers transferring at a particular location, the transfer center's proximity to activity centers, and the security of passengers. Advantages and disadvantages with respect to the establishment of a physical bus transfer center are presented in Table 3 . 
Table 3- Advantages and Disadvantages of Bus Transfer Centers

\begin{tabular}{|l|l|}
\hline Advantages & Disadvantages \\
\hline $\begin{array}{l}\text { Facility can increase the number of } \\
\text { reduces pedestrian obstacles }\end{array}$ & $\begin{array}{l}\text { Significant capital costs in constructing } \\
\text { the facility (especially in prime real } \\
\text { estate locales, e.g. downtown) }\end{array}$ \\
- Facility improves the transfer process & $\begin{array}{l}\text { Off center location (with respect to } \\
\text { major activity centers) may entail }\end{array}$ \\
$\begin{array}{l}\text { Facility can facilitate public/private } \\
\text { partnerships } \\
\text { Architectural design of the facility can } \\
\text { reflect local culture and so realize } \\
\text { community ownership of facility }\end{array}$ & $\begin{array}{l}\text { Facility may attract non transit users to } \\
\text { the detriment of bona-fide users }\end{array}$ \\
\end{tabular}

\section{Bus Transfer Centers - Physical Layout}

The physical layout of a transfer center may also display the following characteristics with respect to bus arrivals/departures: (Vuchic, 1981)

- Not allowing any overtaking

- Allowing independent departures but not independent arrivals

- Allowing independent arrivals and departures.

Generally there are four possible physical layout designs of bus transfer. These are:

- Curb on-street

- Sawtooth off-street

- Multiple islands off-street

- $\quad$ Single island off-street 


\section{Bus Transfer Centers - Operating Practices}

The general operating practice of the bus transfer center is that of the timed (or pulsed) transfer. This is where the bus or transit system is set up to provide quick and convenient transfers among routes. Schedules are designed so that vehicles on different routes arrive and depart from the transfer center at the same time. The challenge for the transit property in optimizing operations is to determine the balance between the time and arrival of buses at the transfer center while at the same time minimizing passenger wait times. It is widely acknowledged by transit providers that the longer the wait time, the less likely the passenger is willing to consider making the trip in question, especially if there are alternative modes or routes available. Shorter connecting times between arriving and departing buses can only be achieved if there is a corresponding increase in service frequency.

With respect to bus operations serving transfer centers, four types predominate. These are as follows (APTA, 2003):

Circular A bus serving an area confined to a specific locale, such as a downtown area or suburban neighborhood with connections to major traffic corridors.

Feeder A bus service that picks up and delivers passengers to a rail rapid transit station or express bus stop or terminal.

Local A bus service stopping at all stops (or as required by passengers) (Gray \& Hoel, 1979).

Express A bus that operates a portion of the route without stops or with a limited number of stops.

As can be seen above, the four different types of bus service serving the transfer center has the potential of increasing 'spatial' connectivity of the immediate locale which in turn, through greater levels of accessibility, enhances the livability of the community in question. 
As to the number of operational bus bays established within the bus transfer center, Vuchic notes that this, "depends on the number of routes, the peak-hour headways on each route, schedule coordination, reliability of operation, and dwell times of buses." (Vuchic, 1981) Thus, a transfer center aiming at optimum operational efficiency will be designed with a certain number of bays that reflect the number of bus routes served as well as the individual headways between buses (both existing and forecasted).

\section{Bus Transfers Centers and Communities - Livable Communities Initiative}

Post World War II saw the gradual spatial expansion of many metropolitan areas to the detriment of transit service patronage and cohesive communities, this development precipitated by the expansion of the highway network and increasing automobile availability. To provide a partial remedy to the decay and relative isolation that had affected many areas hurt by the decentralization of urban areas during the late 1990s, the Livable Communities Initiative was implemented throughout the U.S.A. The challenge of this initiative was, "to strengthen the link between transit and communities by improving personal mobility, transportation system performance, and the quality of life.” (FTA, 1999) This would be achieved by:

- strengthening the link between transit planning and community planning to ultimately provide physical assets that better meet community needs;

- stimulating increased participation in the decision making process by community organizations, which represented various groups/interests;

- increasing access to employment, education facilities, and other community destinations through high quality transit services and facilities; and

- leveraging resources available through other Federal, state, and local programs.

A total of 21 projects throughout the U.S.A. were identified by the FTA at an estimated cost of \$118 million (1999 values). It is interesting to note that not only were transit services integral to the success of this venture, but the physical facilities used by transit passengers were also key to ensuring that communities would benefit from the initiative. Research by the Project for Public Spaces (PPS) noted that, "a transit facility need not be 
just a place for transportation but can also become a setting for community interaction and a place that accommodates a diversity of people.” (National Academy Press, 1997) Two of the 21 transit projects implemented (in the cities of Corpus Christi and Columbus) through the Livable Communities Initiative are discussed in this report.

In order for the 21 projects to be selected in the initial funding, a number of criteria had to be met. For example, the intended project should:

- result from a community planning process and contain community endorsement;

- increase access to jobs, educational opportunities, or social services;

- incorporate community services or other transit and pedestrian-oriented mixed use developments; and

- provide opportunities for small or disadvantaged business participation in the planning, design, and implementation phases of the project.

Community involvement in the development of the project from conception to construction was deemed a prerequisite for funding and selection. Indeed, such an inclusive arrangement is emphasized by Perla et al (1997) where they state that, "political and public support for any public project is paramount to its success. It not only creates avenues for funding, it provides cohesion between local communities.” This project identified that there were communities who were already practicing these principles prior to the FTA Livable Communities project, such as Cedar Rapids and Charlotte, North Carolina. However, the literature on such developments was very sparse.

The Center for Urban Transportation Research also conducted a very brief synthesis on locating transit transfer centers near residential neighborhoods on behalf of the Tulsa Metropolitan Transit Authority. CUTR conducted telephone interviews with almost thirty transit agencies throughout the country in 1999 that had located, or tried to locate, bus transfer facilities nearby residential communities. A white paper entitled "Security Issues Surrounding Transit Transfer Centers in or Near Residential Settings” was developed and shared with the client, and findings were presented at the APTA Intermodal Planning Committee’s annual meeting in 1999. (Volinski et al, 1999) This 
paper concluded that there were steps that transit agencies could take to help gain support for siting transfer centers near residential communities. Many of the principles learned in that synthesis are included in the summary section of this report. Among the key findings were:

- to ensure the merit of the specific location being proposed as a center;

- to ensure as much community participation as possible in planning the facility;

- to make the facility a community asset through additional uses and excellent design; and

- providing high levels of security and maintenance. 


\section{Acknowledgements}

Most of the information in this report was gained through interviews with the following people during site visits to the four cities that were the subject of this report. The authors are grateful for the willingness of these people to take time out from their busy schedules to spend time with the principle investigators to provide historical insight, information, and tours of the facilities in their communities.

\section{Charlotte, North Carolina}

Damien Williams - Management Analyst, Charlotte-Mecklenburg Police Dept.

Boyd F. Cauble - Executive Assistant to the City Manager, Office of the City Manager

Vida Y. Covington - Manager of Special Projects, Charlotte Area Transit System

Moira Quinn - Senior Vice President of Communications \& Chief Operating Officer, Charlotte Center City Partners

John G. Sacclarides - Senior Vice President Corporate Workplace \& Security, Bank of America

Mark W. Thorson - Assistant Property Manager, Lincoln Harris

Ron Tober, Chief Executive Officer and Director of Public Transit, Charlotte Area Transit System

Keith Parker, Chief Operating Officer, Charlotte Area Transit System

Thomas Stringer, Assistant General Manager of Bus Operations, McDonald Transit

Kenneth Powell, Manager of Station Operations, McDonald Transit for CATS

Photos of the Charlotte Downtown Transfer Center are courtesy of the Charlotte Area Transit System.

\section{Corpus Christi, Texas}

Tom Niskala - Transportation Planning Director, Metropolitan Planning Commission and former General Manager of the Corpus Christi Regional Transportation Authority

Linda Watkins, CEO of Lynx in Orlando, Florida and former General Manager of the Corpus Christi Regional Transit Authority

Ricardo Sanchez, Director of Special Projects, Corpus Christi Regional Transit Authority 
John R. Wright - Architect, John R. Wright Architects, Inc.

Sam N. Beecroft - B E Beecroft Company, Inc.

Emmett Harris - Executive Vice President, $1^{\text {st }}$ Commerce Bank

Stuart Sher - Manager of Transportation Services, Corpus Christi Regional

Transportation Authority

David A. Faria - President, Technology Solution Providers

Fred Haley - Director of Service Development, Corpus Christi Regional Transportation Authority

David V. Seiler - Director of Operations, Corpus Christi Regional Transportation Authority

Dorothy Spann, Regent for Delmar Community College and officer of Del Mar Neighborhood Association

\section{Columbus, Ohio}

David J. Baker - President, Urban Growth

Boyce Safford III - Policy Advisor, City of Columbus

Ronald Dozier - Executive Director, Greater Linden Development Corporation

Walter R. Cates Sr. - President \& CEO, The Main Street Business Association

George F. Tabit - Economic Development Manager, Columbus Compact Corporation

Khaled J. Shammout, Transportation Planner, Transystems Corporation

Michael Green, Director of Planning, Central Ohio Transit Authority

Ron Barnes, Deputy Director of Miami-Dade Transit and former President/CEO of the Central Ohio Transit Authority 


\section{Cedar Rapids, Iowa}

Jamie Licko - Marketing Director, Cedar Rapids Downtown District

Sarah Else - Executive Director, Cedar Rapids Downtown District

William Hoekstra - Transportation \& Parking Director, Five Seasons Transportation and Parking Authority

Thomas L. Aller - President, Alliant Energy and former Executive Assistant to the Mayor of Cedar Rapids

Brian Vanous - Director, The Blind Cleaning Company

Ronald R. Moore - President, Burlington Trailways

Linda Waldman, Director of the Cedar Valley Montessori School 


\section{References}

American Public Transportation Association. Public Transportation Fact Book 2003. APTA. Washington D.C. 2003

Bates, Edward Jr. A Study of Passenger Transfer Facilities. Transportation Research Record \# 662. Transportation Research Board. Washington D.C. 1978

Federal Transit Administration Livable Communities Initiative. Building Livable Communities with Transit. September 1999. http://safety.fhwa.dot.gov/fourthlevel/pdf/livable.pdf

Gray, GE \& Hoel, LA. Public Transportation. Prentice-Hall Inc. Englewood Cliffs. 1979

Horowitz, AJ. \& Thompson, NA. Evaluation of Intermodal Passenger Transfer Facilities. Federal Highway Administration. Washington D.C. 1994

Institution of Transportation Engineers. The Location and Design of Bus Transfer Facilities. Washington D.C. February 1992.

National Academy Press \& Transportation Research Board. The Role of Transit in Creating Livable Metropolitan Communities. TCRP Report 22. http://gulliver.trb.org/publications/tcrp/tcrp_rpt_22-b.pdf. 1997

Nelson M, Brand D \& Mandel M. State of the Art of Current Bus Transfer Practices. Transportation Research Record 852, pp 6-12. Washington D.C. 1982

Robinowitz, HZ, Beimborn, E, Lindquist, PS, \& Opper, DM. Market Based Transit Facility Design - Final Report. UMTA-WI-11-0011-1/DOT-T-89-12. Wisconsin University \& Urban Mass Transportation Administration. Milwaukee \& Washington D.C. 1989

Stern, R. Bus Transit Transfers. Proceedings of the 1997 APTA Bus Operations, Technology \& Management Conference. APTA. Washington D.C. 1997

Volinski, J., Rey, J., and Perk, V. Security Issues Surrounding Transit Transfer Centers in or Near Residential Settings, Center for Urban Transportation Research, White Paper, 1999

Vuchic, V.R. Urban Public Transportation Systems and Technology. Prentice-Hall Inc. Englewood Cliffs, New Jersey. 1981

Author Unknown, Cedar Rapids Ground Transportation Center - Case Study: A Public, Private Joint Development 